\title{
A Preliminary Evaluation Capability for Some Two-Dimensional Groundwater Contamination Problems
}

by R. William Nelson and John A. Schur 


\section{DISCLAIMER}

This report was prepared as an account of work sponsored by an agency of the United States Government. Neither the United States Government nor any agency Thereof, nor any of their employees, makes any warranty, express or implied, or assumes any legal liability or responsibility for the accuracy, completeness, or usefulness of any information, apparatus, product, or process disclosed, or represents that its use would not infringe privately owned rights. Reference herein to any specific commercial product, process, or service by trade name, trademark, manufacturer, or otherwise does not necessarily constitute or imply its endorsement, recommendation, or favoring by the United States Government or any agency thereof. The views and opinions of authors expressed herein do not necessarily state or reflect those of the United States Government or any agency thereof. 


\section{DISCLAIMER}

Portions of this document may be illegible in electronic image products. Images are produced from the best available original document. 


\title{
NOTICE
}

This Report was prepared as an account of work sponsored by the United States Government. Neither the United States nor the United States Department of Energy, nor any of their Employees, nor any of their Contractors, Subcontractors, or their Employees, makes any warranty, express or implied, or assumes any legal liability or responsibility for the accuracy, completeness, or usefuiness of any information, apparatus, product or process disclosed, or represents that its use would not infringe privately owned rights.

\author{
Printed in the United States of America \\ Available from \\ National Technical Information Service \\ U.S. Department of Commerce \\ 5285 Port Royal Road \\ Springfield, VA 22161
}

Priese: Printed Copy $\$ 7.25$, Miciuliclie $\$ 3.00$ 
BCSR -38

UC-11.

A PRELIMINARY EVALUATION CAPABILITY FOR SOME

TWO-DIMENSIONAL GROUNDWATER CONTAMINATION PROBLEMS

\section{NOTICE}

PORTIONS OF.THIS REPORT ARE ILLEGIBLE. It has been reproduced from the best available 6epy to permit the broadest possibie avail-

by alility.

R. William Nelson

Staff Specialist

Scientific Consulting \& Programming Department

and

John A. Schur

Member of Technical Staff

Scientific Systems Section

BCS Richland, Inc.

Richland, Washington 99352

Prepared for

Battelle, Pacific Northwest Labroatories

Richland, Washington 99352

as part of the

Transport Modeling Task

Waste Isolation Safety Assessment Program

Work Performed under United States Department of Energy Contract EY-76-C-06-2320

June 1978

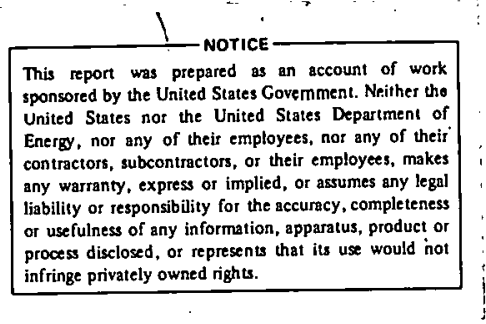


THIS PAGE

WAS INTENTIONALLY

LEFT BLANK 


\section{ABSTRACT}

There are a variety of two-dimensional groundwater pollution problems where a preliminary evaluation of contaminant transport is needed. A common difficulty in making this first assessment is the meager field data usually available. A preliminary evaluation capability has been developed for two-dimensional contamination problems that is consistent with the limited data initially available. Idealizations and simplifications have been introduced with special care so that worst-case final estimates will be provided.

The preliminary evaluation results are produced using interactive computer programs that utilize "self-help" or "coaching" features for the user's convenience. The self-help programs aid the user by asking for the necessary input parameters and by guiding the user, in selecting the options needed to obtain the required results. If the request for data or option selection is unclear, the user simply responds with "Help", whereupon a more detailed explanation is provided. In this way, any particular situation covered by the evaluation procedure and of interest to the user may be quickly and inexpensively evaluated. 
1

THIS PAGE

WAS INTENTIONALLY

LEFT BLANK 
SUMMARY ....................... . . . . .

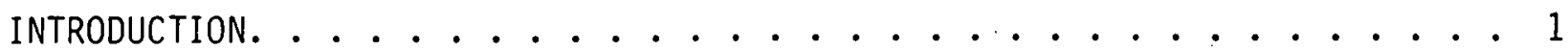
THE PRELIMINARY EVALUATION MODEL. . . . .......... 3

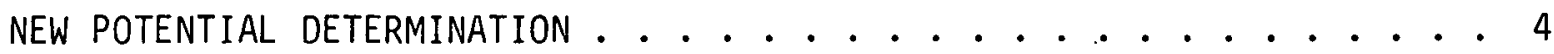
FLOW SYSTEM KINEMATICS.................. . . 5 CONTAMINANT TRASNPORT WITH SORPTION . . . . . . . . . 8 USE OF THE PRELIMINARY EVALIIATION MONFI.S. . . . . . . . . . . 10 PREPARING COMPUTER INPUT. . . . . . . . . . . . 10 INPUT FOR AN EXAMPLE TRANSIENT EVALUATION . . . . . . . . . 15 CONTAMINANT ARRIVAL RESULTS FROM THE MODEL. .......... 23

Fluid Pathlines and Advancing Fronts.......... 23 Location/Arrival-Time Distribution . . . . . . . . . 24

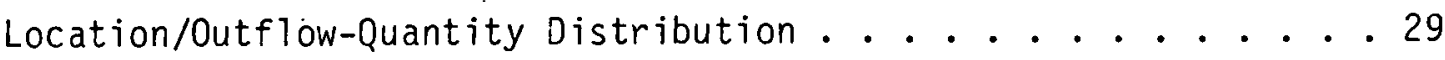
USE OF ARRIVAL DISTRIBUTIONS. . . . . . . . . . . 32 ACKNOWLEDGEMENTS. . . . . . . . . . . . . . . 37

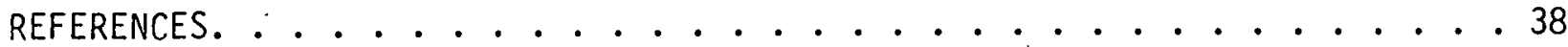

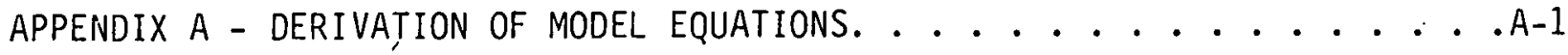
APPENDIX B - USER'S GUIDE FOR THE PRELIMINARY EVALUATION MODELS . . . . . B-I APPENDIX C - MAINTAINING OR MODIFYING THE COMPUTER PROGRAMS ....... C-1 APPENDIX D - DEFINITION OF TERMS. ............... . . . 
THIS PAGE

WAS INTENTIONALLY

LEFT BLANK 


\section{FIGURES}

1 Serpin Time-Dependent Forms ........................ 19

2 Cyclic Time-Dependent Forms . . . . . . . . . . . . 21

3 Example Transient Flow Results for Fluid Particles Departing Pond at 0 and 50 Years..................... 25

4 Example Transient Flow Results for Fluid Particles Departing Pond at

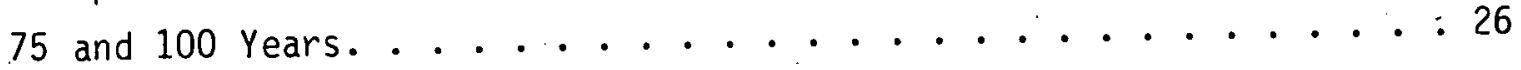

5 Contaminant Location/Arrival-Time Distribution for the Example. Transient Case. . . . . . . . . . . . . 28

6 Contaminant Location/Outflow-Quantity Distribution at the River for the Example Transient Case............... 31

7 The Concentration of Contamination Entering the River at Various Locations and Times for the Example Transient Case. . . . . . . . 33

8 Outflow Rate of Groundwater Contamination with Time for the Example Transient Case........................ 35

A-1 Approximation Error at the Major Source or Pond Boundary Caused by the Proximity of the jth Well ................ . . .

\section{TABLES}

1 Input Parameter Worksheet . . . . . . . . . . . . . 13

2 Input Parameter Worksheet for the Example Transient Case. . . . . . 17

3 Contaminant Arrival Time at River and Outflow Locations Along River for the Example Transient Case. . . . . . . . . . . . 27

4 Contaminant Arrival Location Along River and Unit Outflow Rate for the Example Transient Case. . . . . . . . . . . 30

A-1 Definition of Parameters for the Serpintine Equation Form (A-18). . A A-9 A-2 Definition of Parameters for the Cyclic Equation Form (A-19). . . . A-9 B-1 Input Parameter Worksheet for Example Steady Case with TC-99 Exchange B-33 
THIS PAGE

WAS INTENTIONALLY

LEFT BLANK 


\section{SUMMARY}

A preliminary evaluation capability for two-dimensional subsurface pollution problems has been developed that is both easy to use and inexpensive. This capability is based on a model that was designed to best utilize the limited data usually available in early evaluation of a subsurface pollution problem. At some points, idealization and worst-case approximations were used rather than requiring more elaborate, hard-to-get data. Through the conservative assumptions used, the predictive results should represent the worst-case expectations. Such worst-case estimates can be very useful for an initial evaluation.

A variety of predictive results are provided by the model, which is capable of considering both steady and transient flows either with or without various corrective actions involving pumping or injection wells. Such results include 1) the expected flow paths of the contaminant, 2) the gradual advance of contaminant fronts through the stratum with time, 3) the location where the fluid-transported constituents will first reach the biosphere, and 4) the time necessary for various contaminant quantities to reach the interface with the biosphere. The overall environmental consequences can be evaluated from such results.

Interactive computer programs were developed to make it easy for noncomputer people to use the evaluation capability. These programs aid the user by asking for the necessary input parameters and by guiding the user through selecting the options needed to obtain the required results. If the request for data or option selection is not clear to the user, he simply responds with HELP, and a more detailed explanation is provided. In this way, any particular situation described by the initial predictive model and of specific interest to the user may be quickly and easily evaluated. 
A PRELIMINARY EVALUATION CAPABILITY FOR SOME TWODIMENSIONAL GROUNDWATER CONTAMINATION PROBLEMS ${ }^{(1)}$

by

R. William Nelson

John A. Schur

INTRODUCTION

There are a variety of two-dimensional groundwater contamination problems where a preliminary evaluation is needed. Some of these cases involve sma 11, localized problems where elaborate evaluations are not feasible. Even in large, complicated problems requiring extensive long-term studies, a preliminary evaluation is usually the first step. Common to all of these problems is the lack of sufficient data to support comprehensive initial evaluations.

Accordingly, there is a real need for assessment procedures that seek a balance between predictive sophistication and the amount and quality of data available. Further, such procedures must be easy to use and must provide the results needed in a moderate amount of time and at minimal cost.

A preliminary evaluation capability for two-dimensional groundwater pollution problems was developed as part of the Transport Modeling Task for the Waste Isolation Safety Assessment Program (WISAP). Our approach was to use the data limitations as a guide in setting the level of modeling detail.

This evaluation capability has grown out of earlier developmental efforts and numerous enhancements made in the process of solving a variety of related problems over the past decade. A project for the Research and Development Department of Atlantic Richfield Hanford Company (Nelson, 1970) in the late sixties provided a simplified single source leakage model. Later, while working with pollution problems of a commercial mining operation,

(1) This report was prepared under Project BCA 640 for the Water and Land Resources Department of Battelle, Pacific Northwest Laboratories, as part of the Transport Modeling Task for the llaste Isolation Safety Assessment Program (WISAP). 
the features for considering several injection or pumping wells in addition to the central source were incorporated. Shortly after that, the original central source expression was replaced by the more complete and useful doublet expression used now. Recently, out of an underground siting study of nuclear power plants (Allensworth, et a1., 1977), the feature to consider nuclide holdup due to ion exchange of a single component was first included.

In 1977, Battelle, Pacific Northwest Laboratories, as part of WISAP for the Department of Energy, conducted a detailed evaluation of fluid and contaminant transport models for use in assessing the safety of geological repositories for solidified nuclear wastes. The preliminary two-dimensional evaluation tool that had evolved during the previous decade was selected by WISAP as the needed preliminary evaluation capability.

This document describes the preliminary evaluation capability prepared for WISAP, including the enhancements that were made because of the authors' experience using the earlier capability. Appendixes A through D supplement the report as follows: Complete derivations of the background equations are provided in Appendix A. Appendix $B$ is a comprehensive set of instructions for users of PATHS. It is written for users who have little or no experience with computers. Appendix $C$ is for the programmer. It contains information on how input parameters are passed between programs in the system. It also contains program listings and test case listings. Appendix D is a definition of terms. 


\section{THE PRELIMINARY EVALUATION MODEL}

A preliminary analys is commonly is restricted by lack of field data. In particular, there is insufficient hydraulic conductivity, porosity, or stratum configuration data to enable a detailed description of the actual field situation. Accordingly, the approach used here involved idealizing the model to stay within the available data bounds, followed by selection of conservative alternatives at decision points to assure that the predicted results will represent a worst-case situation.

Several idealizations are involved in the model. The fluid release postulated by the model represents a severe, worst possible failure for the storage structure, if one exists. We are assuming that any metal, concrete or lining material of the structure offers no resistance to flow. In effect, the fluid is assumed to be standing in an unlined, cylindrical, vertical cavity in the porous material. The leakage rate of fluid from the pond or vertical cavern is governed only by the hydraulic conductivity of the material, the hydraulic head in the unlined vertical cavity and the other flow system variables.

The two-dimensional initial-assessment model represents flow in a confined stratum of uniform vertical thickness, and is of large lateral extent in the horizontal plane. The stratum is assumed homogeneous, having isotropic hydraulic conductivity and constant effective porosity. A uniform lateral flow gradient is assumed within the stratum and the superimposed leakage is from a vertical, cylindrical pond or cavern that completely penetrates the entire stratum. A potential energy head is applied at the pond or structure and is completely dissipated at finite radial distance rather than at an infinite distance, thereby introducing a worst-case situation into the evaluation procedure.

The model can consider as many as 35 wells at optional locations. Wells are represented as completely penetrating, vertical line sources with steady or time-dependent flow rates.

The model. considers both steady and transient saturated flow systems. The steady cases are evaluated by holding the uniform gradient, the head in 
the pond, and the well strengths constant. Under such steady conditions, only one set of flow paths, advancing fronts, and travel times.must be calculated since subsequent fluid leaving the pond or wells traverses identical flow paths, gives duplicate contaminant-front configurations, and has the same elapsed travel times. In the transient cases each new set of fluid particles leaving the pond or wells encounters changing velocity effects. Therefore, a range of typical departure times is selected and the flow paths, front configurations, and travel times are calculated successively for each selected set of fluid particles leaving the contaminant source. Usually the moderate extra effort to get the transient results is more than compensated by the more realistic representation provided for practical problems.

The model also considers the effect of equilibrium ion exchange reactions for a single contaminant at trace ion concentration. The approximate equilibrium coefficient, or $k_{d}$ approach is utilized to give the ion exchange delay effects for a single constituent. There are, however, no dispersion effects considered in the preliminary model, since field dispersion data is seldom, if ever, available for preliminary evaluations. Omitting dispersion effects also yields the worst overall results in terms of the amount of contaminants reaching the biosphere.

The preliminary evaluation capability is based on an idealized analytical expression for the groundwater potential in a two-dimensional flow system and direct numerical solution of the kinematic pathline equations to allow the approximate contaminant transport evaluation. This approach, though idealized, provides a fast, inexpensive first-cut evaluation tool, consistent with the amount of field data usually available.

The basis of the evaluation tools is summarized in the following paragraphs. Complete derivation of these summary relations is provided in Appendix $A$; symbols are defined in Appendix $D$ :

NEW POTENTIAL DETERMINATION

The potential distribution for the two-dimensional flow system can be approximated satisfactorily by superposition of elementary flows. In particular, a uniform lateral flow of gradient strength, $U$, inducing flow in the 
positive $x$ coordinate direction, is added to a combined source and positive doublet (Shames, 1962) centered at the origin to represent outflow from the completely penetrating cylindrical pond or cavern of radius $r_{0}$. The pumped wells and injection wells are superimposed as vertical line sinks and sources, respectively, with the center of the $j$ th well located at the point $x_{j}, y_{j}$, to yield an expression for the overall groundwater potential, $\phi$, throughout the porous stratum. Specifically,

$$
\begin{aligned}
\phi= & H-\frac{U R}{H_{0}} \cdot x+\frac{U R r_{0}^{2}}{H_{0}}\left(\frac{x}{x^{2}+y^{2}}\right)-\frac{M_{0}}{2 \pi H_{0}} \ln \left(\frac{\sqrt{x^{2}+y^{2}}}{r_{0}}\right) \\
& -\sum_{j=1}^{j=N} \frac{M_{j}}{2 \pi H_{0}} \ln \sqrt{\frac{\left(x-x_{j}\right)^{2}+\left(y-y_{j}\right)^{2}}{x_{j}{ }^{2}+y_{j}{ }^{2}}}
\end{aligned}
$$

with the remaining variables and parameters defined in Appendix $D$.

The potential, $\phi$, is defined by Equation (1) in the region for all locations $\left(x^{2}+y^{2}\right)>r_{0}{ }^{2}\left(r_{0}\right.$ is the central pond radius) except at the well coordinates $x_{j}$ and $y_{j}$. The potential satisfies the LaPlace Equation describing flow in homogeneous isotropic material. The potential, $\phi$, also satisfies the boundary conditions that $\phi=H \pm \varepsilon$ when $x^{2}+y^{2}=r_{0}{ }^{2}$. As Appendix $A$ shows, $\varepsilon$ is negligibly small if

$$
\frac{r_{0}{ }^{2}}{\left(x_{j}{ }^{2}+y_{j}{ }^{2}\right)}<0.01
$$

Equation (1), subject to Equation (2), provides the potential distribution for subsequent use in determining the flow system kinematics.

\section{FLOW SYSTEM KINEMATICS}

The flow system kinematics provide the pattern, or geometry of flow, in the subsurface system. The pathlines for individual fluid particles through the flow system provide the points of emergence at outflow boundaries. These locations and the arrival time of fluids at outflow boundaries are determined by the path function. The stream function gives the flux rate 
at the outflow boundary, and throughout the entire system. Together, the path function and stream function provide the results needed for the arrival distributions with fluid-coincident contaminants.

The characteristic equations for the pathlines are most useful in generating the flow paths and obtaining the travel times. They come directly from the definition of the macroscopic pore velocity utilizing Darcy's Law, as demonstrated by Equations (A-25) through (A-3I) of Appendix $A$. In particular, from Equations (1) and $(A-27)$, the pair of pathl ine differential equations are

$$
\begin{aligned}
\frac{d x}{d t}= & \frac{U R}{P H_{0}}\left\{1+\frac{r_{0}^{2}}{\left(x^{2}+y^{2}\right)}\left[\frac{2 x^{2}}{x^{2}+y^{2}}-1\right]\right\}+\frac{H}{P \ln \left(\frac{1}{r_{0}}\right)}-\left(\frac{x}{x^{2}+y^{2}}\right) \\
& +\sum_{j=1}^{j=N} \frac{M_{j}}{2 \pi H_{0} P}\left[\frac{\left(x-x_{j}\right)}{\left(x-x_{j}\right)^{2}+\left(y-y_{j}\right)^{2}}\right],
\end{aligned}
$$

and

$$
\begin{aligned}
\frac{d y}{d t}= & \frac{U R}{P H_{0}}\left[\frac{2\left(r_{0}\right)^{2} x y}{\left(x^{2}+y^{2}\right)^{2}}\right]+\frac{H}{P \ln \left(\frac{1}{r_{0}}\right)}\left(\frac{y}{x^{2}+y^{2}}\right) \\
& +\sum_{j=1}^{j=N} \frac{M_{j}}{2 \pi P H_{0}}\left[\frac{y-y_{j}}{\left(x-x_{j}\right)^{2}+\left(y-y_{j}\right)^{2}}\right]
\end{aligned}
$$

The contamination departs from the pond or vertical cavern at $t_{0}$; i.e.,

$$
x\left(t_{0}\right)=x_{0}
$$

and

$$
y\left(t_{0}\right)=y_{0}
$$

where

$$
\left(x_{0}\right)^{2}+\left(y_{0}\right)^{2}=r_{0}^{2}
$$

Simultaneous solution of Equations (3) and (4) using the initial conditions in Equations (5) and (6) is accomplished numerically to yield pathlines and 
travel times to the pumped wells or to the, remote outflow boundary. 'The calculations, using a fourth-order Runge-Kutta numerical solution scheme, are made using a computer program.

The flux, or fluid flow rate, at any outflow boundary is available from the instantaneous stream function, which is simply the complex conjugation of the potential expressions used in Equation (1). Upon superposition of the simple basic flows, the instantaneous stream function (derived in Equations $(A-34)$ through $(A-43)$ in Appendix $A)$ is

$$
\begin{aligned}
\frac{Q_{i}}{Q_{0}} & =\frac{U R \ln \left(\frac{1}{r_{0}}\right)}{2 \pi H_{0}} y+\frac{\operatorname{UR}\left(\frac{1}{r_{0}}\right) r_{0}^{2} y}{2 \pi H_{0}\left(x^{2}+y^{2}\right)}+\frac{H}{2 \pi} \arctan \left(\frac{y}{x}\right) \\
& +\sum_{j=1}^{j=N}\left[\frac{M_{j} \ln \left(\frac{1}{r_{0}}\right)}{4 \pi^{2} H_{0}}\right]\left[\arctan \left(\frac{y-y_{j}}{x-x_{j}}\right)-\arctan \left(\frac{-y_{j}}{x_{0}-x_{j}}\right)\right]
\end{aligned}
$$

where

$$
Q_{0}=\frac{2 \pi D_{0} K_{0} H_{0}}{\ln \left(\frac{1}{r_{0}}\right)}
$$

from Equation $(A-41)$. Equations (8) and (9) are used to determine the relative flux and are most easily visualized in steady flow systems, al though they are equaliy useful on an instantaneous basis at any specific time in a transient flow system.

Often in transient flow systems it is helpful to calculate the variation of the groundwater unit outflow fluxes along a river, for example, rather than use the cumulative stream function. The instantaneous flux per unit outflow length, $q$, can be calculated using

$$
q=P \frac{d x}{d t}
$$

The equation for direct calculation of $q$ is obtained by substituting the expression for $\frac{d x}{d t}$ from Equation (3) into Equation (10).

Equations (8) through (10) provide the outflow rates either as the relative cumulative flux or as the flux per unit length of outflow. These 
results provide the outflow quantity component of the location/outflowquantity distribution required for evaluating the environmental consequences of a subsurface contamination problem. With this data, outflow quantities can be obtained easily on a computer.

The remaining part of the preliminary evaluation capability is a simple extension of the flow kinematics already discussed. It includes the effect of ion sorption on contaminant transport. CONTAMINANT TRANSPORT WITH SORPTION

A single chemical species at trace concentration with equilibrium sorption is readily considered with only minor modifications of the kinematic equations provided in the preceding section. Without considering dispersion, as shown in Appendix $A$ in Equations ( $A-44)$ through ( $A-52)$, the characteristic contaminant transport equations are

$$
\begin{aligned}
\frac{d x}{d t} & =\frac{U R}{P H_{0} K}\left\{1+\frac{r_{0}{ }^{2}}{\left(x^{2}+y^{2}\right)}\left[\frac{2 x^{2}}{x^{2}+y^{2}}-1\right]\right\}+\frac{H}{K P \cdot \ln \left(\frac{1}{r_{0}}\right)}\left(\frac{x}{x^{2}+y^{2}}\right) \\
& +\sum_{j=1}^{j=N} \frac{M_{j}}{2 \pi H_{0} P K}\left[\frac{\left(x-x_{j}\right)}{\left(x-x_{j}\right)^{2}+\left(y-y_{j}\right)^{2}}\right]
\end{aligned}
$$

and

$$
\begin{aligned}
\frac{d y}{d t} & =\frac{U R}{P H_{0} K}\left[\frac{2\left(r_{0}\right)^{2} x y}{\left(x^{2}+y^{2}\right)^{2}}\right]+\frac{H}{K P \ln \left(\frac{1}{r_{0}}\right)}\left(\frac{y}{x^{2}+y^{2}}\right) \\
& +\sum_{j=1}^{j=N} \frac{M_{j}}{2 \pi P H_{0} K}\left[\frac{y-y_{j}}{\left(x-x_{j}\right)^{2}+\left(y-y_{j}\right)^{2}}\right]
\end{aligned}
$$

where

$$
K=1+\frac{B_{d} K_{d}}{P}
$$

with $B_{d}$ as the bulk density of the porous material; $k_{d}$, the equilibrium exchange distribution coefficient; and $P$, the porosity. 
Comparing Equations (11) and (12) with the original kinematic characteristic Equations (3) and (4) shows that the idealized transport involved only incorporating the new parameter $K$ defined by Equation (13). Accordingly, the approximate transport results can be readily obtained through applying the same Runge-Kutta numerical integration scheme as previously used. 


\section{USE OF THE PREL IMINARY EVALUATION MODELS}

The model equations and detailed formulation in Appendix $A$ were utilized to build interactive "self-help" or "coaching" computer programs. These programs allow a user to obtain the results for a specific problem simply and quickly via a remote job entry terminal. Every effort was made to get results to the user quickly and inexpensively. Our intent is to have the user on the computer as quickly as possible, without having to spend time mastering computer programming or learning machine-related details. Interactive programs make using the computer fairly easy. Through the computer terminal, the programs asks questions that the user responds. to by typing in YES, NO, or by providing the input value requested. If the question is confusing, the user may at any time type in HELP, whereupon a more complete description or further suggestions are provided by the computer. The question is then repeated and the user must respond before the program proceeds to the next item.

In the course of this interactive process, all the data inputs and controls are provided. When all the necessary data have been entered, at the user's instruction, the program automatically submits a batch computer run to most economically generate the calculations, listings and plots needed. Subsequently, the results from the batch run are automatically stored in files awaiting interrogation from the terminal. Upon request, the summary results are provided to the user--usually within a short time-at the terminal; plots and more extensive printout, if requested, are produced in the computer center and sent to the user. This gives the user summary information in a matter of minutes and the more detailed results in a few hours. Appendix $B$ provides complete instructions for using the interactive self-help computer programs. Example cases are given in the appendix and in the following section to help use the programs.

\section{PREPARING COMPUTER INPUT}

There are various ways to assemble the input values one needs to use the interactive computer programs. One of them is to collect the case data on the worksheet in Table 1. Benefits of using the worksheet are that consistent units are used for the various input values and that complete 
data are at hand. Another approach is to use the worksheet to collect the first few most pertinent input values and rely more on the coaching features of the programs.

A user may opt to rely exclusively on the coaching programs. This way a user can make a dry run with the programs on a terminal to build an input worksheet. This is done by entering the known input values and making the machine-coached selections. For unknown values or for difficult selections in the dry run, an arbitrary number or choice is made for the trial input. Subsequentiy, the dry run is terminated using the "escape" feature (as instructed by the program) and no actual batch run is made. In. this way, for a few pennies of computer time, the user gets a quick terminal printout that serves as a draft input worksheet. After some checking and a few penciled corrections, the printout becomes a complete and detailed input aid for the actual run. However, the one-page input worksheet in Table 1 . is used for the example preliminary evaluation in the following section. 
THIS PAGE

WAS INTENTIONALLY

LEFT BLANK 


\section{INPUT PARAMETER WORKSHEET}

CASE :

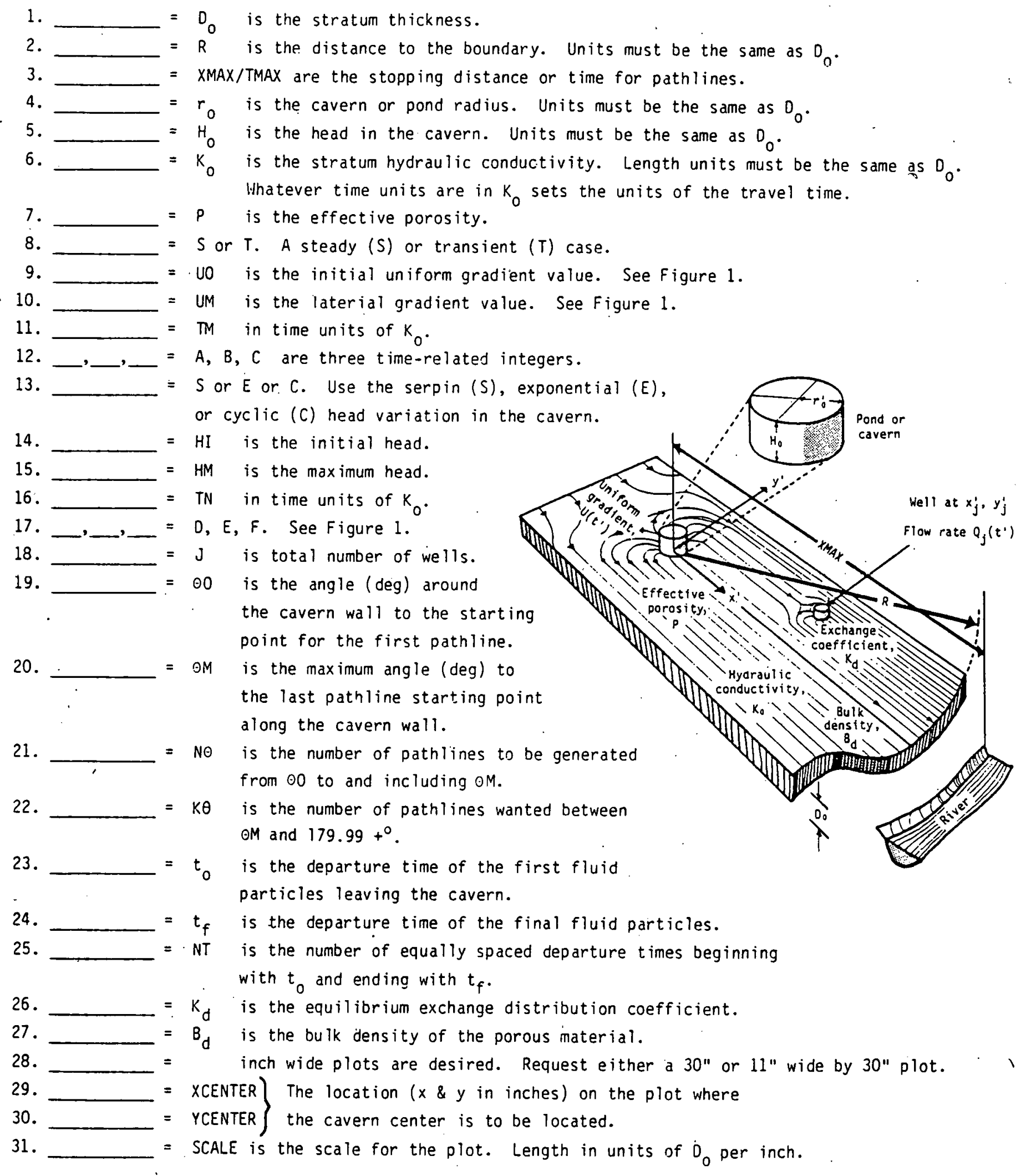




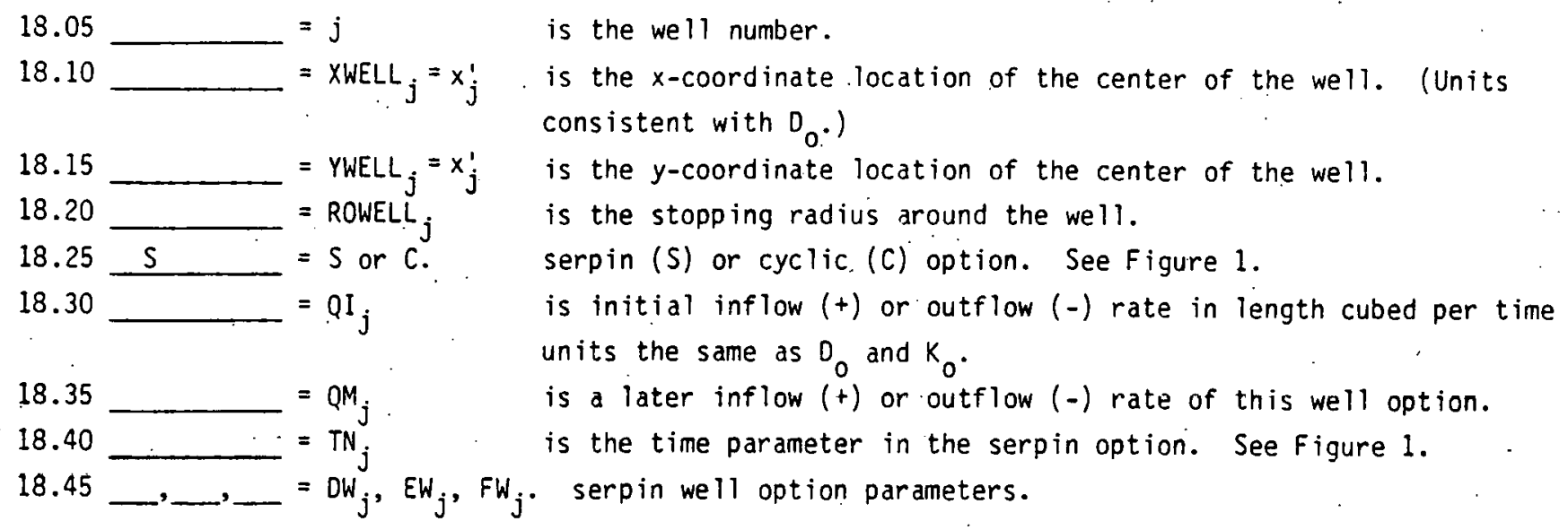

\section{CYCLIC OPTION}

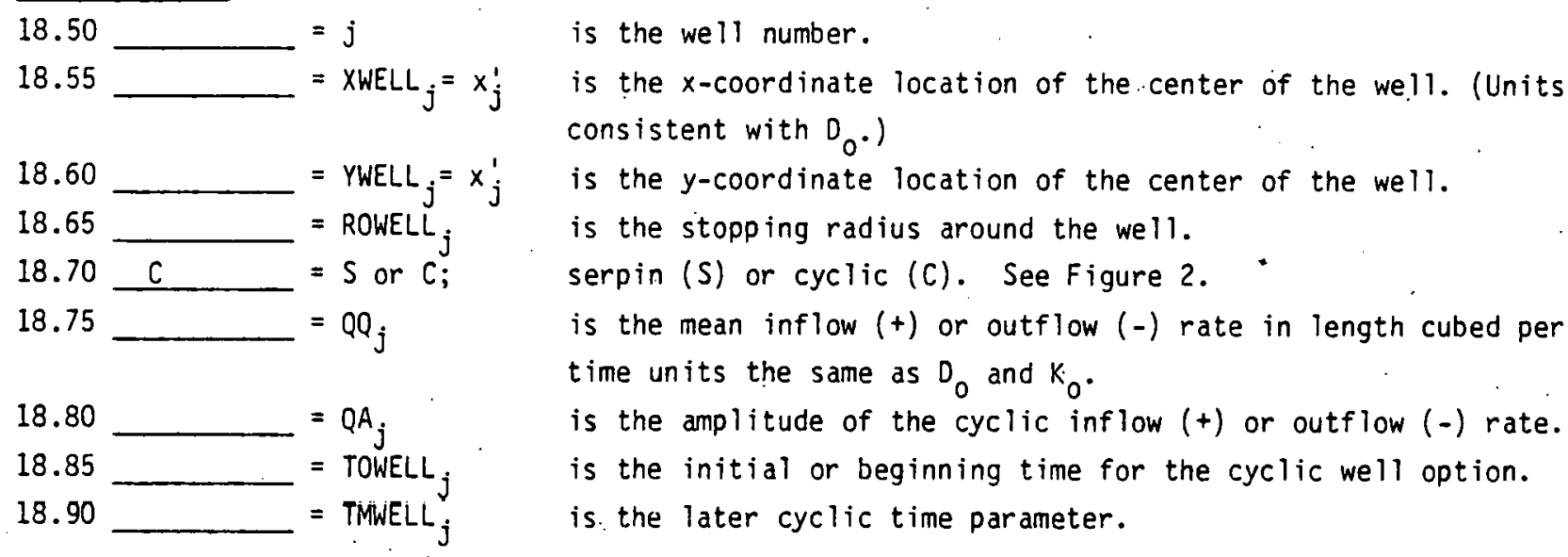

PATHLINE - IRREGULAR STARTING COORDINATES

(If $\Theta O$ in Item 19 equals $O M$ in Item 20 then $N O$ pathlines

will be generated from the individual coordinates provided below.)

21. $=N O$ is the number of input data sets to be entered for starting pathlines $(1 \leq i \leq N \theta)$.

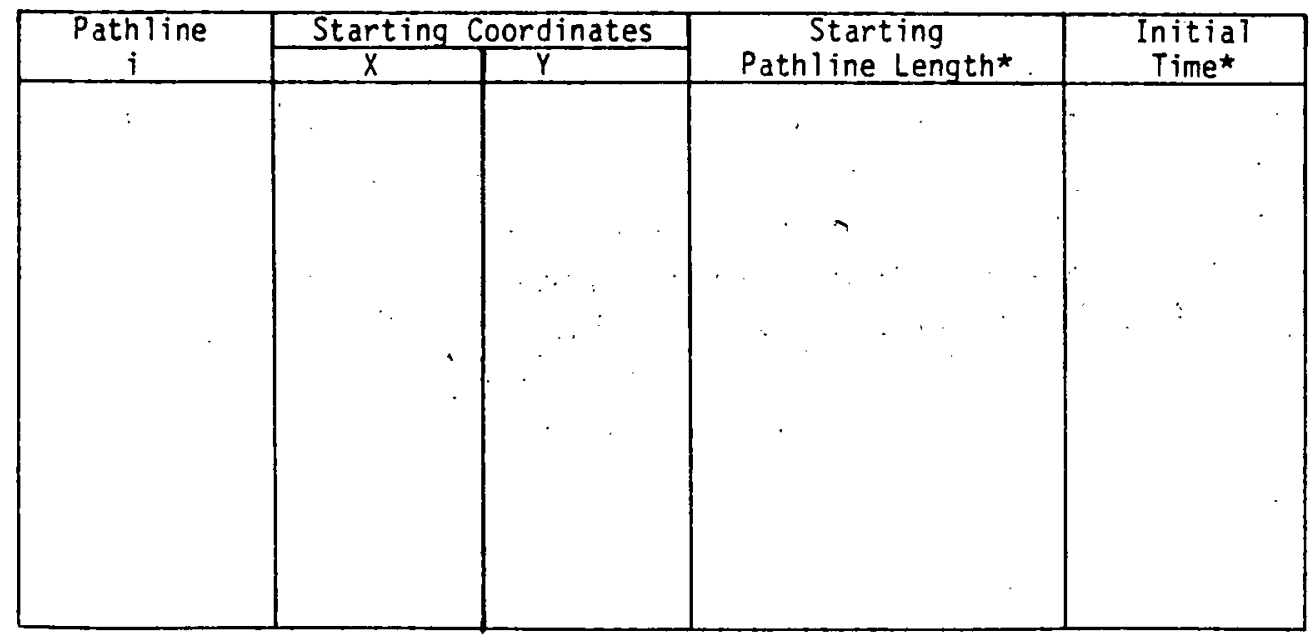




\section{INPUT FOR AN EXAMPLE TRANSIENT EVALUATION}

An example evaluation using the model is included to show what results are obtainable and to help explain the inputs needed. Typical input values using the input parameter worksheet (Table 1) are provided and discussed.

The first seven parameters on the worksheet in Table 2 are the primary variables that must be entered in the model; they should represent the very best measurements or estimates of the respective properties that can be obtained. Parameter 8 simply indicates whether the system involves transient flow or is restricted to steady flow. Parameters 9 through 12 provide the flexibility to represent the change with time of the uniform gradient strength, $U$ (see Figure 1). For this particular example case, the uniform gradient is constant with a value of 0.001 . From Figure $1(a)$, we set $U_{0}=0.001$ and $U_{m}=0.001$ for input items 9 and 10 , which gives $U=U_{0}$ for values for $T M=A=B=C=1$, hence the value of 1 is used in items 11 and 12 .

Parameters 13 through 17 allow the user to represent a variety of pond or cavern head variations with time. If the user has detajled information about the time dependence, a programmer can easily build a subroutine for direct use. However, a look at the consequences of various types of time dependence, rather than a specific detailed representation in time, is probably most useful for an initial evaluation. In the latter case, a series of variations that can be easily used are very helpful. Three broad options have been built into the programs for direct use and we have found that they cover most situations.

The three time-dependent options are the serpin, exponential leakage, and cyclic options. Each is discussed in our example case. For input item 13 (in Table 2), the user selects one of the three time-variation options to be applied. The serpin (S) option will be used for the example transient case so $S$ is entered in item 13. The specific time variation chosen for the example case from the several serpin alternatives is in Figure $1(\mathrm{~g})$. The desired pond or cavern head begins at a 4-foot head, 'gradually increases to a maximum of 8 feet at 50 years and then gradually returns to the original head of 4 feet. Using the schematic in Figure $1(\mathrm{~g})$, the tabular definitions and conditions provide the inputs: $H I=4 \mathrm{ft}, H M=8 \mathrm{ft}, T N=50 \mathrm{yr}, D=0$, $E=1$ and $F=1$, which are entered as input items 14 through 17 , respectively, on the example transient input worksheet in Table 2. 


\section{INPUT PARAMETER WORKSHEET}

\section{CASE: Example Transient Case (Two Wells)}

1. $100 \mathrm{ft}_{\mathrm{e}}=\mathrm{D}_{0}$ is the stratum thickness.

2. $8500 \mathrm{ft}_{\mathrm{E}}=\mathrm{R}$ is the distance to the boundary. Units must be the same as $0_{0}$.

3. $8500 \mathrm{ft}=$ XMAX/TMAX are the stopping distance or time for pathlines.

4. $250 \mathrm{ft} .=r_{0}$ is the cavern or pond radius. Units must be the same as $0_{0}$.

5. Le le $10 f_{1}=H_{0}$ is the head in the cavern. Units must be the same as $0_{0}$.

6. $1825 \mathrm{ft} / \mathrm{y}$ : $=\mathrm{K}_{0}$ is the stratum hydraulic conductivity. Length units must be the same as $D_{0}$. Whatever time units are in $k_{0}$ sets the units of the travel time.

7. $0.2:=P$ is the effective porosity.

8. $T=S$ or $T$. A steady $(S)$ or transient $(T)$ case.

9. $0.001=40$ is the initial uniform gradient value. See Figure 1 .

10. $-0.001=U M$ is the laterial grasient value. See Figure 1 .

11. $\frac{1}{1}=T M$ in time units of $K_{0}$.

12. $L, L, L=A, B, C$ are three time-related integers.

13. $\frac{S}{S}=S$ or $E$ or $C$. Use the serpin (S), exponential $(E)$, or cyclic (C) head variation in the cavern.

14. $\frac{4 \mathrm{ft}}{8}=\mathrm{HI}$ is the initial head.

15. $\frac{\text { ft. }}{\text { f }}=H M$ is the maximum head.

16. 50 yr. $=T N$ in time units of $K_{0}$.

17. $0,1,1=0, E, F$. See Figure 1 .

18. $\frac{2}{2}=\mathrm{J}$ is total number of wells.

19. $0^{\circ}=\theta 0$ is the angle (deg) around the cavern wall to the starting point for the first pathline.

20. $160^{\circ}=G M$ is the maximum angle (deg) to the last pathline starting point along the cavern wall.

21. $\frac{q}{-}=N \theta$ is the number of pathlines to be generated from $\theta 0$ to and including $\Theta M$.

22. $\frac{1}{1}=K \theta$ is the number of pathlines wanted between $\Theta M$ and $179.99+^{\circ}$.

23. $\quad$ Oyr. $=t_{0}$ is the departure time of the first fluid particles leaving the cavern.

24. Leo yr. $=t_{f}$ is the departure time of the final fluid particles.

25. $\frac{5}{5}=$ NT is the number of equally spaced departure times beginning with $t_{0}$ and ending with $t_{f}$.

26. $=\mathrm{K}_{d}$ is the equilibrium exchange distribution coefficient.

27. $=B_{d}$ is the bulk density of the porous material.

28. $\frac{30 \mathrm{~m}}{30}=$ inch wide plots are desired. Request either a 30 " or 11" wide by 30 " plot.

29. 3 in $=$ XCENTER The location ( $x \& y$ in inches) on the plot where

30. $\frac{2 \text { in. }}{2 \text { YCENTER }}$ the cavern center is to be located.

31. Leeo ft/4m: SCALE is the scale for the plot. Length in units of $D_{0}$ per inch. 


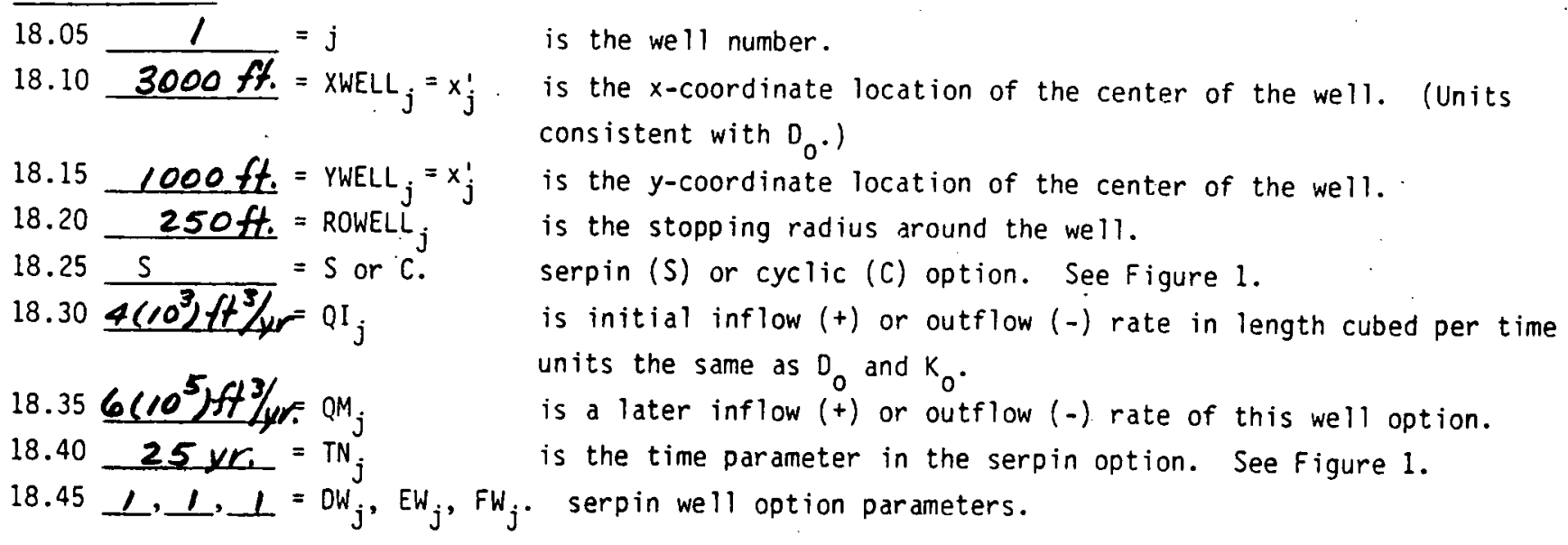

\section{CYCLIC OPTION}

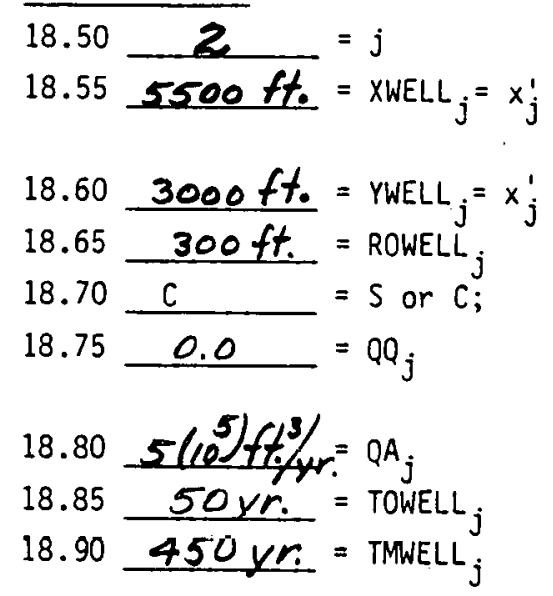

is the we 11 number.

is the $x$-coordinate location of the center of the well. (Units consistent with $D_{0}$.)

is the $y$-coordinate location of the center of the well.

is the stopping radius around the well.

serpin (S) or cyclic (C). See Figure 2.

is the mean inflow $(+)$ or outflow $(-)$ rate in length cubed per time units the same as $D_{0}$ and $K_{0}$.

is the amplitude of the cyclic inflow $(+)$ or outflow $(-)$ rate. is the initial or beginning time for the cyclic well option. is the later cyciic time parameter.

\section{PATHLINE - IRREGULAR STARTING COOROINATES}

(If $\theta 0$ in Item 19 equals $\Theta M$ in I tem 20 then N $\odot$ pathlines

will be generated from the individual coordinates provided below.)

21. $=N O$ is the number of input data sets to be entered for starting pathlines $(1 \leq \mathbf{i} \leq N \theta)$.

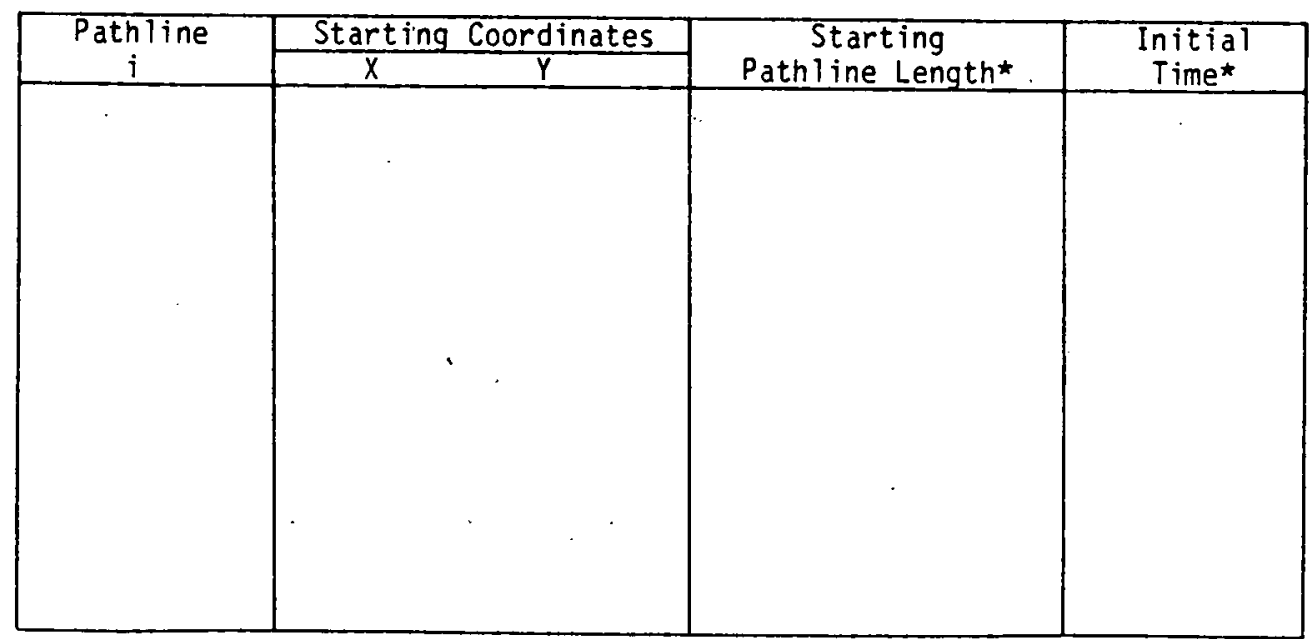




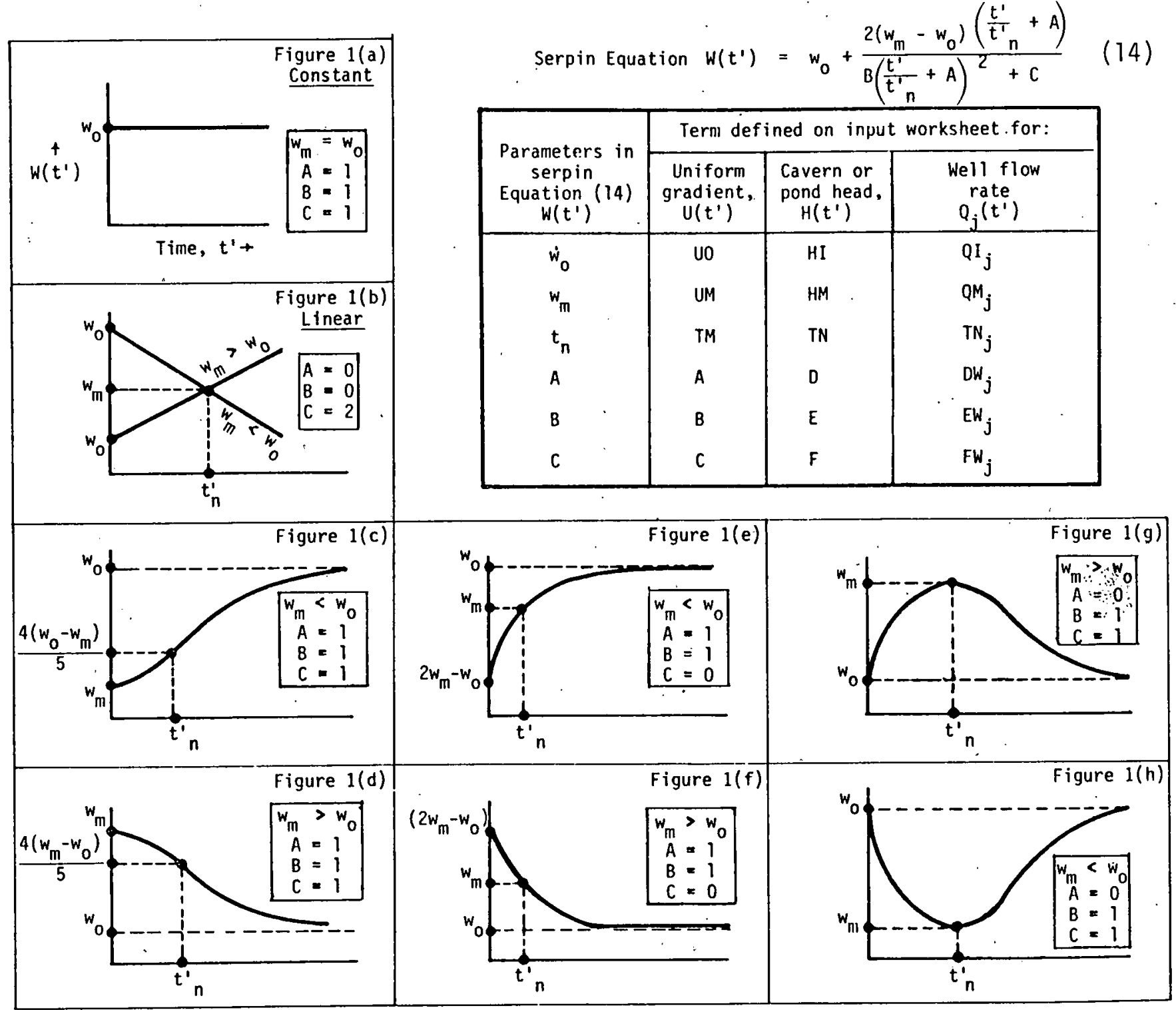

FIGURE 1. Serpin Time-Dependent Forms 
If the exponential leakage (E) option, which considers the case of the head diminishing as the fluid seeps from the cavern, had been chosen then no special inputs would be required for items 14 through 17 . The parameters necessary to calculate the falling head or exponential leakage case have been entered already (see Equations $(A-23)$ and $(A-24)$ in Appendix $A$ ).

Input item 18 is the number of wells to be considered in the flow system. Two injection wells are used in the example transient case, so $J=2$. The specific well data needed are described on the back of the worksheet.

The first injection well with an inflow rate, $Q_{j}\left(t^{\prime}\right)$, is represented by the serpin time dependence illustrated in Figure $1(c)$. The center of the first well (i.e., $j=1$ entered in item 18.05 on the back of the worksheet) is located at $x_{1}=3000 \mathrm{ft}$ and $y_{1}=1000 \mathrm{ft}$. The $x$ and $y$ coordinate distances are always measured from the center of the pond or cavern, which has coordinates $x=0, y=0$. Accordingly, input items 18.10 and 18.15 are 3000 feet and 1000 feet, respectively. The stopping radius, ROWELL $j$, for item 18.20 is required since the well is represented as a singularity. Numerical difficulties will occur if one approaches a well. too closely; two or three hundred feet is a reasonable distance away from such a well, so 250 feet was used in the example.

The injection rate of the first well is represented by the serpin-form time dependence with a lower injection rate $Q_{1}=4000 \mathrm{ft}^{3} / \mathrm{yr}$, a maximum rate $\mathrm{QM}_{1}=600,000 \mathrm{ft}^{3} / \mathrm{yr}$, with a time parameter $\mathrm{TN}_{1}=25 \mathrm{yr}$, and integer parameters of $A=B=C=1$ to complete the input for the first well.

The second well represented by $j=2$ is located at $x_{2}=5500 \mathrm{ft}$ and $y_{2}=3000 \mathrm{ft}$ with a stopping radius of $300 \mathrm{feet}$. These values provide input items $18.50,18.55,18.60$ and 18.65 . This well is used to illustrate the cyclic option for time dependence, so item 18.70 is specified as C. Figure 2 is convenient in selecting the cyclic parameters. For this example case, Figure $2(\mathrm{~b})$ is used with a mean injection rate $\mathrm{QQ}_{2}=0$ beginning at $\mathrm{TO}_{2}=$ $50 \mathrm{yr}$. The amplitude of the injection rate $\mathrm{QA}_{2}$ is $500,000 \mathrm{ft}^{3} / \mathrm{yr}$ with a maximum cycle time. $\mathrm{TM}_{2}=450 \mathrm{yr}$, which completes the well input parameters for the example transient case. 


\section{Cyclic Equation}

$W\left(t^{\prime}\right)=W$ if $W>0$

$W\left(t^{\prime}\right)=0$ if $W \leq 0$

$w=w_{m c}+w_{o c} \sin \left[\left(\frac{t^{\prime}-t_{o c}}{t_{m c}-t_{o c}}\right) 2 \pi\right]$

\begin{tabular}{|c|c|c|}
\hline \multirow[b]{2}{*}{$\begin{array}{l}\text { Parameters in } \\
\text { cyclic } \\
\text { Equation }(16) \mathrm{W}\end{array}$} & \multicolumn{2}{|c|}{ Term defined on input worksheet for: } \\
\hline & $\begin{array}{c}\text { Cavern or pond } \\
\text { head, } H\left(t^{\prime}\right)\end{array}$ & $\begin{array}{c}\text { Well flow rate, } \\
Q_{j}\left(t^{\prime}\right)\end{array}$ \\
\hline$w_{m c}$ & FMC & $Q_{j}$ \\
\hline$w_{o c}$ & HAC & $Q \Lambda_{j}$ \\
\hline$t_{o c}$ & TOC & $\mathrm{TO}_{j}$ \\
\hline$t_{m c}$ & TMC & $T M_{j}$ \\
\hline
\end{tabular}

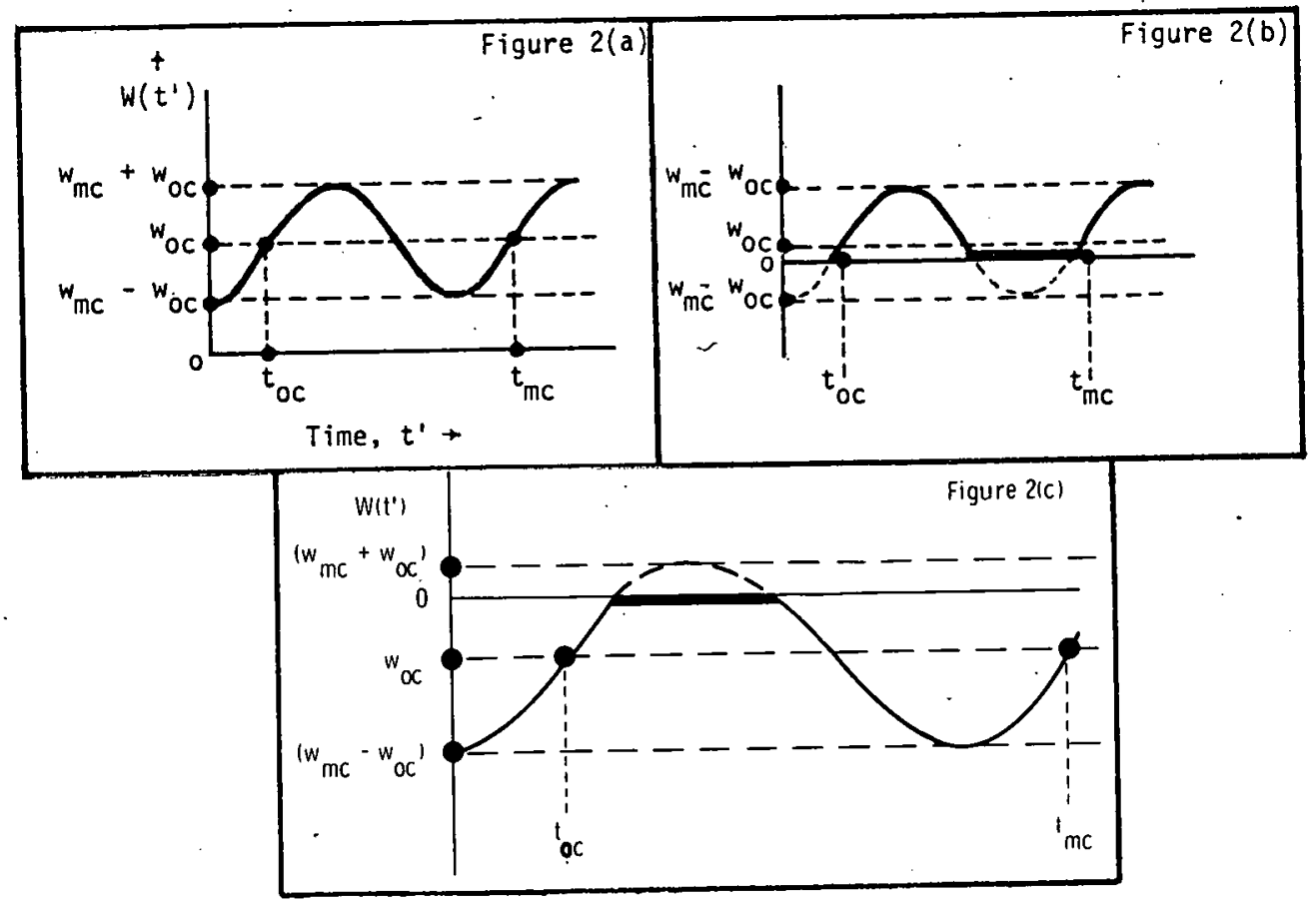

FIGURE 2. Cyclic Time-Dependent Forms 
The remaining input for the example case involves items 19 through 31 in Table 2. Items 19 through 22 allow the user to select the location for starting the pathlines, thereby allowing the fluid particles to be followed. In item 19, the user selects the angle between the $x$ axis and the point on the cavern or pond wall where the first pathline is to originate. One wants to look at the travel along the shortest pathline so a starting angle $\theta 0=0$ is used. The maximum angle of interest was set equal to 160 degrees for $\theta M$. If $\mathrm{N} \theta=9$, then a pathline originating at $\theta=0$ and pathlines beginning every $(160-0) /(9-1)=20 \mathrm{deg}$ around the cavern wall, up to and including the last pathl ine beginning at 160 degrees, are generated. This should provide a good beginning set of fluid particle pathlines. The input parameter $k \theta$ is also set to 1 here to get an additional pathline between 160 and 179.99 degrees. Use of the $K \theta$. parameter is helpful in getting more pathlines near 180 degrees without specifically using the latter value. There is a stagnation point (i.e., a point of zero velocity) upstream of $\theta=180$ that will use excessive computer time if one attempts to generate a path through or very near it. The $K \theta$ input feature allows pathlines to be generated near 180 degrees while minimizing the difficulties with the stagnation point.

The next three parameters (items 23 through 25) specify the times for which fluid particles leaving the cavern wall will be traced. The first contaminated fluid particles leaving the cavern should be followed su $t_{0}$ is set equal to zero (item 23). A useful final set of fluid particles to follow in time are those departing at 100 years, $t_{f}=100 \mathrm{yr}$ (item 24). The value for NT $=5$ was chosen, which means the fluid particles departing at $0,25,50,75$ and 100 years will be generated by the model, so NT = 5 is shown for input item 25 .

No input values are provided for data items 26 and 27 (the $k_{d}$ and bulk density) since exchange reactions for a particular ion are not considered in this example case. Individual fluid particles or the movement of a perfect tracer such as tritium, sulfate, or chloride are being evaluated in this example.

The remaining worksheet inputs in Table 2 are needed to generate plots of the results. Item 28 determines the width of the plot. If a rather narrow plot is expected, as in our example case, then,11-inch wide paper is specified. When in doubt, it is usually best to request the 30 -inch 
width. The XCENTER and YCENTER values in items 29 and 30 specify the location, in inches, from the lower right-hand corner of the plotting sheet where the center of the cavern or pond will be positioned on the plots. In this example, 3 inches to the right of the lower left-hand corner of the plotter paper and 2 inches above should work. The last input item is the plotting scale. It is the number of length units in the real problem to be represented per inch of length on the plot. A plot scale of $1000 \mathrm{ft} / \mathrm{in}$. is used in this case. This scale and the case title are automatically added to the finished computer-generated plot.

This example worksheet (Table 2) contains the major inputs needed by the user. Those few additional questions not specifically covered by the worksheet either will be obvious to the user or readily available using the HELP feature. So, armed with an input worksheet (that reflects the case at hand), a terminal and the Appendix B User's Guide, a computer novice should now be able to get the arrival results needed. (The example transient case is presented in complete detail in Appendix B.)

CONTAMINANT ARRIVAL RESULTS FROM THE MODEL

The contaminant arrival results are available from the interactive and batch runs described in Appendix B. Among the results provided are 1) the fluid or contaminant flow paths and the rate of advance and shape of the contaminant fronts moving through the subsurface region, 2) the location and time of contaminant arrival at the biosphere interface, and 3) the amount of contaminated fluid arriving with passing time. These are the results necessary to evaluate the environmental consequences ( $\mathrm{Nel}$ son, 1976). The example case results will be used to illustrate the results obtained from the preliminary evaluation methods.

Fluid Pathlines and Advancing Fronts

The fluid pathline provides the expected location of the fluid at various times during the gradual movement from the pond or cavern to the remote boundary (river, in this example). The pattern of the advancing front is developed by following representative fluid particles along the paths traversed with passing time. If, at a specific time, a line is passed through the location of each particle on its pathline, an isochronal line 
(i.e., the position of the advancing front of fluid particles at that particular time) is determined. In this way, the changing locations of fluid particles are conveniently indicated by the pathlines and isochronal lines.

The pathlines and isochronal lines for the example transient case, obtained using the PATHS program, are shown in Figures 3 and 4 . In Figure 3, the pathlines and advancing fronts in time denoted by the numbers are shown for the fluid departing from the pond at 0 and 50 years. Figure 4 shows the results for fluid particles leaving the pond at 75 and 100 years.

The flow results in the figures were obtained from the type of computergenerated plots shown near the end of Appendix $B$ as example output of the PATHS program. Each number placed along the pathl ines in the machine plots corresponds to a time in the individual pathl ine. For example, the number one is for 100 years, 2 for 200 years. The advancing front isochronal 1 ines at a given time are represented by connecting like numbers on the plots in Figures 3 and 4 .

The overall flow pattern and advancing front results provide considerable insight into the system response. The pattern is also very useful in physically interpreting the arrival results provided in the next two sections. The Location/Arrival-Time Distribution

The location/arrival-time distribution gives the locations where the contaminants will reach the groundwater outflow boundary with passing time. In our example, this is the location, as a function of time, where the contaminated groundwater will enter the river.

The interactive model provides the arrival data as summary results, which are listed in Table 3. The results labeled "Y" in column 3 of the computer output table in the section, Summary File-BQ3VH_ in Appendix C and labeled as $S$ in column 3 of Table 3 are plotted against the travel times in column 2 to provide the location/arrival-time distribution shown in Figure 5. The several curves in the figure represent the arrival along the river bank of contaminated water that departed from the pond at time zero, 25, 50, 75, 100 and 125 years. The opening between 800 and 1200 feet along the river containing no arrival curves results from the injected uncontaminated water entering the first well (see Figures 3 and 4). Similarly, the vug-shaped open area in the arrival curves around 3000 feet in 


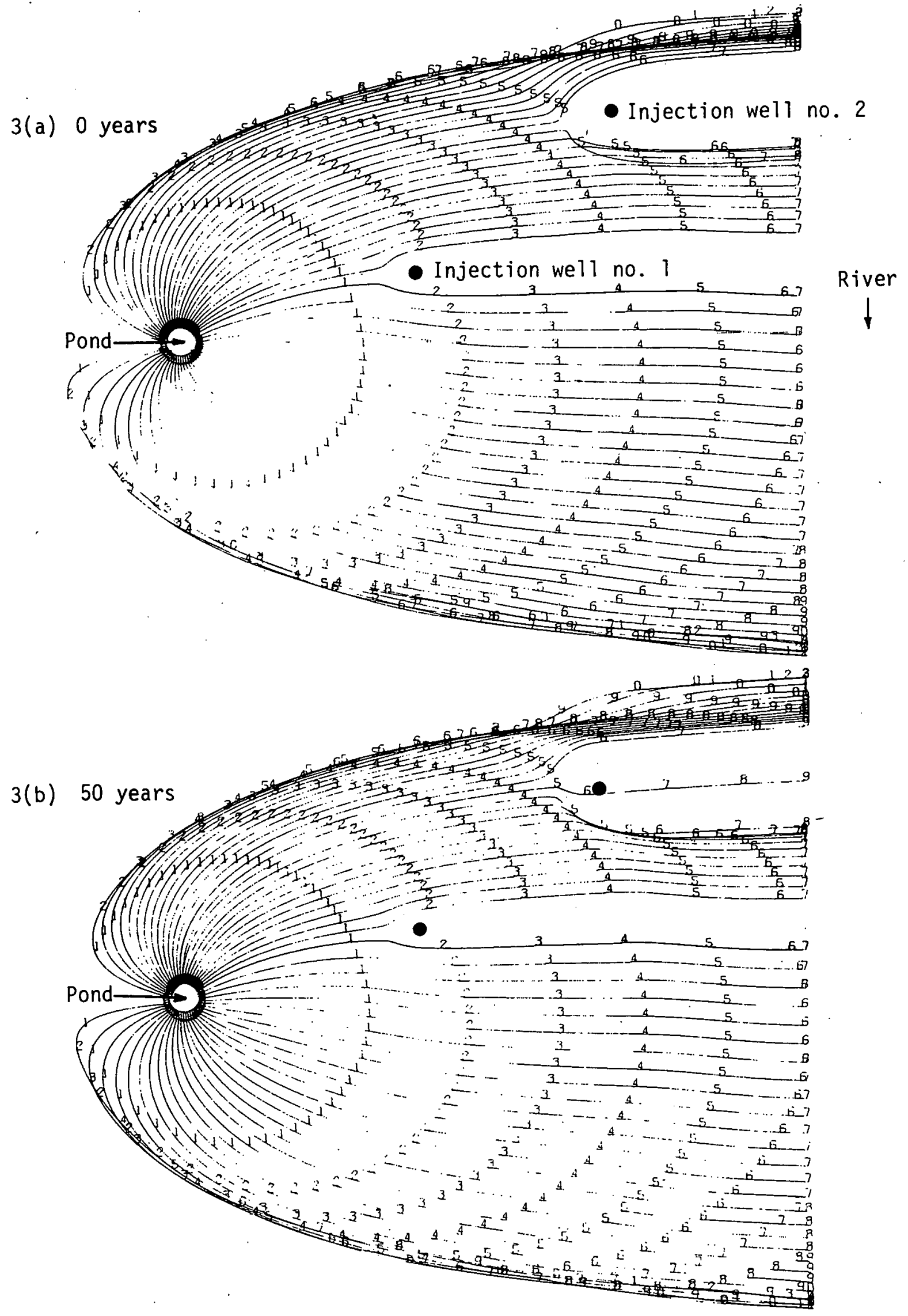

FIGURE 3. Example Transient Flow Results for Fluid Particles Departing Pond at 0 and 50 Years 

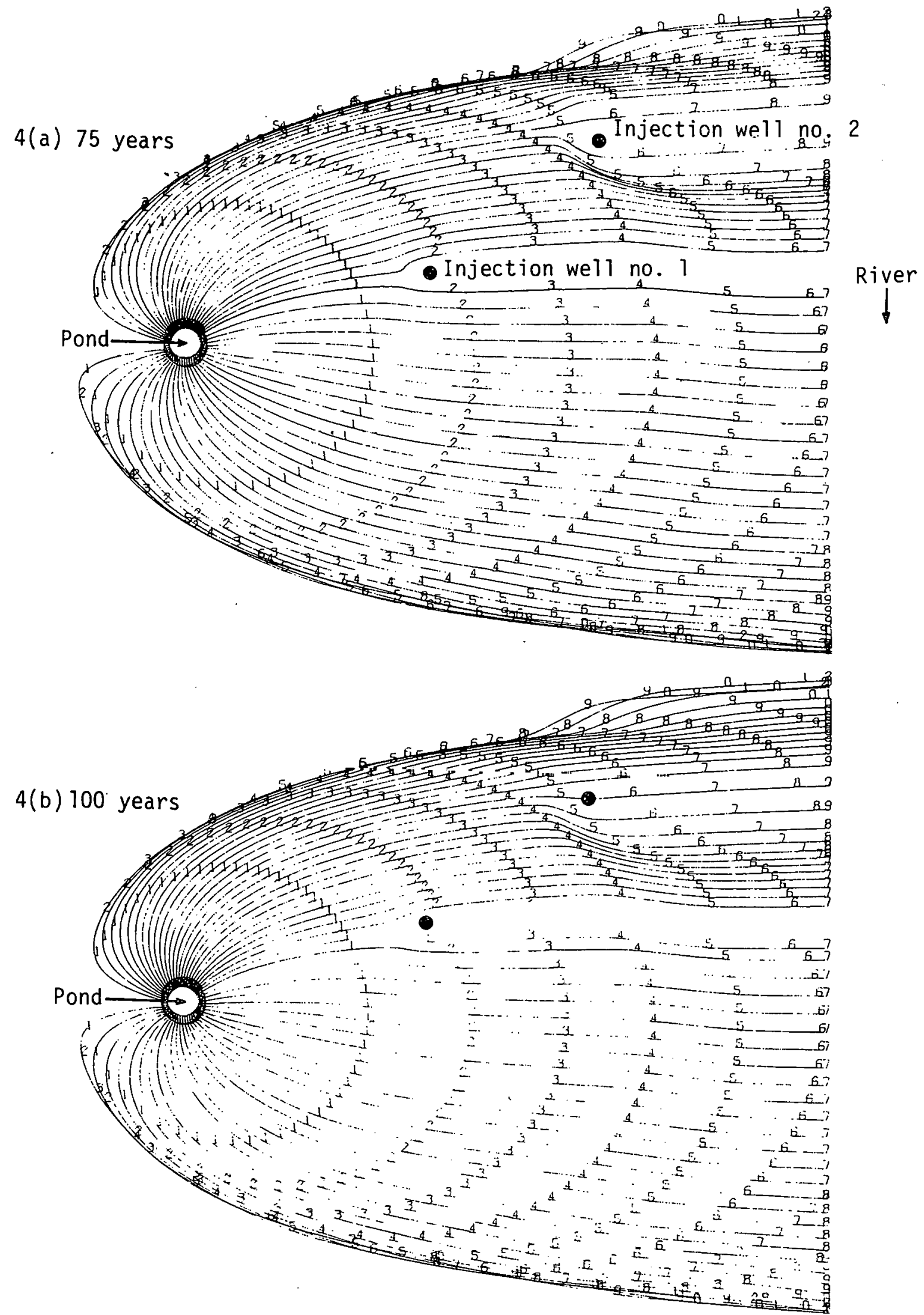

FIGURE 4. Example Transient Flow Results for Fluid Particles Departing Pond at 75 and 100 Years 
TABLE 3. Contaminant Arrival Time and Outflow Locations Along River for the Example Transient Case

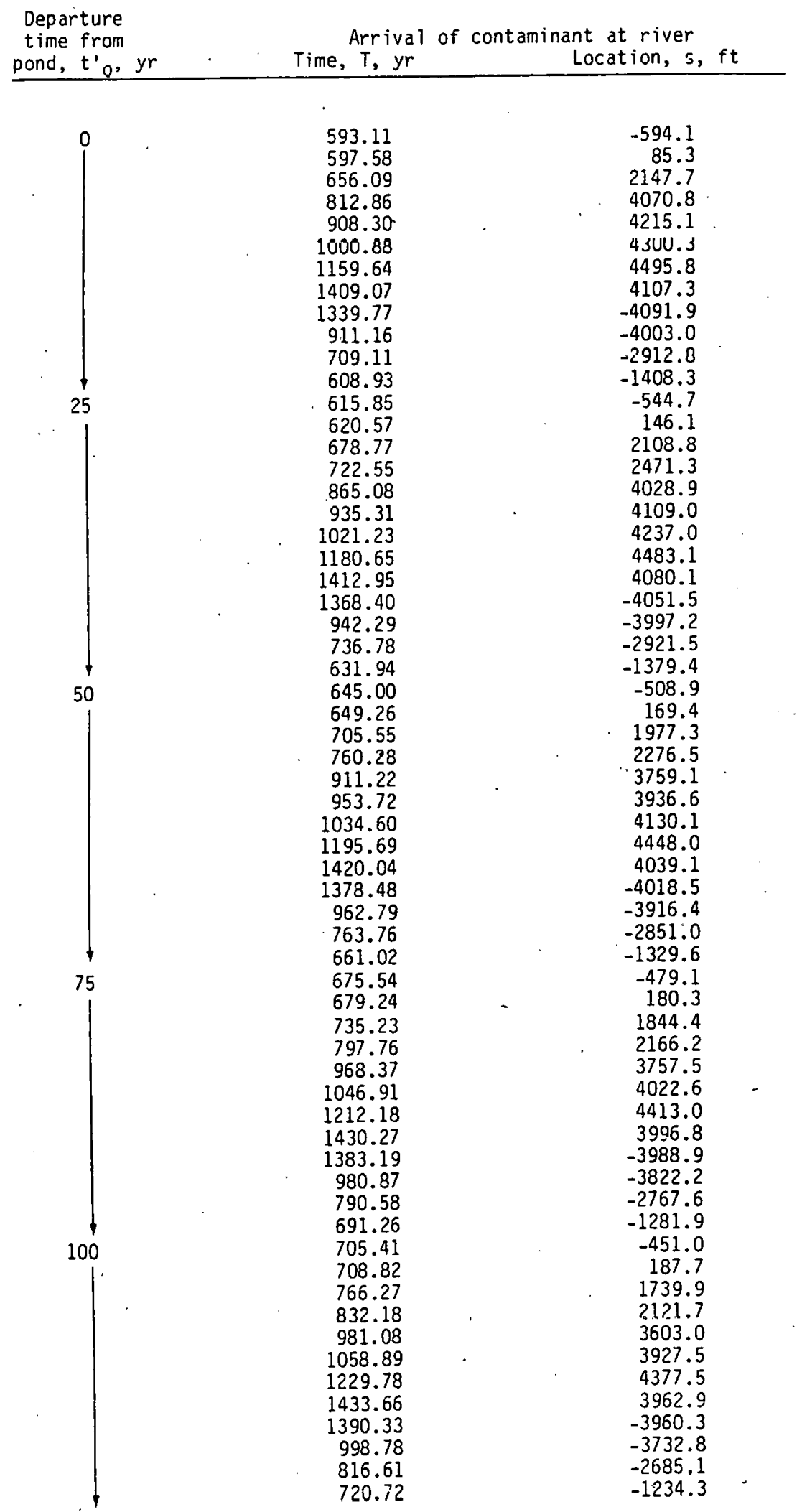




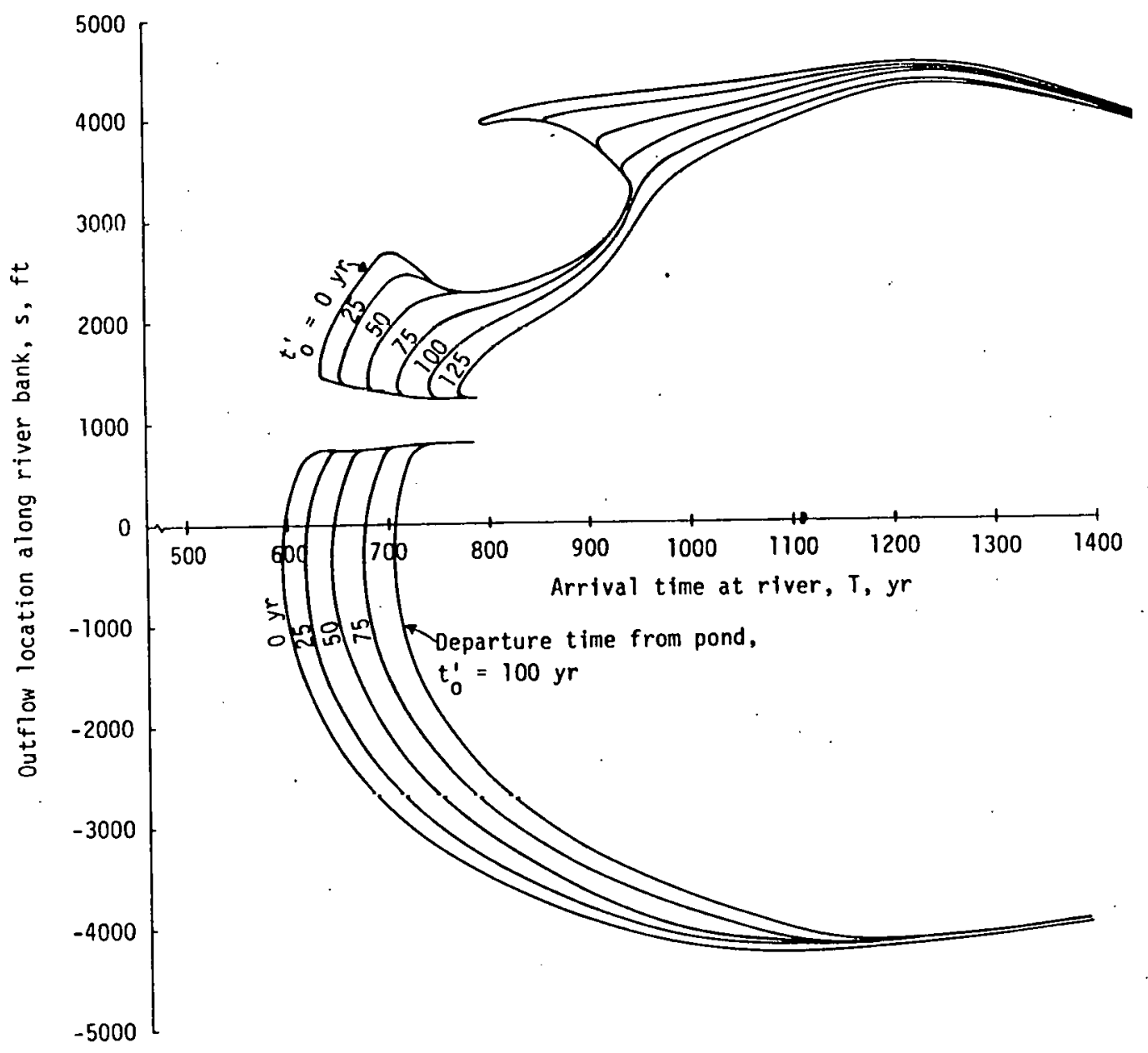

FIGURE 5. The Contaminant Location/Arrival-Time Distribution for the Transient Example Case. 
Figure 5 is caused by the fluid injected into the second well. In both instances, the flow system results in Figures 3 and 4 are helpful in understanding the outflow-location/arrival-time response functions shown in Figure 5 .

The location/arrival-time results (in Table 3 and shown in Figure 5) are the first results required to evaluate the environmental consequences. The second set of results is discussed in the next section using the example evaluation results. The two sets of results are then used to provide the overall environmental consequences.

The Location/Outflow-Quantity Distribution

The location/outflow-quantity results give the amount of contaminated groundwater outflow at the various locations along the river. The particular unit outflow rates are provided by the interactive LOCQAR program, discussed in detail for the example case in Appendix B.

The LOCQAR program is easy to execute; since it requires very 1 imited input, no special input sheets are needed. As the GROUND program (i.e., batch computer run part of PATHS) is executed, most of the inputs required for LOCQAR are placed on a special file for subsequent use. Few requests. for data from the user are made by the LOCQAR program. Those requests utilize the prompting and HELP features, as in PATHS, and can be answered directly from the location/arrival-time curves as in Figure 5 . Instructions for using LOCQAR and complete example runs are provided in Appendix $B$ in the section "Executing LOCQAR."

The results from LOCQAR are shown in Table 4. In particular, the arrival times at various locations along the river are provided along with the unit outflow rate of contaminated fluid. The unit outflow rate is the water outflow volume per unit time per unit distance along the river bank. Such a unit outflow rate is required since the rate changes both with location along the river and with time.

From the results in Table 4 , the graph of the location/outflow-quantity distribution was prepared as shown in Figure 6 . Some caution in using the plotted results is necessary since the curves representing various arrival times can be confusing. The curve for an arrival time, $T=600 \mathrm{yr}$, has a maximum value for $q$ of $228.4 \mathrm{ft}^{3} / \mathrm{yr} / \mathrm{ft}$. The outflow rate values for the 
TABLE 4.- Contaminant Arrival Location Along River and Unit Outflow Rate for Example Transient Case

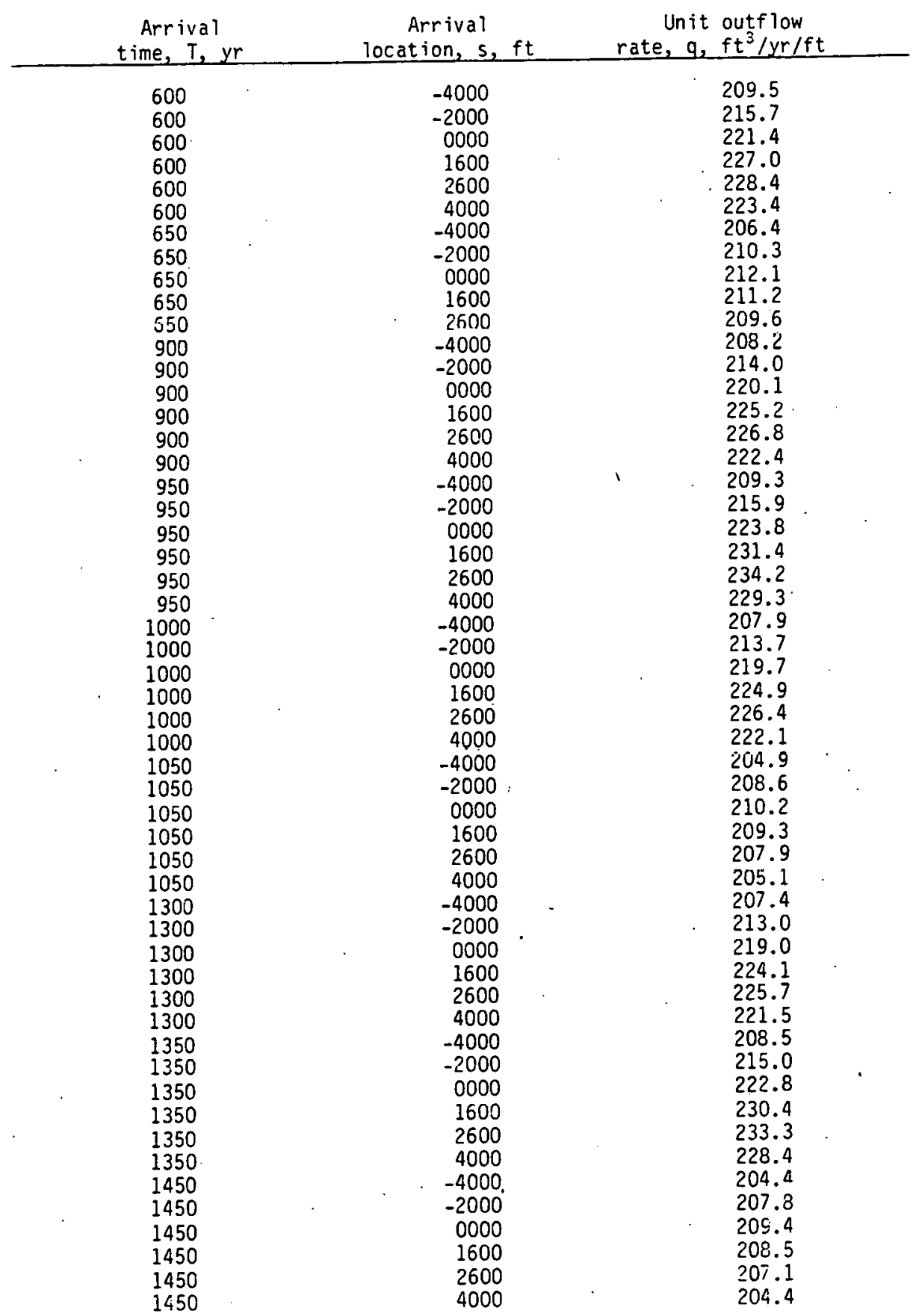




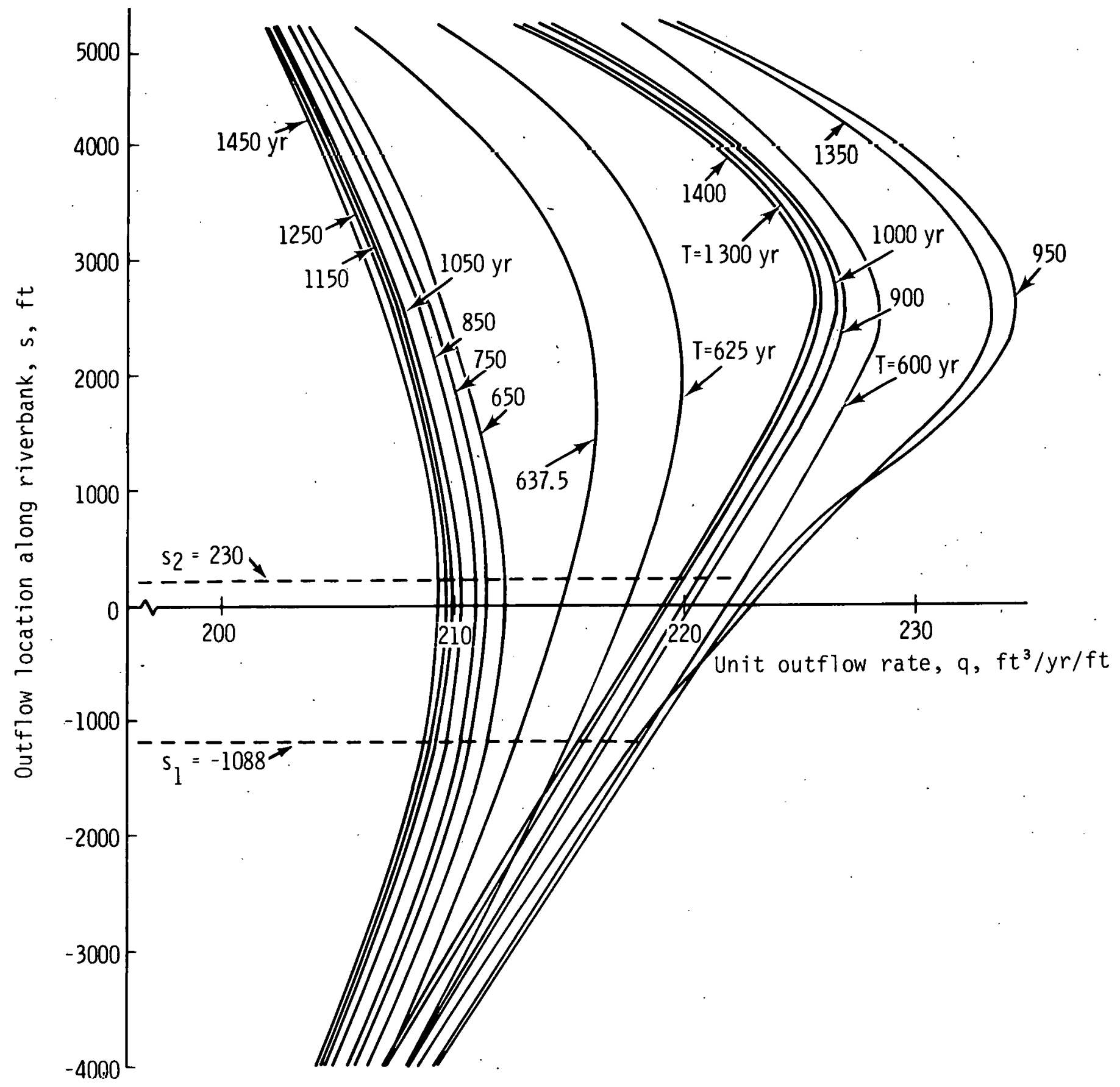

FIGURE 6. Contaminant Location/OutflowQuantity Distribution at the River for the Example Transient Case 
curve $T=625 \mathrm{yr}$ in Figure 6 is smaller or 1 ies to the left of the $600 \mathrm{yr}$ curve as do the curves for 637.5, 650, and $750 \mathrm{yr}$. The curve for $T=850 \mathrm{yr}$ is also displaced slightly to the left and is a local minimum curve. For $T=900 \mathrm{yr}$, the curve is displaced considerably to the right. The $950 \mathrm{yr}$ curve is still further displaced to the right and is the maximum $q$ curve in the Figure over most of the range of $\mathrm{s}$. The $1000 \mathrm{yr}$ curve recedes again to the left, with smaller q values, as do the $1050 \mathrm{yr}$ and $1150 \mathrm{yr}$ curves. Similarly, the $1250 \mathrm{yr}$ curve is slightly left and is another local minimum curve. However, the $1300 \mathrm{yr}$ curve is again significantly displaced to the right with the trend continuing to the local maximum curve for $T=1350 \mathrm{yr}$. The curves recede again to the left passing the $1400 \mathrm{yr}$ curve and ending with $\mathrm{T}=1450 \mathrm{yr}$ as the most extreme left-hand curve. Such a pattern of initially diminishing unit outflow rates-which later reverse, then increase cyclically until a maximum is reached at $T=950 \mathrm{yr}$ and then recede--requires special care in using the plot.

USE OF ARRIVAL DISTRIBUTIONS

The two arrival distributions are easy to use to determine the concentrations and amount of contaminants that will interface with the environment. The concentration along the outflow boundary (the river, in the example) is always available from the lucation/arrival-time distribution.

The concentration arrival distribution is similar to the results in Figure 5 since only water-coincident contaminants are considered, and the input concentration at the pond is constant. No exchange reactions are considered in the example and the contaminant source concentration, $C_{0}$, is assumed constant over the first 25 years. After the first 25 years, no more contaminant will enter the pond or cavern. Under such conditions and with the worst-case assumption (no dispersion occurs), the concentration arrival distribution involved only using a portion of the location/arrival-time results from Figure 5 .

In Figure 7, the concentration/arrival-time distribution is shown and provides the concentration entering the river with passing time. The same concentration as departed from the cavern reaches the river since the contaminant input was uniformly distributed between the zero and 25-year departure-time curves, and no exchange occurred with the porous material. 

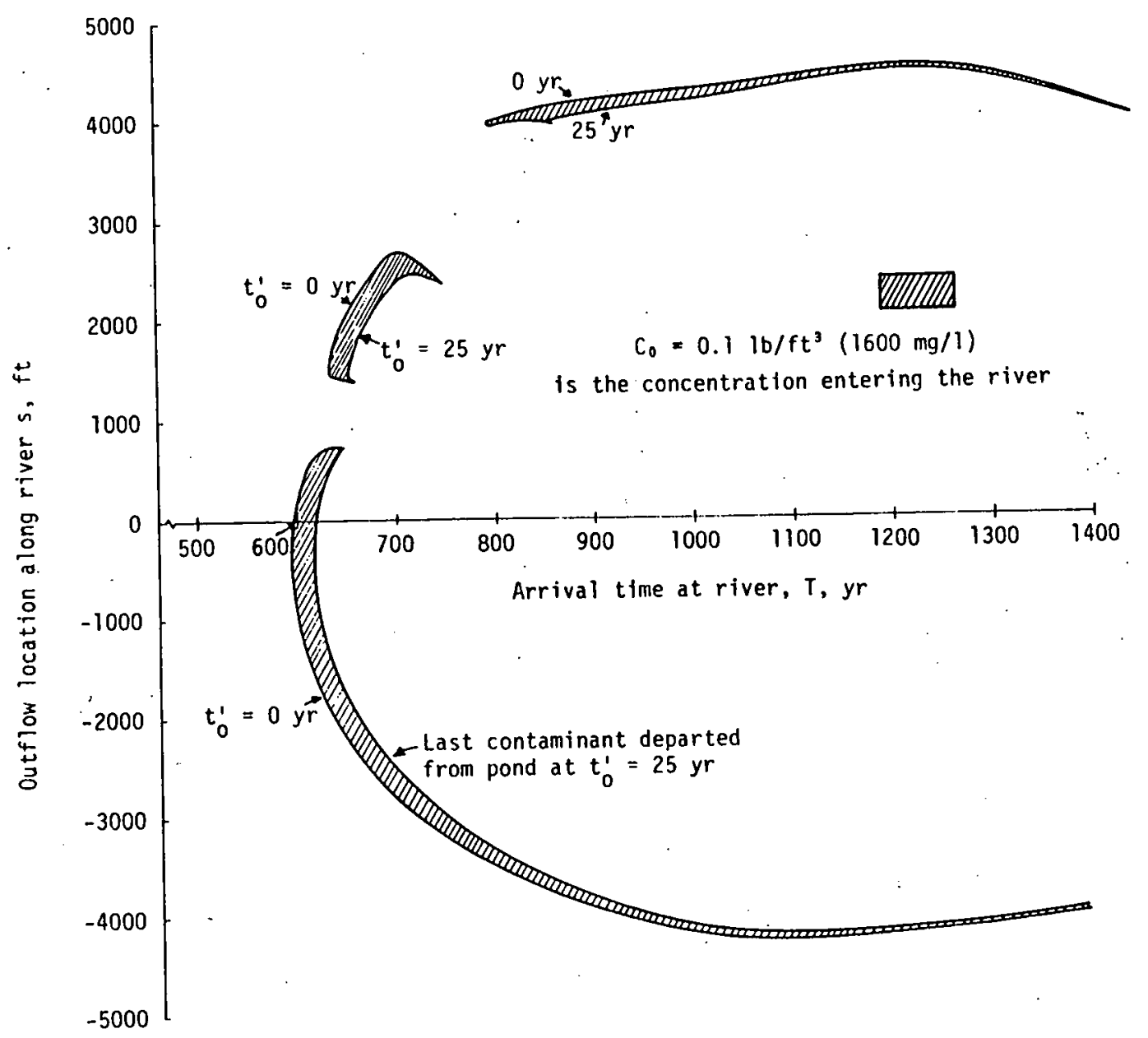

FIGURE 7. The Concentration of Contamination Entering the River at Various Locations and Times for the Example Transient Case 
Through the use of Figure 7, various combinations of locations with times can be considered to yield the worst-case dose of contaminant to the biosphere. Accordingly, the concentration arrival distribution provides the first results required to evaluate the environmental consequences.

The second set of results needed is the outflow rate of contaminant into the river as time passes. Such results are available by using the concentration/arrival-time results and location/outflow-quantity distributions together. By combining the concentration and fluid outflow rate into the river, the actual contaminant outflow rate as a function of time is obtained. Specifically, the rate of contaminant entering the river, $W_{T}$, has the integral form

$$
w_{T}=\left.\int_{s_{1}}^{s_{2}} c_{0} \cdot q\right|_{T} d s
$$

where $W_{T}$ is the contaminant outflow rate.

$C_{0}$ is the concentration in the pond.

$q$ is the unit outflow rate of groundwater into the river.

$T$ is the particular arrival time at which $q$, hence $W_{T}$, is evaluated.

$s_{1}$ is the location (lower 1 imit) where contaminated fluid enters the river.

$\mathrm{s}_{2}$ is the location (upper limit) where contaminated fluid is entering the river.

Suppose one wanted to evaluate the contaminant outflow rate using Equation (17) at $T=600 \mathrm{yr}$. From Table 3, or more directly. from Figure 7, at $T=600 \mathrm{yr}$ the contaminated water is seen to enter the river between $s_{1}=-1088$ and the location $s_{2}=230 \mathrm{ft}$. Use of these locations in Figure 6 indicates the $q$ variation with distance along the river. Using the q variation and the locations in Equation (17) and using $C_{0}=0.11 \mathrm{~b} / \mathrm{ft}^{3}$ gives

$$
W_{600}=\left.0.1 \int_{-1088}^{230} q\right|_{600} ^{2} d s
$$


or upon evaluating

$$
W_{600}=28,872 \mathrm{lb} / \mathrm{yr}=0.0549 \mathrm{1b} / \mathrm{min}
$$

As a second example, consider the arrival time $T=800 \mathrm{yr}$. From Figure 7, two outflow intervals are seen at $T=800$ years. The first outflow length, $s$, is between -3540 and -3400 feet. The second outflow is between 3973 and 4017 feet. Accordingly, the contaminant outflow is

$$
w_{800}=\left.0.1 \int_{-3540}^{-3400} q\right|_{800} d s+\left.0.1 \int_{3973}^{4017} q\right|_{800} d s
$$

or

$$
W_{800}=4,336 \mathrm{lb} / \mathrm{yr}=0.00825 \mathrm{lb} / \mathrm{min}
$$

Other evaluations of the type just illustrated provide the complete contaminant outflow rate in time that is shown in Figure 8.

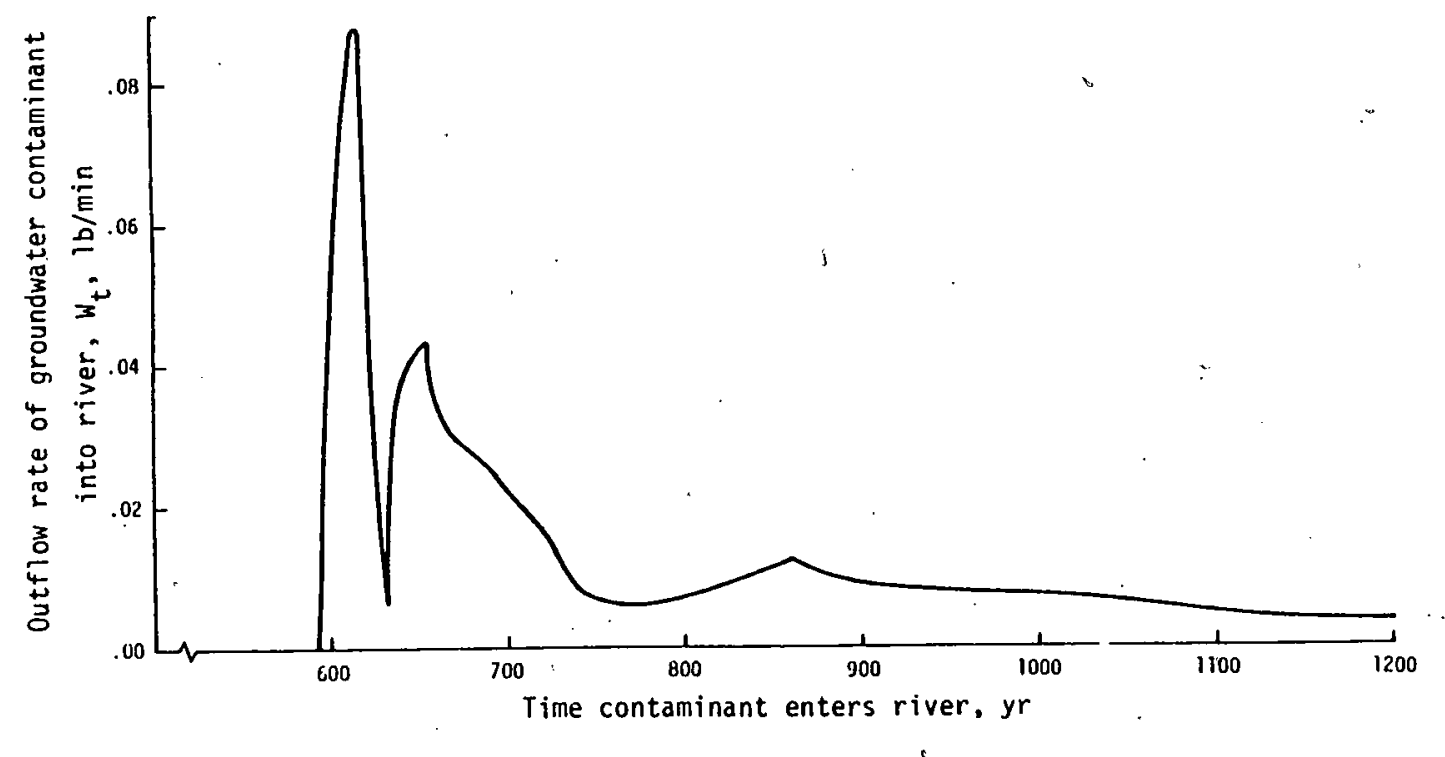

FIGURE 8. The Outflow Rate of Groundwater Contamination for the Example Transient Case. 
From the contaminant arrival curve in Figure 8, twio consequences for the example are noted that are typical. The peak value is most important and, second, the significantly extended tail of the curve. The peak value of 0.087 pounds per minute is immediately apparent and always considered; however, the tail part of the curve is sometimes overlooked too quickly. By itself; this low value may not be significant, but, if it is combined with the tails of several other contaminant sources on a river or stream, then the additive effect may become important. Therefore, the entire curve is really needed if the environmental consequences are to be considered in any detail.

This completes the example evaluation using the prel iminary evaluation capability. If a user wants more experience using the interactive programs, a second example steady case is provided in Appendix B. Our experience shows that the programs are quite helpful in providing preliminary evaluations for a group of two-dimensional subsurface pollution problems. 


\section{ACKNOWLEDGMENTS}

The authors express special appreciation to Battelle staff members John R. Raymond, Modeling Task Lèader, and Harry C. Burkholder, Project Director of the WISAP effort, who encouraged the work in its final form and enabled the documentation of the PATHS, GROUND and LOCQAR programs.

Particular appreciation is expressed to Niall W. Kline of BCSR for his programming and ullier specid? assistance in producing the numerous special sample runs used in this document. Special credit is also due Lea LaZelle and Robert Stallcop of the BCSR staff who capably handled the many editorial and graphical aspects in preparation of this report. 


\section{REFERENCES}

Allensworth, James A., et a1., 1977. Underground Siting of Nuclear Power Plants: Potential Benefits and Penalties. U. S. Nuclear Regulatory Commission Report NUREG-0255 - SAND76-0412. Prepared by Sandia Laboratory, $257 \mathrm{pp}$.

Gi11, S., 1951. A Process for the Step-by-Step Integration of Differential Equations in an Automatic Digital Computing Machine. Proc. Cambridge Philos. Soc., Vol. 47, pp 96-108.

Nelson, R. William, Robert T. Toyooka and David A. Moe, 1970. An Initial Model of Fluid Movement from Deep Underground Storage Caverns. Informal Report CSC-7006-01 to Atlantic Richfield Hanford Company, Richland, Washington.

Nelson, R. William, 1976. Evaluating the Environmental Consequences of Groundwater Contamination. Management Summary and Technical Papers. United States Energy. Research and Development Administration, Richland Operations; BCS Richland, Inc. Report BCSR-6. 129 pp.

Shames, I. H., 1962. Mechanics of Fluids. McGraw-Hill, New York, New York. 

APPENDIX A

\section{DERIVATION OF MODEL EQUATIONS}

The equations for the idealized model described in the report are presented here and useful results are derived. The model was designed to enable estimates of expected contaminant transport consequences when limited field data is available. Accordingly, the model is necessarily simplified and idealized as the representation of the real situation. However, special care was exercised to assure that minimum worst-case estimates for the fluid travel times would be provided by the model.

A GROUNDWATER POTENTIAL SOLUTION

The model assumes isothermal conditions and describes the saturated flow of an incompressible fluid through a two-dimensional lateral stratum of thickness or depth, $D_{0}$. The stratum is a porous material that is homogeneous and isotropic with respect to hydraulic conductivity, $K_{0}$, and the effective porosity, $P$. A uniform lateral gradient, $U$, of the fluid in the stratum provides a velocity in the $x$ direction. Though the lateral gradient is uniform in direction, the gradient strength, $U$, may vary with time. A cylindrical cavity of radius $r^{\prime}{ }_{0}$ and length $D_{0}$ completely penetrates the stratum or porous slab. The flow from the cylindrical cavity depends upon the cavern head, $H^{\prime}$, which generally is some function of time. Wells are introduced into the model as completely penetrating vertical line sources again with time-varying injection or withdrawal rates.

The objective for the idealized model is to consider a range of typical transient situations. The time dependence enters through the uniform gradient, $U$, the cavern head, $H^{\prime}$, and the well flow rates. Each of these are represented by a moderately general variable/functional form for the time dependence. In this way, a variety of transient situations can be evaluated directly and most others can be approximated quite satisfactorily. The transient forms of variation are. shown schematically in Figures 1 and 2 of the report; the steady situations are available by setting the time-varying parameters to appropriate constants. 
We begin by considering a potential function formed by superposition of elementary flows. A uniform lateral flow is added to a combined source and positive doublet centered at the origin. Away from the origin several pumping or injection wells are superimposed as completely penetrating vertical line sinks and sources. Specifically,

$$
\begin{aligned}
\phi^{\prime}= & -U x^{\prime}-\frac{M_{0}}{2 \pi} \ln \sqrt{\left(x^{\prime}\right)^{2}+\left(y^{\prime}\right)^{2}}+\frac{U x^{\prime}\left(r_{0}^{\prime}\right)^{2}}{\left(x^{\prime}\right)^{2}+\left(y^{\prime}\right)^{2}} . \\
& -\sum_{j=1}^{j=N} \frac{M_{j}}{2 \pi} \ln \sqrt{\left(x^{\prime}-x_{j}^{\prime}\right)^{2}+\left(y^{\prime}-y_{j}^{\prime}\right)^{2}}+C_{0}^{\prime}
\end{aligned}
$$

where

$$
\begin{aligned}
& \phi^{\prime}= \phi^{\prime}\left(x^{\prime}, y^{\prime}, t^{\prime}\right) \text { is the potential energy function that } \\
& \text { satisfies the Laplace Equation } \\
& U= U\left(t^{\prime}\right) \text { is time-dependent uniform flow gradient } \\
& M_{0}= M_{0}\left(t^{\prime}\right) \text { is the major time dependent source strength } \\
& \text { located at the origin } \\
& r_{0}^{\prime}= \sqrt{\left(x_{0}^{\prime}\right)^{2}+\left(y_{0}^{\prime}\right)^{2}} \text { is the radius of the major source } \\
& M_{j}= M_{j}\left(t^{\prime}\right) \text { is the source or sink strength of the jth well 10- } \\
& \text { cated with center at }\left(x_{j}^{\prime}, y_{j}^{\prime}\right) \\
& x_{j}^{\prime} \text { and } y_{j}^{\prime} \text { are respectively } x^{\prime} \text { and } y^{\prime} \text { coordinates of the center of } \\
& \quad \text { the jth well } \\
& N \text { is the total number of wells in the flow system } \\
& C_{0}^{\prime} \text { is a constant to be determined } \\
& x^{\prime} \text { and } y^{\prime} \text { are the Cartesian coordinate variables } \\
& t^{\prime} \text { is time }
\end{aligned}
$$

A convenient set of dimensionless variables is:

$$
\begin{aligned}
& x=\frac{x^{\prime}}{R} \\
& y=\frac{y^{\prime}}{R}
\end{aligned}
$$




$$
\begin{aligned}
& \dot{r}_{0}=\frac{r_{0}^{\prime}}{R} \\
& r_{j}=\frac{r_{j}^{\prime}}{R} \\
& \phi=\frac{\phi^{\prime}}{H_{0}} . \\
& H=\frac{H^{\prime}}{H_{0}} \\
& t=\frac{K_{0} H_{0}}{R^{2}} t^{\prime}
\end{aligned}
$$

Substituting Equation ( $A-2)$ into $(A-1)$ provides the potential in dimensionless form

$$
\begin{aligned}
\phi= & -\frac{U R}{H_{0}} x-\frac{M_{0}}{2 \pi H_{0}} \ln \sqrt{R^{2}\left(x^{2}+y^{2}\right)}+\frac{U R r_{0}^{2} x}{H_{0}\left(x^{2}+y^{2}\right)} \\
& -\sum_{j=1}^{j=N} \frac{M_{j}}{2 \pi H_{0}} \ln \sqrt{R^{2}\left[\left(x-x_{j}\right)^{2}+\left(y-y_{j}\right)^{2}\right]}+C_{i}
\end{aligned}
$$

$C_{1}$ is to be specified such that around the major source wall described by

$$
x_{0}^{2}+y_{0}^{2}=r_{0}^{2}
$$

the condition to be satisfied is

$$
\phi=H
$$

Therefore, upon substituting into $(A-3)$ and solving for $C$ gives

$$
C_{1}=H+\frac{M_{0}}{2 \pi H_{0}} \ln \left(R r_{0}\right)+\sum_{j=1}^{j=N} \frac{M_{j}}{2 \pi H_{0}} \ln \left[R \sqrt{\left(x_{0}-x_{j}\right)^{2}+\left(y_{0}-y_{j}\right)^{2}}\right](A-6) \text {. }
$$


Substitution of Equation $(A-6)$ into $(A-3)$ yields

$$
\begin{aligned}
\phi= & H-\frac{U R}{H_{0}} x+\frac{U R r_{0}^{2}}{H_{0}}\left(\frac{x}{x^{2}+y^{2}}\right)-\frac{M_{0}}{2 \pi H_{0}} \ln \left(\sqrt{\frac{x^{2}+y^{2}}{r_{0}}}\right) \\
& -\sum_{j=1}^{j=N} \frac{M_{j}}{2 \pi H_{0}} \ln \sqrt{\frac{\left(x-x_{j}\right)^{2}+\left(y-y_{j}\right)^{2}}{x_{j}{ }^{2}\left(1-\frac{x_{0}}{x_{j}}\right)^{2}+y_{j}^{2}\left(1-\frac{y_{0}}{y_{j}}\right)^{2}}} .
\end{aligned}
$$

The dependence in Equation (A-7) would be simplified considerably if

$$
x_{0} \ll x_{j} \text { and } y_{0} \ll y_{j}
$$

which would imply that the wells with centers at $x_{j}, y_{j}$ cannot be too close to the main source wall defined by Equation $(A-4)$. If $(A-8)$ is true, then

$$
\left(1-\frac{x_{0}}{x_{j}}\right)^{2} \approx 1
$$

and

$$
\left(1-\frac{y_{0}}{y_{j}}\right)^{2} \approx 1
$$

We assume Equations $(A-8)$ and $(A-9)$ are satisfied and then derive the expression for the error, introduced. That is, Equation $(A-7)$ becomes

$$
\begin{aligned}
\phi= & H-\frac{U R}{H_{0}} x+\frac{U R r_{0}{ }^{2}}{H_{0}}\left(\frac{x}{x^{2}+y^{2}}\right)-\frac{M_{0}}{2 \pi H_{0}} \ln \left(\frac{\sqrt{x^{2}+y^{2}}}{r_{0}}\right) \\
& -\sum_{j=1}^{j=N} \frac{M_{j}}{2 \pi H_{0}} \ln \sqrt{\frac{\left(x-x_{j}\right)^{2}+\left(y-y_{j}\right)^{2}}{x_{j}{ }^{2}+y_{j}{ }^{2}}}
\end{aligned}
$$

The error term associated with assuming Equation $(A-9)$ is obtained by setting $x=x_{0}, y=y_{0}$ and using Equation $(A-4)$ in $(A-10)$ to give the error. introduced by the $j$ th well as 


$$
(\phi-H)_{j}=\frac{M_{j}}{2 \pi H_{0}} \ln \sqrt{\frac{\left(x_{0}-x_{j}\right)^{2}+\left(y_{0}-y_{j}\right)^{2}}{\left(x_{j}{ }^{2}+y_{j}{ }^{2}\right)}} .
$$

If we consider part of the expression under the radical and the sketch below, then using the Law of: Cosines

$$
\begin{aligned}
& \left(x_{0}-x_{j}\right)^{2}+\left(y_{0}-y_{j}\right)^{2}= \\
& r_{j}^{2}+r_{0}^{2}-2 r_{j} r_{0} \cos \left(\theta_{0} \div \theta_{j}\right)
\end{aligned}
$$

or

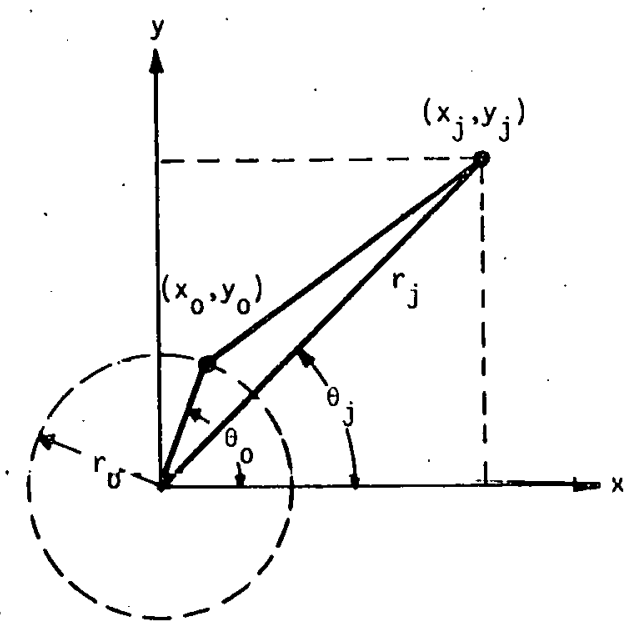

$$
\frac{\left(x_{0}-x_{j}\right)^{2}+\left(y_{0}-y_{j}\right)^{2}}{r_{j}^{2}}=1+\frac{r_{0}^{2}}{r_{j}^{2}}-\frac{2 r_{0}}{r_{j}^{2}} \cos \left(\theta_{0}-\theta_{j}\right),
$$

But the left-hand side is the expression under the radical in Equation $(A-11)$, so substituting and rearranging that equation gives

$$
\varepsilon \equiv \frac{(\phi-H) j}{\frac{M_{j}}{2 \pi H_{0}}}=\ln \sqrt{1+\frac{r_{0}}{r_{j}}\left[\frac{r_{0}}{r_{j}}-2 \cos \left(\theta_{0}-\theta_{j}\right)\right]} .
$$

The approximation error, $\varepsilon$, is expressed as the ratio of the major source boundary condition to the $j$ th well strength, which by the right-hand side of Equation (A-13) is a function of $r_{0} / r_{j}$ and the differences of angles $\left(\theta_{0}-\theta_{j}\right)$. The magnitude of error depends primarily on the size of $r_{0} / r_{j}$ since the cosine is bounded. That is, if $r_{0} / r_{j}$ is small enough then negligible error will be introduced. In Figure $A-1$, the expression for error given by Equation (A-13) is plotted for a range of $r_{0} / r_{j}$ values. As $r_{0} / r_{j}$ becomes smaller the error becomes essentially insignificant. For values of $r_{0} / r_{j}$ less than 0.01 , the error is always less than 1-percent maximum. Such a value is reasonable and is recommended for general use. Accordingly, Equation (A-10) approximately satisfies the boundary conditions so long as: 


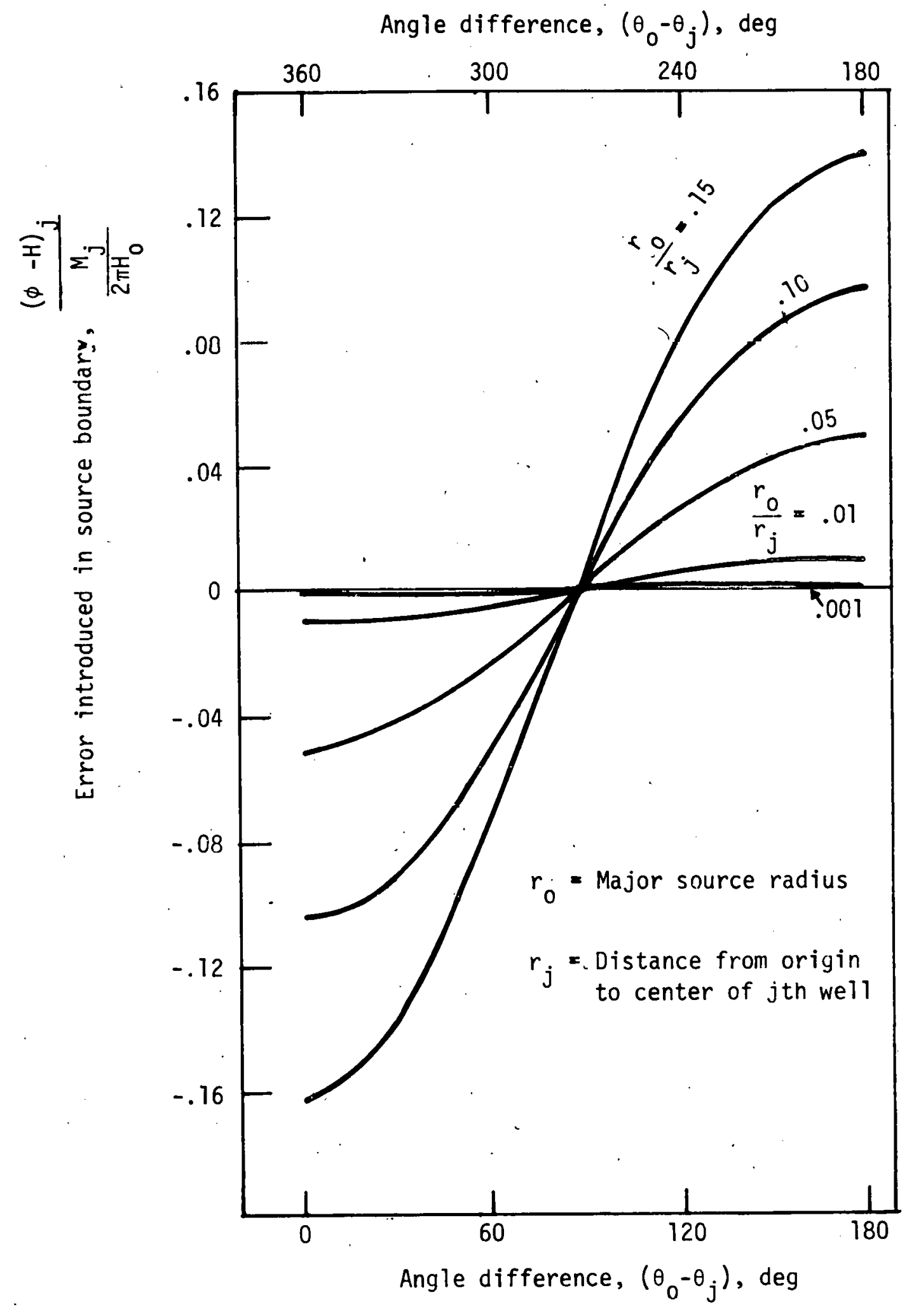

FIGURE A-1. Approximation Error at the Major Source or Pond Boundary Caused by the Proximity of the jth Well 


$$
\frac{r_{0}}{r_{j}}<0.01
$$

Equation $(A-14)$ is the criterion used to assure that $\varepsilon$ is small enough for general use.

We can assure conservatism in the calculated travel times of fluid particles by using the slightly higher gradients associated with flow to a finite remote boundary rather than to an infinite boundary. These slightly higher gradients result if all of the major source head, $H$, is dissipated at the finite radial distance $R$. In dimensionless form it is equivalent to stating that $H$ is dissipated at $x^{2}+y^{2}=1$, or more specifically,

$$
H-\frac{M_{0}}{2 \pi H_{0}} \ln \left(\frac{1}{r_{0}}\right)=0
$$

Solving for $M_{0} /\left(2 \pi H_{0}\right)$ gives

$$
\frac{M_{0}}{2 \pi H_{0}}=\frac{H}{\ln \left(\frac{1}{r_{0}}\right)}
$$

Substituting Equation $(A-16)$ into $(A-1 U)$ gives as the final dimensionless potential function:

$$
\begin{aligned}
\phi=H & -\frac{U R}{H_{0}} x+\frac{U R r_{0}^{2}}{H_{0}}\left(\frac{x}{x^{2}+y^{2}}\right)-\frac{H}{\ln \left(\frac{1}{r_{0}}\right)} \ln \left(\frac{\sqrt{x^{2}+y^{2}}}{r_{0}}\right) \\
& -\sum_{j=1}^{j=N} \frac{M_{j}}{2 \pi H_{0}} \ln \sqrt{\frac{\left(x-x_{j}\right)^{2}+\left(y-y_{j}\right)^{2}}{\left(x_{j}{ }^{2}+y_{j}{ }^{2}\right)}}, \frac{r_{0}}{r_{j}}<0.01
\end{aligned} .
$$

where

$M_{j}=\frac{Q_{j}}{D_{0} K_{0}}$ is the well source or sink strength.

$Q_{j} \quad$ is the volume inflow or outflow rate of the well; i.e., $Q_{j}$ is positive for an injection well and negative when a well is pumped: 
$D_{0}$ is the constant stratum thickness

$K_{0}$ is the uniform hydraulic conductivity, and the other terms are as already defined or as shown in Appendix $D$.

Equation (A-17) can be shown to be a solution of the Laplace Equation that describes flow of an incompressible fluid in a homogeneous isotropic porous medium. Since the fluid is incompressible, the transient flow systems are impulsively generated by boundary conditions that change in time. In Equation (A-17) the variables $H, U$, and $M_{j}$ through $Q_{j}$ may all be time dependent. Under many conditions of expected use for the model, the time dependence may not be known in detail. In these initial evaluations, it is often a matter of considering the consequences of various types of variation rather than detailed representation. Accordingly, considerable flexibility is needed and several functional forms for the time dependence were considered. From this evaluation came some particular functional forms. The most useful form found is a slight modification of the classical serpintine expression of the form

$$
W\left(t^{\prime}\right)=w_{0}+\frac{2\left(w_{0}-w_{m}\right)\left(\frac{t^{\prime}}{t_{n}^{\prime}}+A\right)}{B\left(\frac{t^{\prime}}{t_{n}^{\prime}}+A\right)^{2}+C}
$$

where $w_{0}, w_{m}, t_{n}^{\prime}, A, B$ and $C$ are arbitrary parameters. This serpin equation form was used to describe the time dependence of $U, H$ and $Q_{j}$ with the specific parameters defined as shown in Table A-1. 

TABLE A-1. Definition of Parameters for the Serpintine Equation
Form $(A-18)$.

\begin{tabular}{|c|c|c|c|c|}
\hline $\begin{array}{c}\text { Parameter in } \\
\text { Equation }(A-18) \text {, } \\
w\left(t^{\prime}\right)\end{array}$ & $\frac{\text { Parameter }}{U\left(t^{\prime}\right)}$ & defined & $\frac{\text { in serpintine }}{H\left(t^{\top}\right)}$ & $\begin{array}{c}\text { forms for } \\
Q_{j}\left(t^{\prime}\right)\end{array}$ \\
\hline$w_{0}$ & UO & & HI & $Q I_{j}$ \\
\hline$w_{m}$ & UM & & HM & $Q M_{j}$ \\
\hline$t_{n}^{\prime \prime}$ & TM & 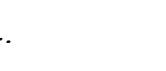 & TN. & $\mathrm{TN}_{j}$ \\
\hline$A^{\prime \prime}$ & $A$ & & $D$ & $D W_{j}$ \\
\hline B & B & & $E$ & $E W_{j}$ \\
\hline$c$ & C & & $\mathrm{F}$ & $\mathrm{FW}_{j}$ \\
\hline
\end{tabular}

The second convenient functional form used to describe the time dependence of $H$ and $Q_{j}$ is

$$
w\left(t^{\prime}\right)=w_{m c}+w_{o c} \sin \left[2 \pi \frac{\left(t^{\prime}-t_{o c}\right)}{\left(t_{m c}-t_{o c}\right)}\right]
$$

which provides a continuous cyclic-type fluctuation. The parameters for describing $H$ and $Q_{j}$ are shown in Table A-2.

TABLE A-2. Definition of Parameters for the Cyclic Equation Form (A-19)

\begin{tabular}{ccc}
$\begin{array}{c}\text { Parameter in } \\
\text { Equation } \\
W\left(t^{\prime}\right)\end{array}$ & $\frac{\text { Parameter defined in cyclic form for }}{H\left(t^{\prime}\right)}$ & $Q_{j}\left(t^{\prime}\right)$ \\
\hline$w_{m C}$ & $H M C$ & $Q Q_{j}$ \\
$w_{O C}$ & $H A C$ & $Q A_{j}$ \\
$t_{o c}$ & $T O C$ & $T O_{j}$ \\
$t_{m c}$ & $T M C$ & $T M_{j}$
\end{tabular}

A third form for the time-dependent head $H$ in Equation (A-17) is useful when considering worst-case accidentals leakage into the ground from liquid-storage facilities. It is the falling head case where the fluid level diminishes in the storage facility at the rate that fluid seeps 
from the structure. Consider the cylindrical fluid volume of radius $r_{0}^{\prime}$ and height $H^{\prime}$; then the instantaneous volume change $\frac{d v^{\prime}}{d t^{\prime}}$ or $Q^{\prime}$ the outflow rate is

$$
\frac{d v^{\prime}}{d t^{\prime}}=\dot{Q}^{\prime}=-\pi\left(r_{0}^{\prime}\right)^{2} \frac{d H^{\prime}}{d t^{\prime}}
$$

but the instantaneous outflow rate, $Q_{0}$, is

$$
Q=\frac{2 \pi D_{0} K_{0} H^{\prime}}{\ln \left(\frac{R}{r_{0}}\right)}
$$

Substituting $(A-21)$ into $(A-20)$ gives upon rearranging

$$
\int_{H_{0}}^{H^{\prime}} \frac{d H^{\prime}}{H^{1}}=\int_{0}^{t^{\prime}}-\frac{2 D_{0} K_{0}}{\left(r_{0}^{\prime}\right)^{2} \ln \left(\frac{R}{r_{0}^{\prime}}\right)} d t^{\prime}
$$

and upon evaluating the integrals one obtains

$$
\frac{H^{i}}{H_{0}}=\exp \left[-\frac{2 D_{0} K_{0}}{\left(r_{0}\right)^{2} \ln \left(\frac{R}{r_{0}{ }^{1}}\right)} \cdot t^{\prime}\right]
$$

and using the Equations $(A-2)$ to form the dimensionless equivalent yields

$$
H=\exp \left[-\frac{2 D_{0}}{H_{0} r_{0}^{2} \ln \left(\frac{1}{r_{0}}\right)} t\right]
$$

which is the exponential expression for the declining head in the circular source as leakage occurs from storage facility.

Experience in using the above time-dependent forms shows them usually to be adequate. However, in some instances where specific forms are needed, it may be convenient to write a particular computer subroutine to replace the serpin form. Usually the six parameters 
provide sufficient input capacity for any special time-dependent routine that may be needed.

\section{THE KINEMATIC PATHLINES}

The equations for the fluid pathlines are available from Darcy's Law expressed as a pore velocity using the potential equations already derived. Specifically, the dimensional pore velocity, $\underline{u}^{\prime}$, is

$$
\underline{u}^{\prime}=-\frac{K_{0}}{P} \nabla^{\prime} \phi^{\prime} \text {. }
$$

If the dimensionless velocity, $\underline{u}$, is

$$
\underline{u}=\frac{R}{K_{0} H_{0}} \underline{u}^{\prime}
$$

Using Equation ( $A-2)$ gives the dimensionless pore velocity expression

$$
\underline{u}=-\frac{1}{P} \nabla \phi
$$

or in components

$$
\frac{d x}{d t}=u_{x}=-\frac{1}{p} \frac{\partial \phi}{\partial x}
$$

and

$$
\frac{d y}{d t}=v_{y}=-\frac{1}{p} \frac{\partial \phi}{\partial y}
$$

where the expression for $\phi$ is provided by the potential solution in Equation (A-17). Differentiation of Equation (A-17) first with respect to $x$, then with respect to $y$ and substitution into Equations $(A-28)$ and (A-29), respectively, gives the pair of pathline differential equations, i.e.,

$$
\begin{aligned}
\frac{d x}{d t}= & \frac{U R}{P H_{0}}\left\{1+\frac{r_{0}^{2}}{\left(x^{2}+y^{2}\right)}\left[\frac{2 x^{2}}{x^{2}+y^{2}}-1\right]\right\}+\frac{H}{P \ln \left(\frac{1}{r_{0}}\right)}\left(\frac{x}{x^{2}+y^{2}}\right) \\
& +\sum_{j=1}^{j=N} \frac{M_{j}}{2 \pi H_{0} P}\left[\frac{\left(x-x_{j}\right)}{\left(x-x_{j}\right)^{2}+\left(y-y_{j}\right)^{2}}\right],
\end{aligned}
$$


and

$$
\begin{aligned}
\frac{d y}{d t}= & \frac{U R}{P H_{0}}\left[\frac{2\left(r_{0}\right)^{2} x y}{\left(x^{2}+y^{2}\right)^{2}}\right]+\frac{H}{P \ln \left(\frac{1}{r_{0}}\right)}\left(\frac{y}{x^{2}+y^{2}}\right) \\
& +\sum_{j=1}^{j=N} \frac{M_{j}}{2 \pi \mathrm{PH}_{0}}\left[\frac{y-y_{j}}{\left(x-x_{j}\right)^{2}+\left(y-y_{j}\right)^{2}}\right]
\end{aligned}
$$

The simultaneous solution of these two pathline equations beginning from the initial conditions

$$
x\left(t_{0}\right)=x_{0}
$$

and

$$
y\left(t_{0}\right)=y_{0}
$$

yields the path of the fluid particle that was located at $x_{0}, y_{0}$ at time $t_{0}$. By successively considering other combinations of $x_{0}, y_{0}$ and $t_{0}$, i.e., other starting points and times, the entire field of fluid particle pathlines can be obtained.

The system of equations made up of $(A-30)$ through $(A-33)$ generality cannot be solved in closed form, particularly when $U, H$ and/or $M_{j}$ take on the time-dependent forms of Equations $(A-18),(A-19)$ and $(A-24)$, therefore, a modified fourth-order Runge-Kutta numerical method is conveniently used to calculate the pathlines (Gill, 1951). In this way the macroscopic flow paths of fluid particles are directly calculated.

The Stream Function

The stream function is needed to provide complete environmental results. The stream function is directly available from the previously derived potential function Equation $(A-17)$ as the complex conjugate. The stream function $\psi$ in dimensionless variables is 


$$
\begin{aligned}
\psi= & -\frac{U R}{H_{0}} y-\frac{U R r_{0}^{2} y}{H_{0}\left(x^{2}+y^{2}\right)}-\frac{I I}{\ln \left(\frac{1}{r_{0}}\right)} \arctan \left(\frac{y}{x}\right) \\
& -\sum_{j=1}^{j=N} \frac{M_{j}}{2 \pi H_{0}}\left[\arctan \left(\frac{y-y_{j}}{x-x_{j}}\right)-\arctan \left(\frac{-y_{j}}{x_{0}-x_{j}}\right)\right]
\end{aligned}
$$

Equation $(A-34)$ can be rewritten in polar coordinates $(r, \theta)$ to give

$$
\begin{aligned}
& \psi=-\frac{U R}{H_{0}} r \sin \theta-\frac{U R r_{0} \sin \theta}{H_{0} r}-\frac{H}{\ln \left(\frac{1}{r_{0}}\right)} \theta \\
&-\sum_{j=1}^{j=N} \frac{M_{j}}{2 \pi H_{0}} {\left[\arctan \left(\frac{r \sin \theta-r_{j} \sin \theta_{j}}{r \cos \theta-r_{j} \cos \theta_{j}}\right)\right.} \\
&\left.-\arctan \left(\frac{-r_{j} \sin \theta_{j}}{r \cos \theta-r_{j} \cos \theta_{j}}\right)\right]
\end{aligned}
$$

We note that $\psi=0$, when $r=r_{0}$ and $\theta=0$ and, further, that when $r=r_{0}$ and $\theta=2 \pi$ so that all of the outfliow from the circular source is included, then $\psi=\psi_{S}$, which gives

$$
\psi_{S}=-\frac{2 \pi H}{\ln \left(\frac{1}{r_{0}}\right)}
$$

and using Equation $(A-16)$ gives

$$
\psi_{s}=-\frac{M_{0}}{H_{0}}
$$

but the source strength $M_{0}=Q /\left(D_{0} K_{0}\right)$, so

$$
\psi_{\mathrm{S}}=-\frac{Q}{\mathrm{D}_{0} \mathrm{~K}_{0} \mathrm{H}_{0}}
$$

where $Q$ is the volume outflow rate from the source. Equating $(A-37)$ with $(A-39)$ and solving for $Q$ gives 


$$
Q=\frac{2 \pi D_{0} K_{0} H_{0} H}{\ln \left(\frac{1}{r_{0}}\right)}
$$

which, with all terms reduced to dimensional form, is identical to Equation $(A-21)$.

It is convenient to use a single reference outflow $Q_{0}$, which is obtained by setting $H=1$, i.e. $H^{\prime}=H_{0}$, in Equation $(A-40)$. That is,

$$
Q_{0}=\frac{2 \pi D_{0} K_{0} H_{0}}{\ln \left(\frac{1}{r_{0}}\right)}
$$

which corresponds to defining a $\psi_{0}$ through reducing Equation $(A-37)$ to

$$
\psi_{0}=-\frac{2 \pi}{\ln \left(\frac{1}{r_{0}}\right)}
$$

If Equation (A-34) is divided by $(A-42)$ and the resulting $\psi / \psi_{0}$ is equated to $Q_{i} / Q_{0}$, then one obtains

$$
\begin{aligned}
\frac{Q_{j}}{Q_{0}} & =\frac{\text { UR } \ln \left(\frac{1}{r_{0}}\right)}{2 \pi H_{0}} y+\frac{\text { UR } \ln \left(\frac{\tilde{1}}{r_{0}}\right) r_{0}{ }^{2} y}{2 \pi H_{0}\left(x^{2}+y^{2}\right)}+\frac{H}{2 \pi} \arctan \left(\frac{y}{x}\right) \\
& +\sum_{j=1}^{j=N}\left[\frac{M_{j} \ln \left(\frac{1}{r_{0}}\right)}{4 \pi^{2} H_{0}}\right]\left[\arctan \left(\frac{y-y_{j}}{x-x_{j}}\right)-\arctan \left(\frac{-y_{j}}{x_{0}-x_{j}}\right)\right]
\end{aligned}
$$

\section{SIMPLIFIED CHEMICAL TRANSPORT WITH SORPTION}

A single chemical species at trace concentration with equilibrium sorption is readily considered with only minor modification of the kinematic equations already provided. In particular, if the hydrodynamic dispersion is ignored since it is so very small in a homogeneous porous material, then the chemical transport equation using an equilibrium distribution coefficient, $K_{d}$, and the bulk density, $B_{d}$, of the porous material is 


$$
\nabla^{\prime} \cdot\left(C^{\prime} \underline{u^{\prime}}\right)=\left(1+\frac{B_{d^{K}}{ }^{\prime}}{P}\right) \frac{\partial C^{\prime}}{\partial t^{\prime}}
$$

or the dimensionless equivalent expression upon using Equations (A-2), (A-25) and $(A-26)$ is

$$
\nabla \cdot\left(C^{\circ} \underline{u}\right)=\left(1+\frac{B_{d} K_{d}}{P}\right) \frac{\partial C^{\circ}}{\partial t}-
$$

where $C^{0}=C^{1} / C_{0}$ with the $C_{0}$ being the original source concentration at $t=0$. Expanding the equation gives

$$
\underline{u} \cdot \nabla C^{0}=K \frac{\partial C^{0}}{\partial t}
$$

since

$$
\nabla \cdot \underline{u}=\frac{1}{p} \nabla \cdot q \equiv 0
$$

by conservation of mass in a homogeneous material, and where

$$
K=\left(1+\frac{B_{d} K_{d}}{P}\right)
$$

Inspection of Equation (A-46) shows it to be a first-order partial differential equation, which is reduceable to the set of Characteristic Equations

$$
\frac{d x}{d t}=\frac{1}{K} u_{x}
$$

and

$$
\frac{d y}{d t}=\frac{1}{k} v_{y}
$$

But comparison with the kinematic Equations (A-28) and (A-29) shows that characteristic equations for the idealized contaminant transport are within a constant multiplier of the original kinematic expressions. Accordingly, it is no more difficult to solve for the idealized approximate chemicals transport equations; i.e., 


$$
\begin{aligned}
\frac{d x}{d t}= & \frac{U R}{P H_{0} K}\left\{1+\frac{r_{0}^{2}}{\left(x^{2}+y^{2}\right)}\left[\frac{2 x^{2^{2}}}{x^{2}+y^{2}}-1\right]+\frac{H}{K P \ln \left(\frac{1}{r_{0}}\right)}\left(\frac{x}{x^{2}+y^{2}}\right)\right. \\
& +\sum_{j=1}^{j=N} \frac{M_{j}}{2 \pi H_{0} P K}\left[\frac{\left(x-x_{j}\right)}{\left(x-x_{j}\right)^{2}+\left(y-y_{j}\right)^{2}}\right] \\
\frac{d y}{d t}= & \frac{U R}{P H_{0} K}\left[\frac{2\left(r_{0}\right)^{2} x y}{\left(x^{2}+y^{2}\right)^{2}}\right]+\frac{H}{K P \ln \left(\frac{1}{r_{0}}\right)}\left(\frac{y}{x^{2}+y^{2}}\right) \\
+ & \sum_{j=1}^{j=N} \frac{M_{j}}{2 \pi P H_{0} K}\left[\frac{y-y_{j}}{\left(x-x_{j}\right)^{2}+\left(y-y_{j}\right)^{2}}\right]
\end{aligned}
$$

Equations $(A-51)$ and $(A-52)$ reduce identically to Equations $(A-30)$ and $(A-31)$ when no exchange occurs. So if there is no exchange then $K_{d}=0$ in Equation $(A-48)$; hence $K=1$ so $(A-36)$ and $(A-37)$ reduce to the kinematic equations of $(A-51)$ and $(A-52)$. 
APPENDIX B

USER'S GUIDE FOR THE PRELIMINARY EVALUATION MODELS. 
APPENDIX B

\section{USER'S GUIDE FOR THE PRELIMINARY EVALUATION MODELS}

\section{USING THE TERMINAL}

The interactive PATHS program was written utilizing a conversational mode; it is tutorial and aids the user in providing the proper reply. Most responses will require a yes $(Y)$ or no $(N)$ answer or some numerical value. Details and examples of this will be given later. Other than knowing how to respond to prompting questions, the user needs little knowledge of computer commands.

Before working with the computer, bureaucratic details of being funded and given a project ID, user ID, password, and account number must be completed. Having these, a terminal and a phone, the Univac 1100/44 may be called by dialing 942-7841. After placing the phone in the acoustic coupler, and without prompting from the Univac, type in the terminal ID (written on the terminal). After the Univac responds to this, follow up with the USERID/PASSWORD, IPROJECT-ID, and address, as shown in the example following. Note that the symbol > (greater than) prompts the responses that are entered by the user.

ILTIES

EHITE: IISEFITHFESULFII:

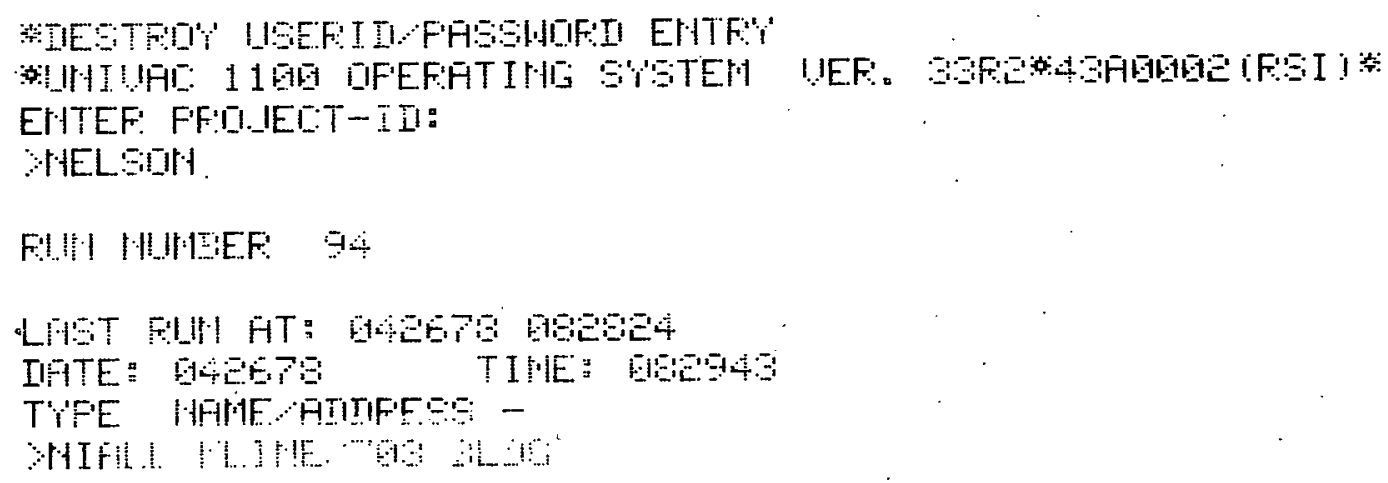


At this point, PATHS could be executed. The beginning sequence of this is

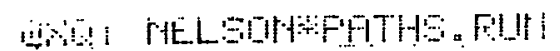

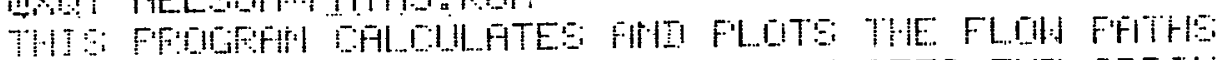

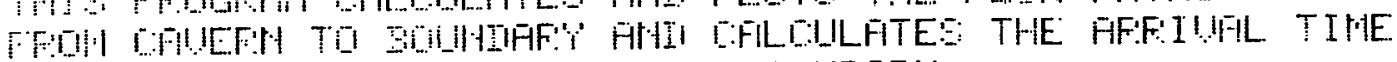

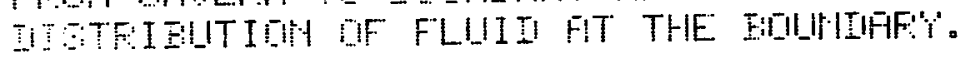

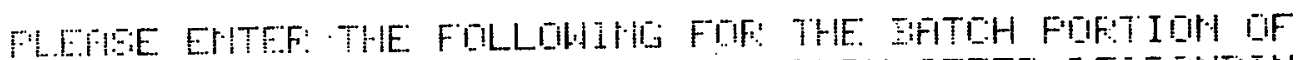

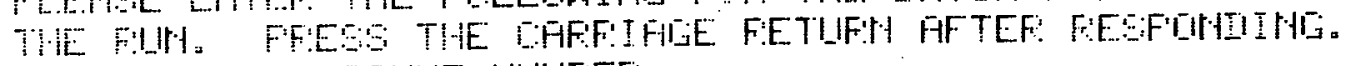

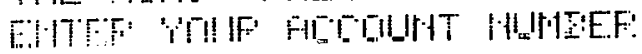

PAE

Wher Metis

Hil:

FITE: FHET 13

FFIIII

EHTF: HHIE TMPESE

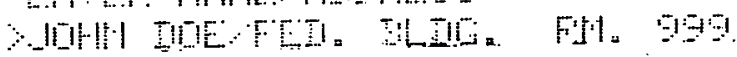

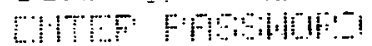

भा

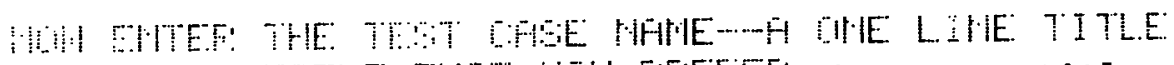

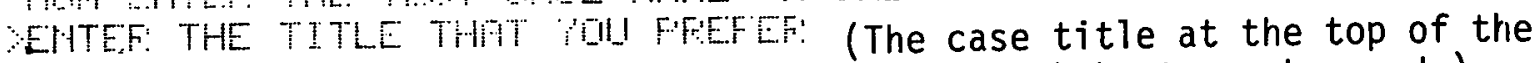

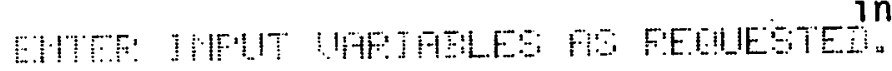
input worksheet can be used.)

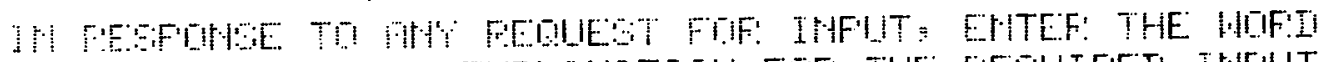

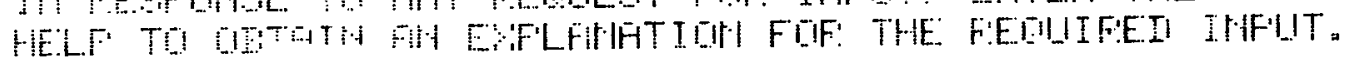

IIII

$>100$

The PATHS program now has control and directs the user to respond appropriately. If you make a mistake while responding to PATHS, it can be erased (backspaced over). To do this, depress the control key and type the letter $H$. If the carriage has been returned and bad data thereby entered, PATHS can be terminated by typing the master character 0 . After this, begin again, starting with the QXQT statement. However, you may choose to note the mistake and continue with the intent of later modifying the job stream created. In this instance, continue to respond to all questions until the end. When PATHS asks if the batch job is to be submitted, reply NO. This way a copy of the job stream is saved. Following PATHS, the Univac EDITOR may be entered to modify the job stream appropriately for batch submittal. See "Using EDITOR for Minor Run Changes"for details. 
SAMPLE JOB

The following job stream was entered through PATHS as an example. See the input parameter worksheet from Table. I in the report.

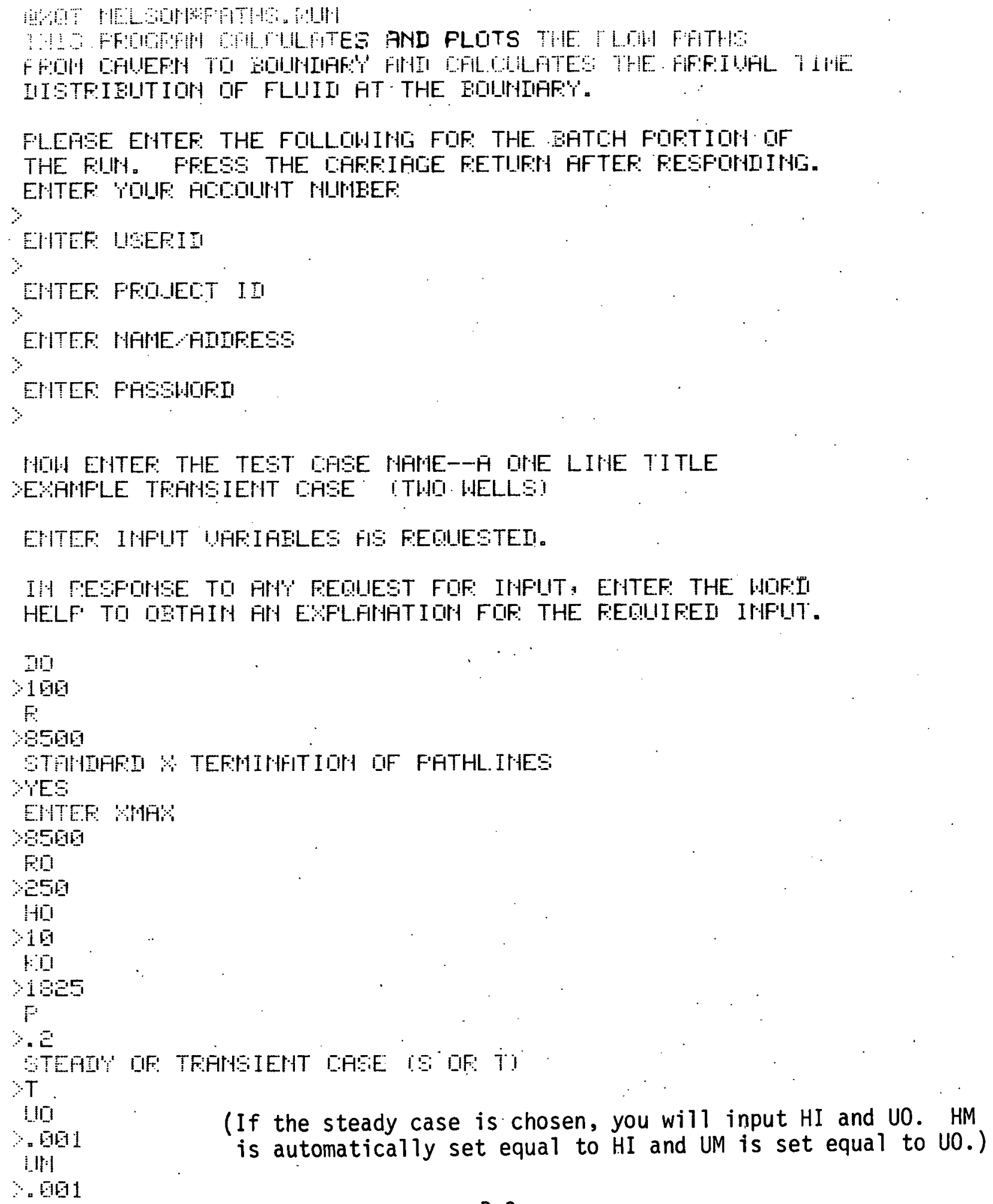

(If the steady case is chosen, you will input $H I$ and UO. HM is automatically set equal to $H I$ and UM is set equal to UO.) 


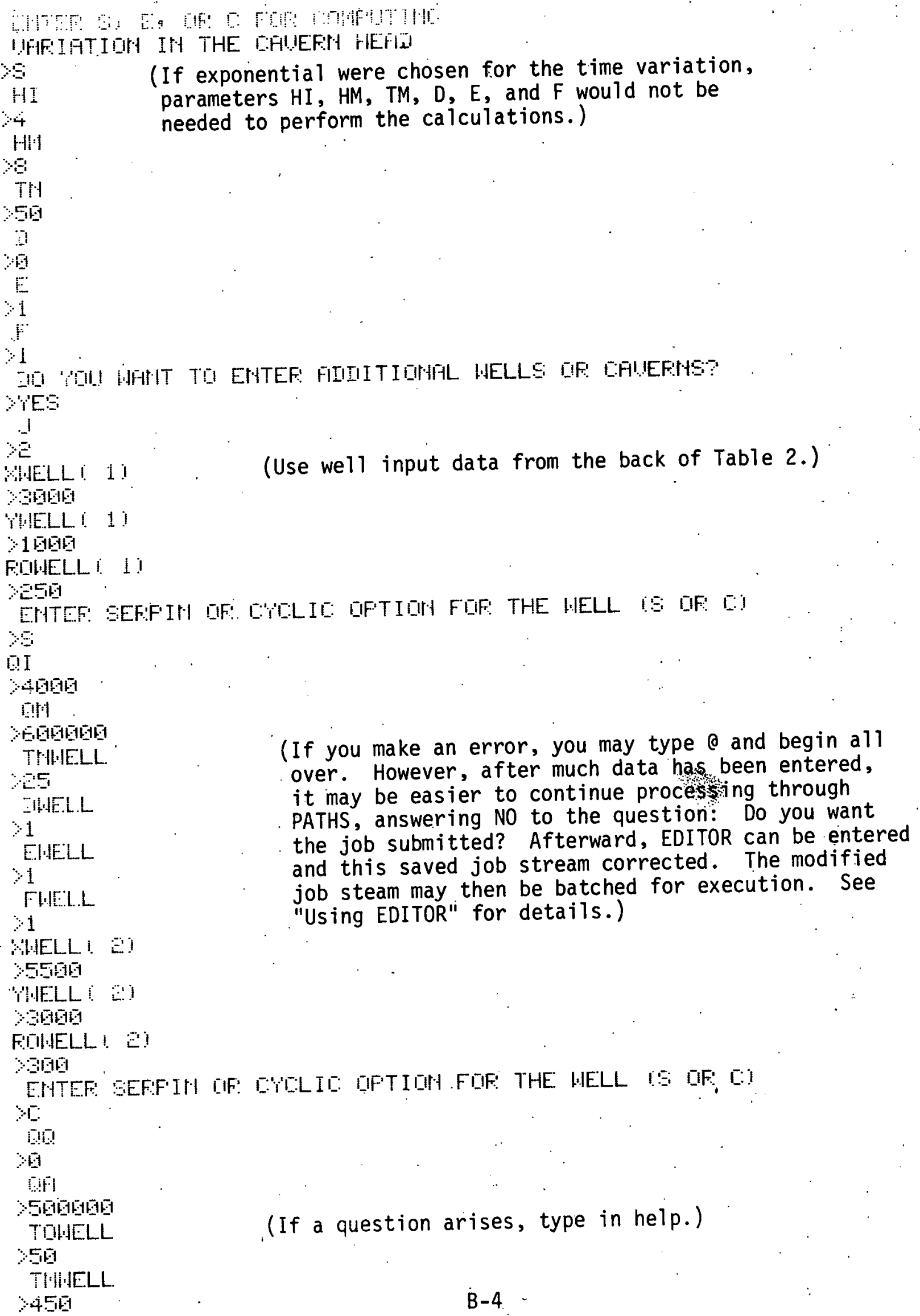




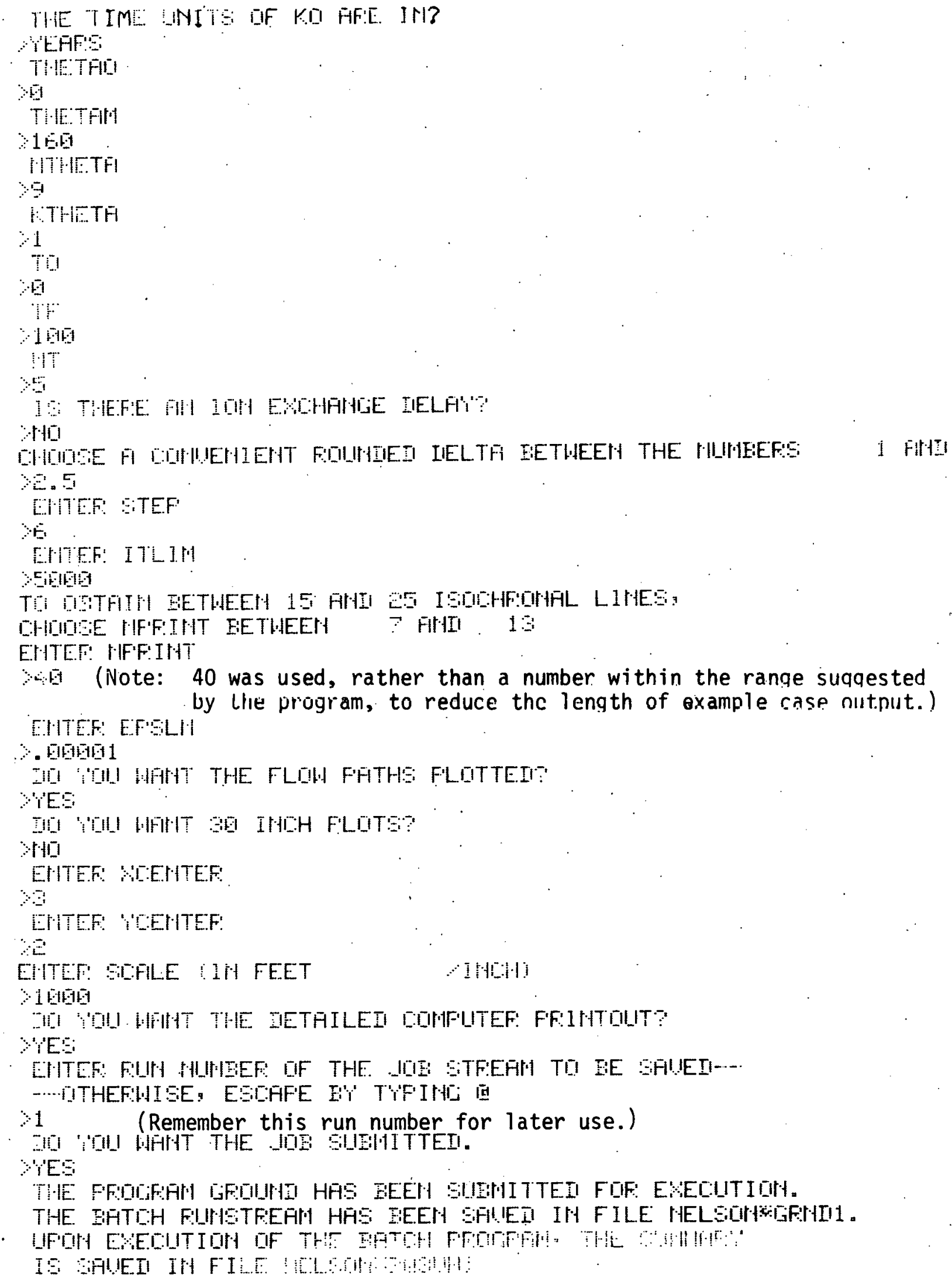




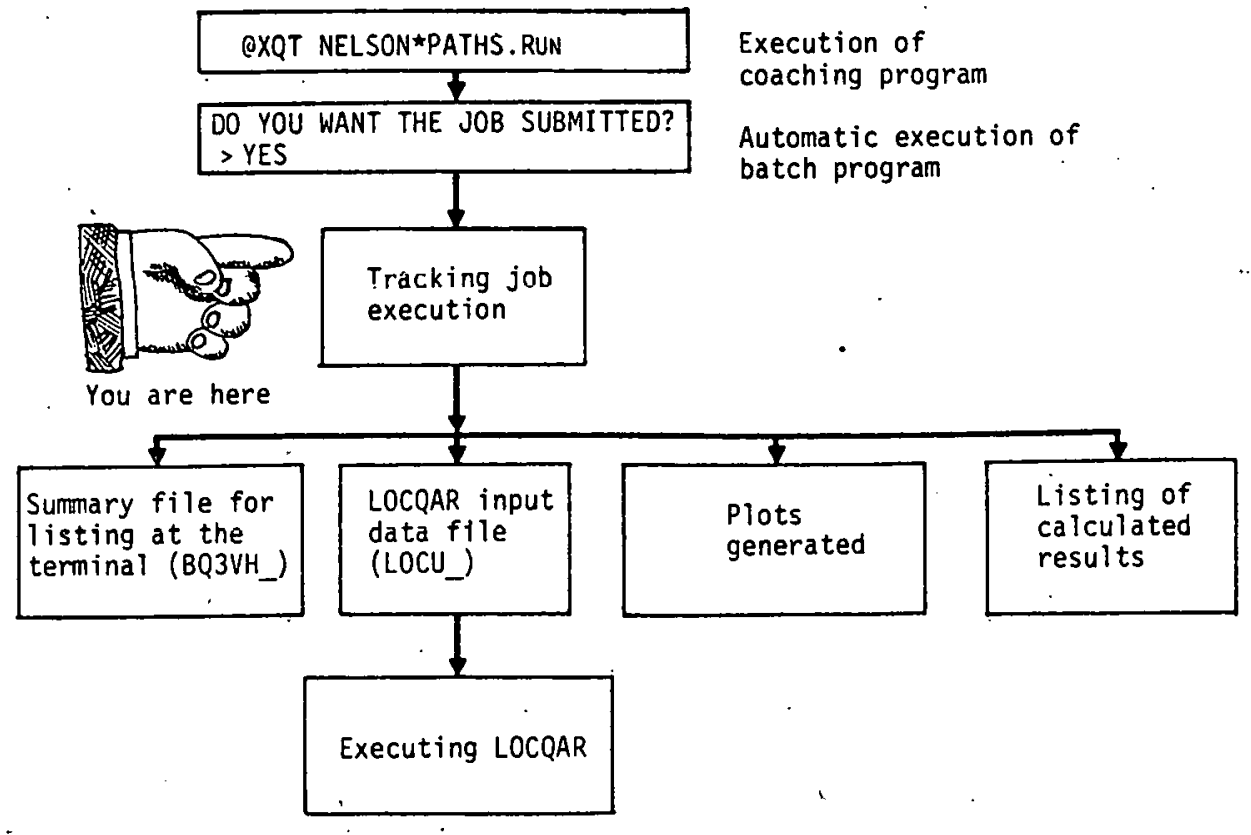

Finally, to quit interacting with the Univac properly, type OFIN and follow up with OOTERM. The carrier detect light will go off on the terminal and the phone can be taken off the acoustic coupler. However, after finishing with the interactive part of job submittal, it is a good idea to verify the successful entry of the batch portion into the execute queue. Also, you may wish to preview the summary file created by the batch run's (GROUND's) execution, and to execute the program LOCQAR. Discussions of these follow.

The detailed printed output from responding YES to the question: "Do you want the job submitted?" can be seen under the topic "Example Transient case."

\section{TRACK ING JOB EXECUTION}

After starting the batch job, type @acons to check its progress.

Follow this by $T$ as shown below.

.).1CDP

$X T$

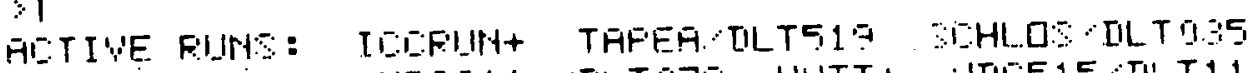

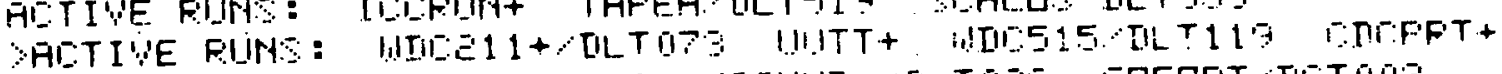

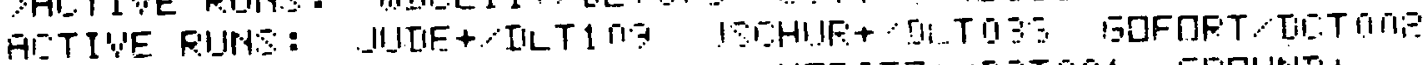

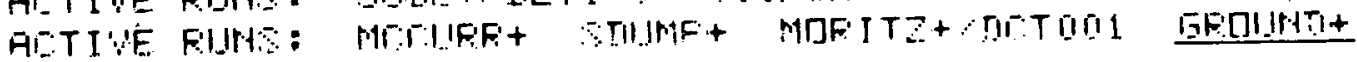


A11 the jobs currently in execution are listed. If another job GROUND is already queued, a later entry will by called GROUNE, and one after that GROUNF and so on.

Information on the progress of execution of a particular job can be obtained by typing RC and then the job name. This is shown below for GROUND.

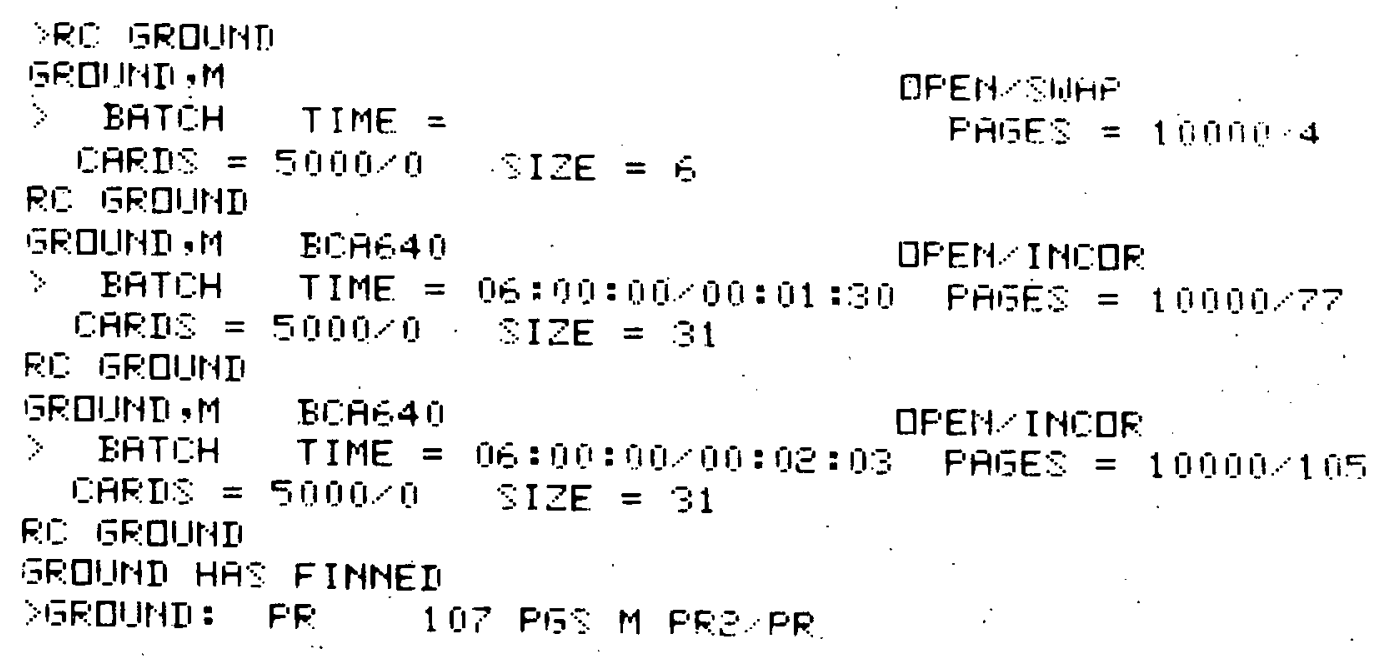

Notice that progress is monitored until the job has finished. Of course, in normal practice, job monitoring to this detail is not necessary. Type QOEND CONS when finished monitoring the job. Once the batched job GROUND has finished successfully, the two files it generates (PROJID*BQ3VH_. and PROJID*LOCQ_.) are available for the user. (Note: PROJID is the user project ID and the _ is the run number. For the example transient problem, these are respectively NELSON*BQ3VHI. and NELSON*LOCQ1.).

SUMMARY FILE - BQ3VH_.

With the successful execution of the GROUND program, you may view from the terminal a summary of the flow paths calculated. This way you have the summary results and can partially review calculated results before the longer printed output is delivered. To do this type OED,R PROJID*BQ3VH_. followed by $P$ !. This is shown with the ensuing results for the example case stored on NELSON*BQ3VHT. . 
AED,F HELSDH EOOYH1.

FEATI-CH'L' $T$ WMUE

EI 15FE-TUE-04 $11 \% 78-14: 03: 11-60.9$

EIIT I: (P! means to print all lines in the file.)

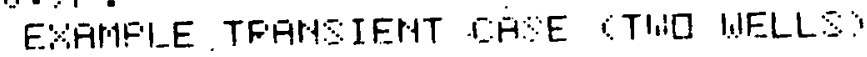

THE TIEFFFTIIFE TIME IS

THE IHITIAI, DITTELDW FETTE IS HIE IT: FEET

- 101 YEFFO

. $1300606+0107$

FEF: YEAF:

THE IHITIAL. FELATIUF EAEEFT MEAT TS

$\because$

FFET

$\theta .51000+1100$

$8.4999+193$

$=75,49+110 \%$

$0.493+0103$

$5.53440+100$

$9.4939+00$

$8.4943+103$

$8.4996+100$

. $4599+103$

$8.4945+110$
' $i$

FEET

$-5.94146+110$

. $519+101$

1 . $1540+002$

$=14700+00$

$\therefore .7160+010$

$4.07075+109$

$4.21505+103$

$4.900 \mathrm{E}+003$

$4.4957+603$

$4.1073+040$
4007

FATH L.FHETH FEET

B.

E. $3115 n+110$

$=.7480+100$

E.

6. $-2041+193$

1. $9075+014$

1. nr. 11.34+1114

1. $10.96+104$

1. $=1774+1114$

1. . $5.95+1114$ 
THE IDEFAFTTIRE TIME IS

THE IHITIAL DUITFL DU. F:ATTE IS

2.5.

\section{QILEIE: FEET PEF YEAFS}

$.23412530+007$

THE IHITIFL FELATIVE RAWEFH HEAII IS

. จேัก

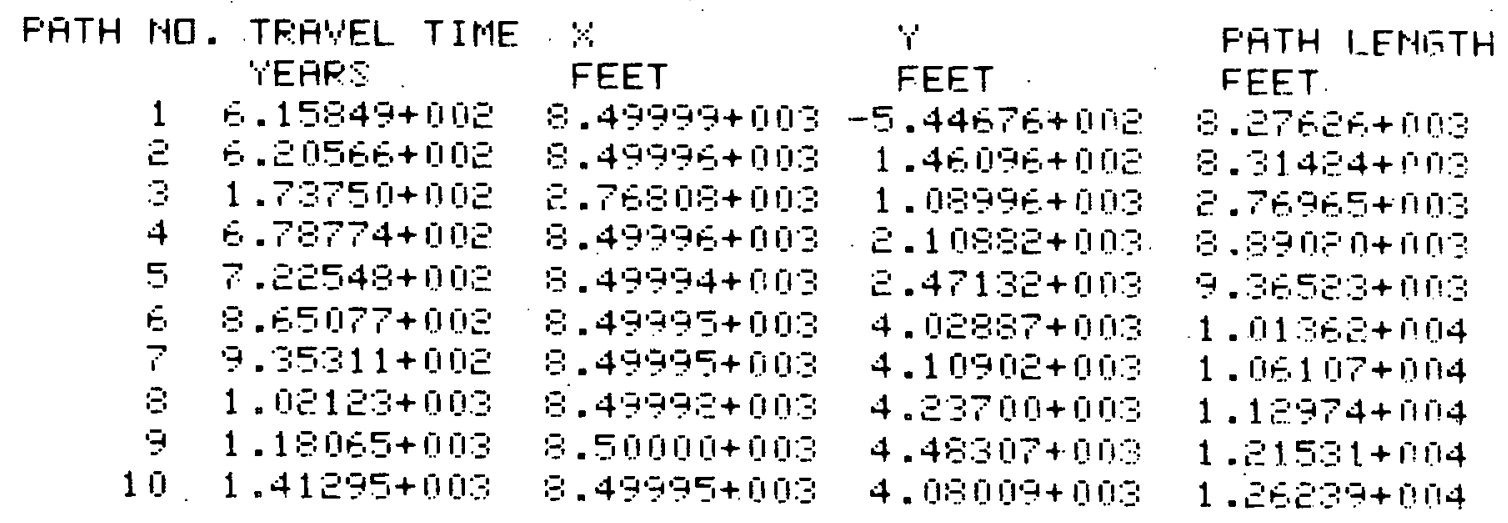

THE IIEF'AF:TIIFE TIME IS

511.010 YEAFS

THE IHITIHL DIITFLDW FETTE IS DIEIE: FEET FEF: 'TEAFS $.2601398+007$

THE IHITIAL FELATI'UE EAWEFH HEAII IS . B1010

\begin{tabular}{|c|c|c|}
\hline FATH & 140. & $\begin{array}{l}\text { TFE'WEL TIME } \\
\text { YEAFS }\end{array}$ \\
\hline & 1 & $\therefore .45014+000$ \\
\hline & $\Xi$ & E.4585+ \\
\hline & 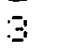 & $1.9796+100$ \\
\hline & 4 & $7.05540+010$ \\
\hline & 5 & 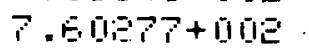 \\
\hline & $E$ & $9.11=15+010$ \\
\hline & $\vec{i}$ & ․ . $\because 724+00 \Xi$ \\
\hline & $\Xi$ & 1. . $03400+003$ \\
\hline & 9 & $1.19589+003$ \\
\hline & 10 & 1. . $40004+000$ \\
\hline
\end{tabular}

$\because$ FEET

8 . 4996+010 $8.4995+100$ $27530+00$ 3 . $4993+103$ $8.49995+103$ $8.4996+000$ $8.4997+078$ $8.50000+00 \%$ 6 . 5000000 $8.4993+003$
$Y$

\section{FEET}

$-5.08999+100$

1.6979+0

1. $04029+010$

1. $7734+015$

E. $2754+00$

$3.75919+010$

$3.955+003$

$4.13010+003$

$4.44799+0109$

4 . 0390100
FFTH LEHETH FEET

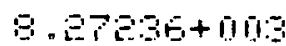

8. $3104+1103$

2. $74411+010$

6. $8700+1018$

9 . $58011+10$

1 . 101 $19+1104$

1. $05185+0104$

1. $12006+1114$

1. $20519+0104$

1. $=1.46+104$ 
THE IIEFAFETIIFE TIME IS

THE. INITIAL DIITFL QIU FATE IS COUETI: FEET
75 . OUIO YEAFS

FEF: YEAFS

$.25013995+0177$

THE IHITIAL FELATI'E I.AWEFH HEAT IS TES

\begin{tabular}{|c|c|c|c|c|c|}
\hline FETH & $1+10$. & $\begin{array}{l}\text { TFHEEL TIME } \\
\text { TEAFS }\end{array}$ & $\begin{array}{l}\because \\
\text { FFET }\end{array}$ & $\begin{array}{l}\because \\
\text { FFET }\end{array}$ & $\begin{array}{l}\text { FETH I.FHISTH } \\
\text { FEET }\end{array}$ \\
\hline & 1 & $\therefore$ F5ESE+010E & 8 . & $-4.79104+100$ & $\because .8-918+1103$ \\
\hline & 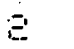 & S. . & $3.4967+1108$ & 1.80307+010 & 8 - $3069+100$ \\
\hline & 3 & $\Xi . \Xi 350+00$ & ․75 & $9.98=0$ & 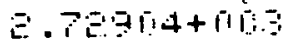 \\
\hline & 4 & $7.9 c 234+00:$ & 6 . 49995+ & $1.94441+105$ & 5 . $545 F+10 \%$ \\
\hline & 5 & $7.97760+00 z$ & $6.49999+005$ & $=10010+000$ & $=51501+103$ \\
\hline & $E$ & G. $251=+100$ & $5.7001+003$ & $5.0056+010$ & E.490105+110: \\
\hline & 7 & 9. А. & $6.49793+003$ & $9.7554+1914$ & $1: 0414:+1114$ \\
\hline & $\Xi$ & 1. $64091+0193$ & $9.49490+100$ & 4. $0=250+0 n=$ & $1.100 r+114$ \\
\hline & 9 & 1. $: 181:+103$ & $0.49979+019$ & $4.413010+000$ & 1.1945 .1114 \\
\hline & (1) & 1.458 & $8.4999+109$ & $3.9981+013$ & 1.24079+11144 \\
\hline
\end{tabular}

THE - TIEFAETTIIFE I TIME IS

THE. IHITIA! DIITFLD!! FATE IS PUF: IE FEET FEF YEFHS

THE THITIAI, FELATIUE TAUEFH HEAL IS
1 110. 1100 YEASS $.241250+117$

.78011

$$
\begin{aligned}
& \text { FATH MO. TFEMEL TIME } \\
& \text { YFAFS }
\end{aligned}
$$

\section{FEET}

EQF : 111

i. : $?$ Exit

After the summary file has been listed on the terminal and control is returned to the user, i.e.; when the system prints the symbol >, type in EXIT to get out of the editor.

These summary results are the basic arrival data required to evaluate the contamination problem. Specifically, the above results are contained in Table 3 in the body of the report. 


\section{EXECUTING LOCQAR}

After GROUND has completed execution and after the summary file BQ3VH has been reviewed, the LOCQAR program can be executed to calculate fluid arrival locations and outflow quantities. To execute LOCQAR from the terminal, type OXQT NELSON*LOCQAR.RUN . NOW LOCQAR asks for the information it needs. Like PATHS, LOCQAR is tutorial and aids in answering its questions. Typing HELP solicits clarification of LOCQAR's questions, as shown below.

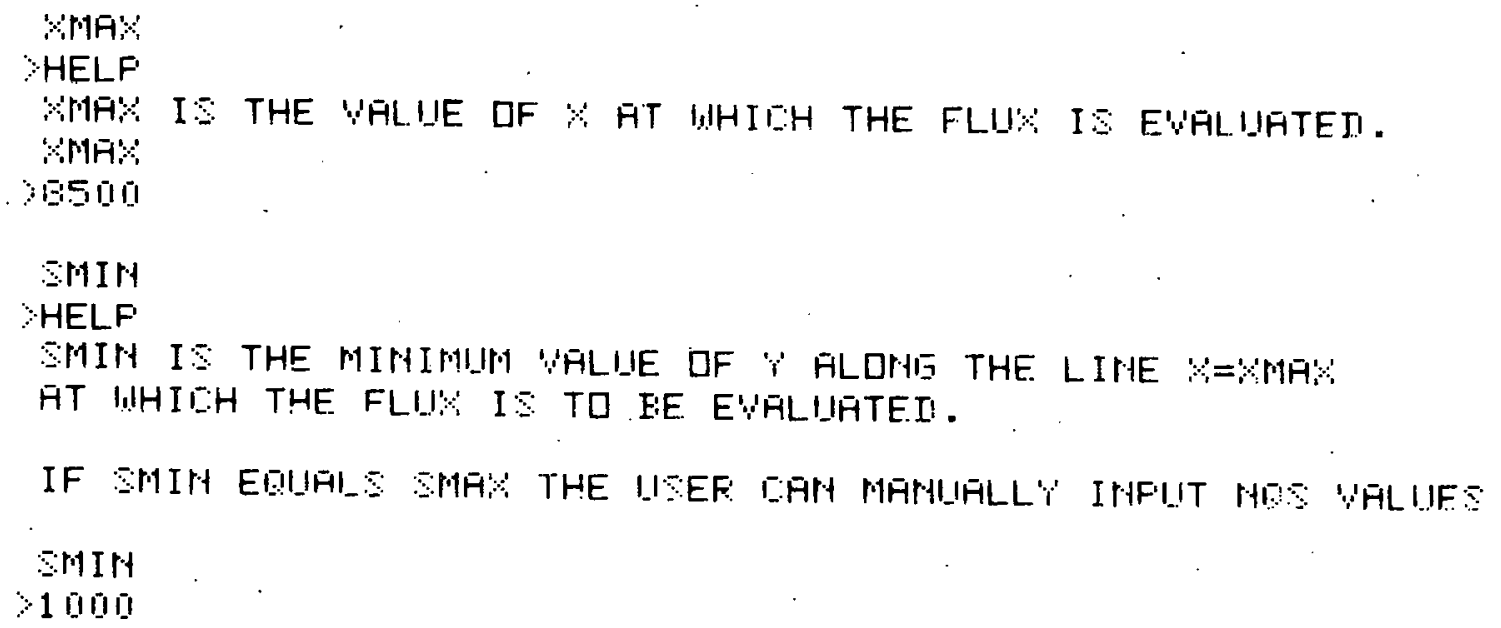

Following is an execution of LOCQAR using the file created by the transient case. 


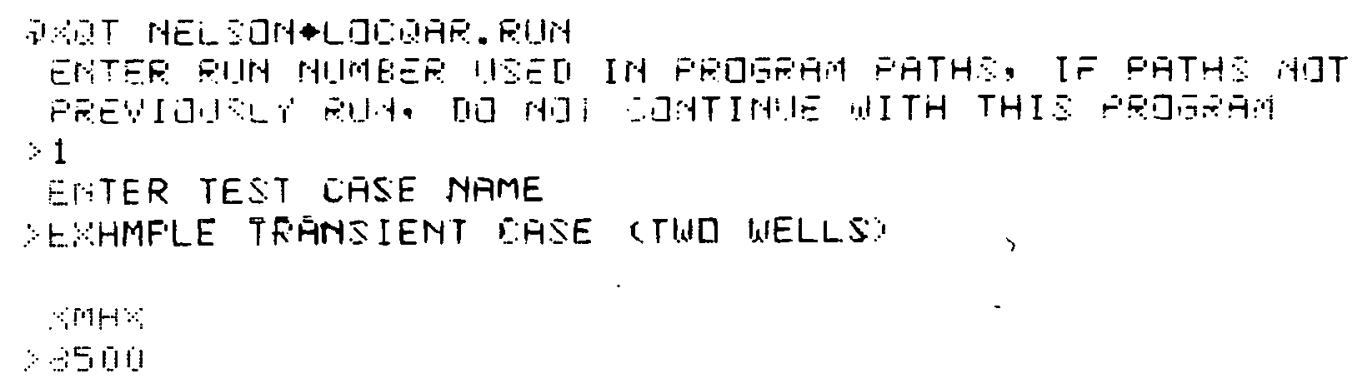

(These results are the arrival outflow data required to evaluate the contamination problem. They are contained in Table 4 in the report.) 


\section{USING EDITOR FOR MINOR RUN CHANGES}

Often it is quicker for the user to edit the batch run stream created by PATHS rather than to create a new job stream by rerunning PATHS. To facilitate this, the following flow diagram shows the data names read by the GROUND program. Most of these names can be recognized from the input parameter worksheet data in Table 1 of the report. The others, superscripted by an asterisk $\left(^{*}\right)$, are variables set by PATHS. They are primarily used to direct the flow of execution of the GROUND program.
1. ORUN ...
2. OIDENT . . .
3. QPASSWD
4. QASG,UP . .
5. QUSE 4., ...
6. OTP,W PLOT*BP400. 18

7. QXT NELSON*GROUND. RUN

8. TEST CASE NAME (A one line title)

9. $\mathrm{R}, \mathrm{R}, \mathrm{HO}, \mathrm{KO}$

10. RO, RO, Do, UO

11. UM, P, TM

12. PATH* $, K D, B D$

13. CHEM, PROJ, VH $3 *$, IPROJ*

14. A, B, C, KTHETA

15. THETAO, THETAM, TO, NTHETA

16. TF, TMAX, EPSLN, ITLIM

17. DELTA, TN, STEP, NT

18. XMAX, XCENTER, YCENTER, NPRINT

Note: The variable VH3 contains the run number used by the PATHS system for a particular job. In the example, transient case,

19. SCALE, D, E, F

20. HI, HM, P9

21. HMC, HAC, TOC, TMC

22. $S S, J, P 1 *$

23. ROWELL(J), XWELL(J)

24. $\operatorname{YWELL}(\mathrm{J}), \operatorname{TNWELL}(\mathrm{J})$

25. QI (J), QM(J), DWELL (J)

26. $\operatorname{EWELL}(J), F W E L L(J), Q A(J), Q Q(J)$

27. TOWELL(J), TMWELL(J)

28. $\operatorname{WSS}(J)^{\star}$ the value of VH 3 is 1 . .

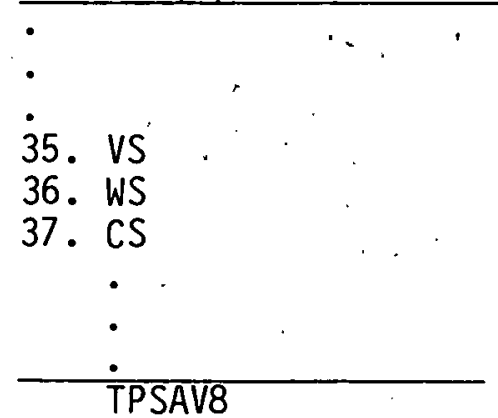

Skips if $\mathrm{J}=0$. Otherwise, . loops through these :
(When THETAO = THETAM, a list of XSTART and YSTART values are printed out here.) 
To explicate further, the batch run stream of the sample problem for the transient case is shown below.

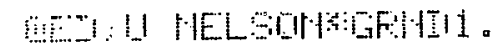

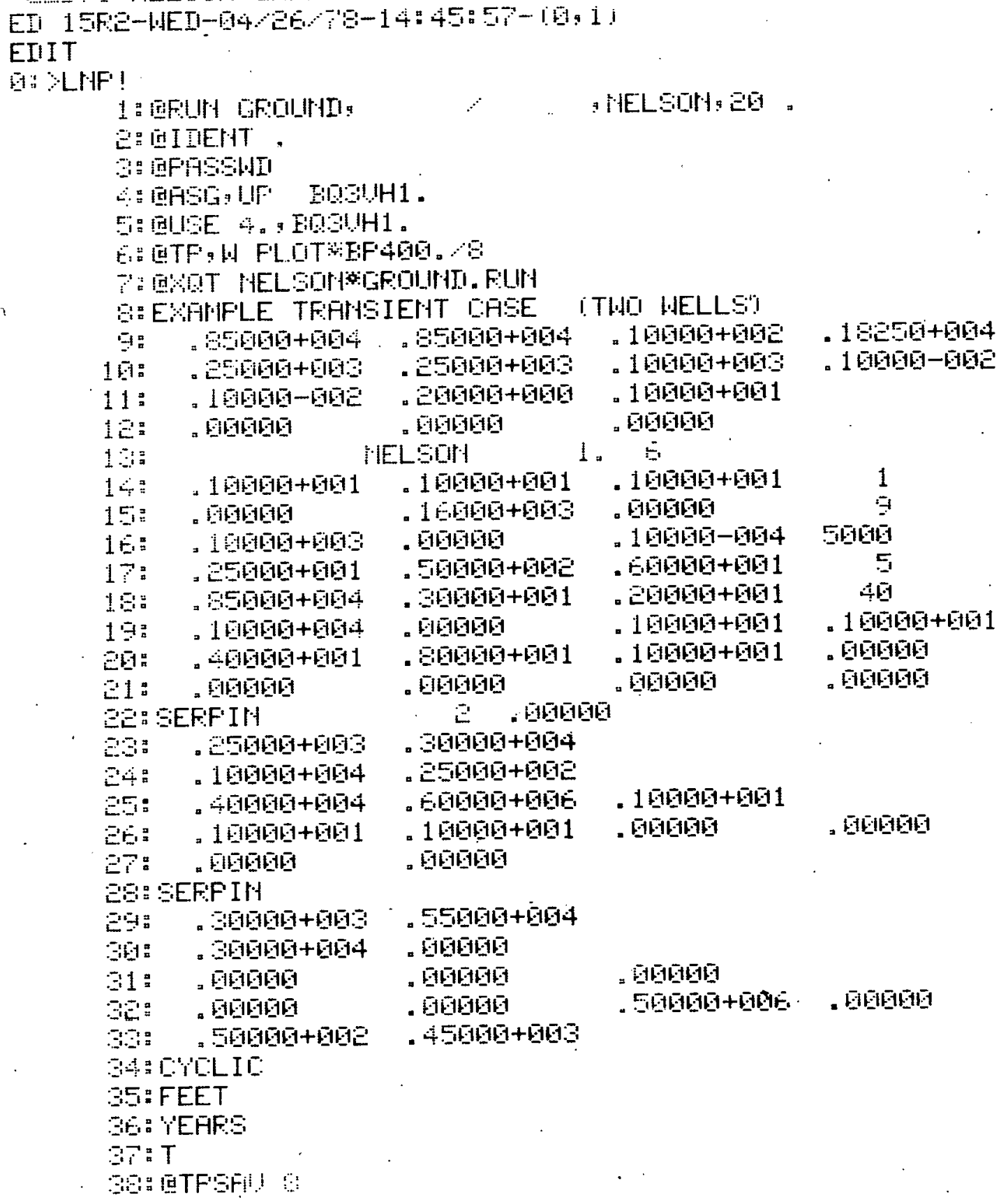

This can be compared with the sample data entered earlier in the PATHS program. (Already shown under "Sample Job.") 
Note the first command on this listing: OED, UQ NELSON*GRND1. . This. brings the run stream generated to the Univac EDITOR. NELSON is the PROJECT ID entered in PATHS under which the batch file is cataloged. GRND1 is the file name. GRND is always the prefix, and the number appended, 1 in this case, is the number of the job stream the user gave PATHS. (See the note near the end of topic "Sample Job" or item 78 in the detailed run stream, Appendix C). Next, the edit command LNP! lists the entire run stream for viewing. With this list the data can be checked and modified as desired. For example to change variable $.85000+004$ on line 18 to $.96000+003$, one can do the following:

18 (Positions to line 18)

C /.85000+004/.96000+003/1

This would make the change. The tailing 1 says to make the change only to the first line. If this change were to be made to any like variables in the ensu-. ing 10 lines, you should enter $C-/ .85000+004 / .96000+003 / 1$.

STARTING JOB EXECUTION

After the batch stream has been modified, type EXIT. This frees the file with all the changes that have been made and control leaves the EDITOR. (To leave EDITOR with the batch stream left in its original state, type OMIT.) Tu submit the file into the input stream for execution, type OSTART NESLON*GRNDI.

[Note: For additional detailed information on most of the available EDITOR commands and system control commands refer to UNIVAC 1100 Series EXEC 8 hardware/Sof tware Summary (UP-7824 Rev. 1).] 


\section{CAUTION}

When starting an execution of GROUND, it is important to realize that GROUND itself will generate and catalog two files: the summary file PROJID*BQ3VH_. and the data file read by LOCQAR, cataloged PROJID*LOCQ_. . (Once again PROJID is the user project ID, and the _ stands for the job run number.) If these files should exist from a prior run of GROUND, they will precipitate a fatal error should GROUND be reexecuted. Two alternatives are available to the user: the first, and simplest, is to delete these files if they exist. This is done by typing CDELETE followed by the file name. The example below shows the deletion of the file NELSON*BQ3VH 8 ..

$\because D E L E T E$ HELSOH+EOSHY

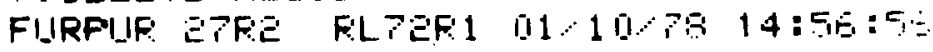

Alternatively, you could change the number of the file BQ3VH _. that is used on cards 4, 5 and 13 of the run stream (see "Using EDITOR"). Thus $\mathrm{BQ} 3 \mathrm{VH} 1$. could be changed to $\mathrm{BQ} 3 \mathrm{VH} 9$. if $\mathrm{BQ} 3 \mathrm{VH} 9$. does not already exist. Along with this, the internally assigned and cataloged file LOCQ_., should have its file number changed appropriately. It is set by variable. VH3.. (See line 13, in "Using EDITOR".)

As $B Q 3 V H 1$. was changed to $B Q 3 V H 9$., VH3 should be changed from 1 . to 9 ..

\section{FILES}

Keeping track of the files accumulated by the PATHS program can be done by taking an audit of the files cataloged. Do this by typing QAUDIT as shown in the following example. 
DHAIIIT

CATALOE EOE 14 APR $78-07: 44: 47$

\begin{tabular}{|c|c|c|c|c|c|c|c|c|}
\hline $\begin{array}{l}\text { TFAEK } \\
\text { EםIIHAT }\end{array}$ & $\begin{array}{l}\text { HIIH } \\
\text { FEF }\end{array}$ & $\begin{array}{l}\text { TFK } \\
\text { MAY }\end{array}$ & $\begin{array}{r}\quad \square F \\
A S B\end{array}$ & \multicolumn{2}{|c|}{ FLÄБ: } & $\begin{array}{c}\text { IIFTE } \\
\text { EFEATED }\end{array}$ & $\begin{array}{l}\text { LAST } \\
\text { ASE }\end{array}$ & FILE HAME \\
\hline 35 & $E 1$ & $1 \Xi \Xi T$ & 55 & F & $E$ & 012479 & 0413 & WEI SOH + DEOFF: 13 \\
\hline 45 & 71 & $15.5 T$ & $=5.5$ & $\mathrm{~F}$ & $\mathrm{E}$ & 012578 & 6415 & 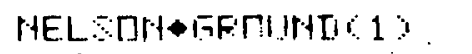 \\
\hline 41 & 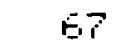 & $141 T$ & 94 & $\mathrm{~F}$ & $\mathrm{E}$ & 0118476 & 1413 & $H+F L \triangle \square H \leftrightarrow F A T H S C 1 \%$ \\
\hline 1 & 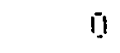 & 1Е厂 & 1 & $F^{\prime}$ & E & 1041370 & 0413 & HEI $\triangle$ OHAEMOH 19 \\
\hline 1 . & 1] & $1 \Xi \Xi T$ & $\Xi$ & $F$ & E & $07+1179$ & 1411 & HEL $\triangle D H+F H O Y H E C I \%$ \\
\hline$\Xi$ & 1 & $1: \Theta T$ & 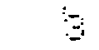 & $\mathrm{F}$ & $\mathrm{E}$ & $0412 \div 3$ & $04.1 \Xi$ & 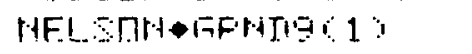 \\
\hline 1 & 1 & $12: 0 T$ & 1 & $\mathrm{~F}$ & Ei & 041270 & 0412 & 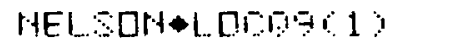 \\
\hline$\Xi$ & 1 & $1: 9 T$ & 4 & $F^{\prime}$ & $\mathrm{E}$ & $94 \div 1279$ & 0412 & HFLSOH+1FFH+JE 19 \\
\hline 1 & 0 & $1: B T$ & 1 & $\mathrm{~F}$ & $\mathrm{E}$ & 941279 & $041 \mathrm{O}$ & IHEL SOH O DIDEC 19 \\
\hline 1 & 0 & 1E:T & 1 & $F^{\prime}$ & $\mathrm{E}$ & 041273 & 10412 & HELSOH+EHOHEC1 \\
\hline 1 & II & $1 B: T$ & 4 & $F$ & E & $19+9778$ & 14010 & HEI $Y \Pi+1+10619$ \\
\hline 34 & 30 & $1 \Xi \Xi T$ & 1 & $\mathrm{~F}$ & E & 041178 & 0411 & HEL SOH+TFMF(1) \\
\hline SE & $\Xi$ & $500 T$ & 9 & $\mathrm{~F}$ & $\mathrm{E}$ & $04+379$ & 04.13 & HELSRH+FEUTSIDH 13 \\
\hline 3 & $\Xi 9$ & $1:: T$ & 10 & $\mathrm{~F}$ & $E$ & 047778 & 0.410 & HELSDH+1!T IL 61 \% \\
\hline 1 & 0 & $1 \mathrm{EQT}$ & 14 & $\mathrm{~F}$ & E & 048798 & 04.13 & 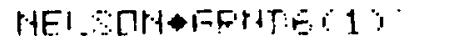 \\
\hline 1 & 0 & $1 \mathrm{ET}$ & $\Xi$ & $\mathrm{F}$ & $\mathrm{E}$ & 0407978 & $\square+11$ & 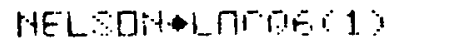 \\
\hline 1 & 0 & $1 \Xi B T$ & 14 & $F$ & $\mathrm{E}$ & 041178 & 11413 & HELSOH + BFHII L 19 \\
\hline 34 & $\vdots$ & $1 Z: B T$ & 1 & $\mathrm{~F}$ & $\mathrm{E}$ & 041178 & 11411 & HELSOH+ETFMFO 13 \\
\hline 10 & 9 & $120 T$ & 1 & $\mathrm{~F}$ & E & 041175 & 14.11 & HELSOHAL TFHFC 1 ? \\
\hline 1 & 0 & $1 \mathrm{EST}$ & $\Xi$ & $F$ & E & 0421.79 & 9411 & HELODH+1 ח101:19 \\
\hline 1 & II & $1: \because T$ & 4 & $\mathrm{~F}$ & E & 041270 & 0410 & HELSDH IFFHTIO 13 \\
\hline 1 & DI & $120 T$ & 1 & $F$ & $\mathbf{E}$ & 041278 & 0410 & HELSOH-1.M1R7619 \\
\hline 1 & प & $1 \Xi: 8 T$ & 9 & $\mathrm{~F}$ & E & 041078 & 04013 & HEL $O H+1,1 F . \mid$ THAT:19 \\
\hline 1 & $\underline{0}$ & $1: B T$ & 1 & $\mathrm{~F}$ & E: & 041078 & 0412 & 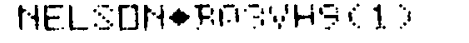 \\
\hline 1 & प1 & 1.ET & 14 & $\mathrm{~F}$ & E & 040403 & 0411 & 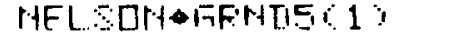 \\
\hline 1 & !) & LEET & 1 & $\Gamma$ & $\mathrm{E}$ & $04 \div 4=7=$ & 11404 & HFL SOH+1_C10561) \\
\hline 1 & 1] & $12: T$ & 1 & $F^{\prime}$ & $E_{i}$ & $041=78$ & 14410 & HEL SDH FI FHF 19 \\
\hline
\end{tabular}

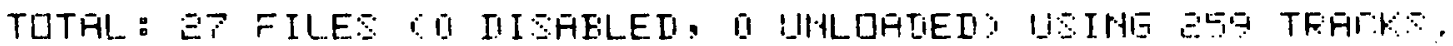

Files should be deleted when they are no longer needed. This avoids paying for unneeded disc storage, and reduces the likelihood of trying to create files with file names already cataloged.

\section{EXAMPLE TRANSIENT CASE}

The printed output following comes from entering information to the PATHS program shown in "Sample Job". Notice the individual path histories for each of the 10 paths followed by the summary page. This would be repeated five 
times for the transient cases for the years $0,25,50,75$, and 100. However, to save space only the first is completely shown and primarily summary information is subsequently shown. This summary information, incidentally, is the same as that obtained from file BQ3VH1, under "Summary File - BQ3VH_" previously. The complete output for the example transient case is provided on microfiche near the end of Appendix $C$.

The five plots that follow are also from this run. Normal production plots need not have such large numbers along the pathlines. They have been macie larger here so they will be legible.

Following the output of the example transient case, a steady case is presented to further illustrate some additional alternatives. Among these features are the ion exchange delay and the input of irregularly located starting coordinates for the pathlines. 


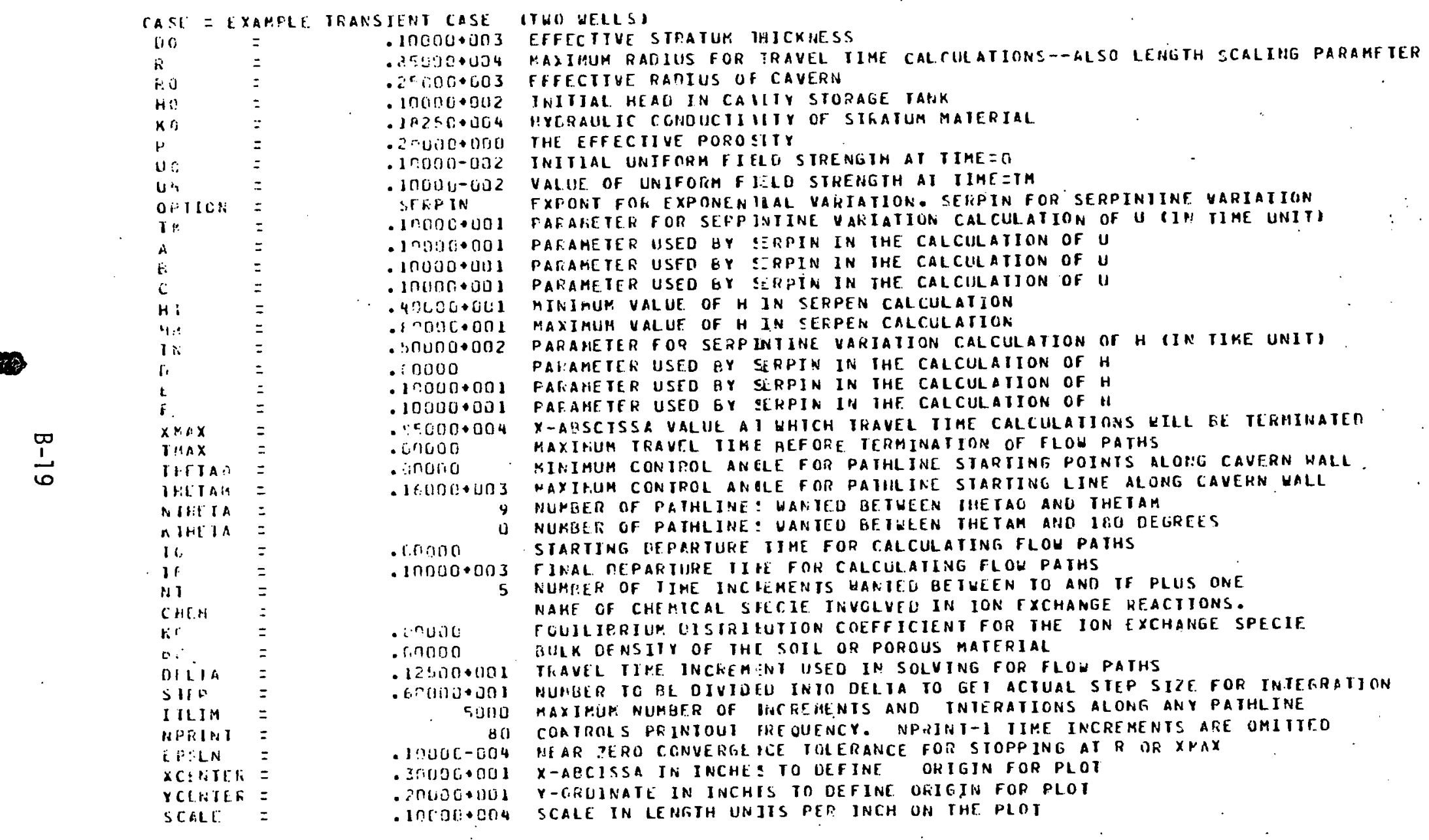




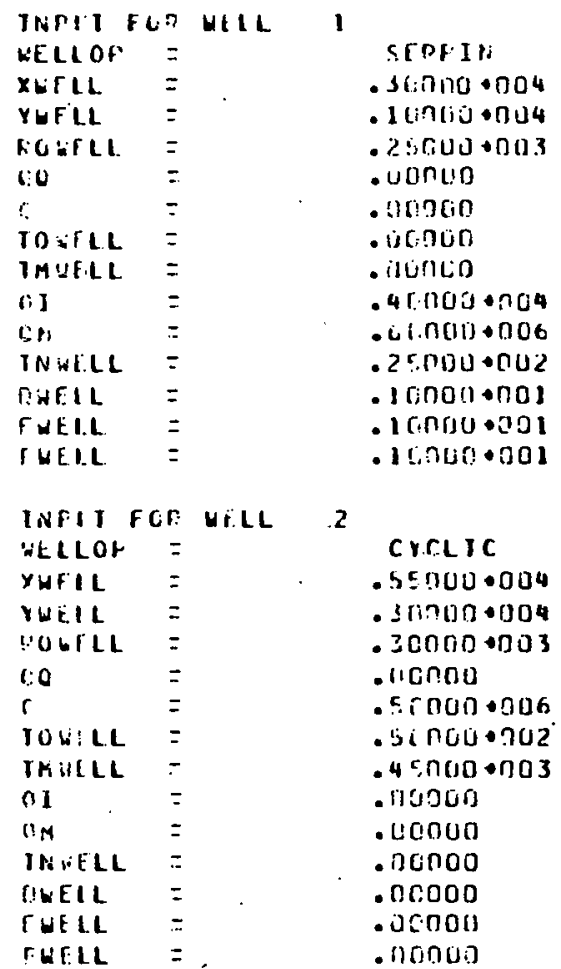

$x$-COOKOTNATF OF THE WRLL

$Y$-COORUINATE OF THE DE.LL

SIOFPING RATILIS OF IHE VELL

IHE HEAN INFLOUIOI (R OUIFLCHI-) RAIE OF THE HELL

THE MAXIMUA IHFLONI IOR DUIFLOU (-I RATE OF THE HELL

IHE EEGIINING TIME CF IHE. CYCLIC FLOW FOR IHE UELL

IHE EAIIIAC IIME OF IHF CYCLIC FLOW FOR IHE HELL

IHE EAIIIAC TIME OF IHE CYCLIC FLO

IHE MAXIMUT FLOU RA IE OF THF HELI

PARALEIER USEO IN C ILCULATING HELL FLOU RATE

PATARETER USED IN CALCULATING HELL FLOH RATE

Parameier usen in Colcultating hell flom rate

PABAMEIER USED IN CALCULAIING LELL FLOH RATE

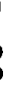

A) IHI SUCCESSFLI CONCLUSION OF GROUND IHE FOLLOUING I ILES ARE CATALOUGED: NELSON + LOCUI. ANU NEISON\&BOTYHI. 


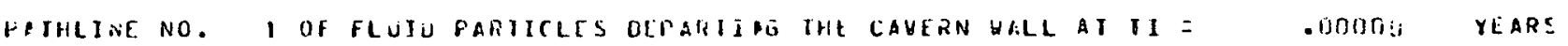

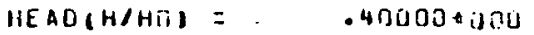

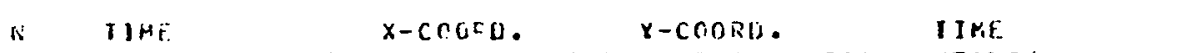

CIMEHSTONIESS DIAFNSICNLESS TIMENSIONIESS YEARS

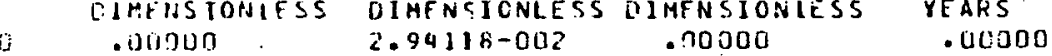

$12.52595-00 ? \quad 2.86454-001 \quad-1.85 ? 33-102 \quad 1.000000002$

F 5.0514.1-.ju? 4.61129-001 $\quad-4.41471-\{02 \quad 2.00000 \cdot 092$

$\because 7.57765-342 \quad 0.09 .646-1101 \quad-5.34281-\{42.3 .000000002$

$4 \quad 1.31938-041 \quad 7.4544 i j-001 \quad-5.68986-102 \quad 4.00000002$

$5 \quad 1.26757-1111 \quad 8.76849-001 \quad-6.10537-602 \quad 4.999990002$

$5+1.44965-361 \quad 9.99995-1101 \quad-7.00682-102 \quad 5.933400402$

\begin{tabular}{|c|c|c|}
\hline $\begin{array}{l}x-\cos \theta 0 . \\
\text { FEE } \\
2.50000 \cdot 302\end{array}$ & $\begin{array}{l}\text { Y-COORU. } \\
\text { FEE T } \\
\text {.00000 }\end{array}$ & $\begin{array}{l}\text { PATH LENGTH } \\
\text { FEEI } \\
\text {. OOOOJ }\end{array}$ \\
\hline 2.51986 .003 & $-1.57448 .000 ?$ & $2.27688 \cdot 003$ \\
\hline 3.919590 .903 & $-3.75250+0012$ & $\begin{aligned} 3.69357+003 \\
.00000\end{aligned}$ \\
\hline $5.17349 \cdot 003$ & -4.541390002 & $\begin{array}{c}4.95044+003 \\
.00000\end{array}$ \\
\hline $6.33624+003$ & $-4.83638+0012$ & $\begin{array}{r}6.11357+003 \\
.00000\end{array}$ \\
\hline $7.45322 \cdot 003$ & $-5.18957+002$ & $\begin{array}{c}7.23128+003 \\
.00000\end{array}$ \\
\hline $8.49996 * 003$ & $-5.955 A 0 \cdot 002$ & $8.28084+0113$ \\
\hline
\end{tabular}

JiHe $x$-COOCD. $\quad$-CCORD. TIAE

DIMCNSILHLFSS DIMFNSICNLESS OIMENSIOHIESS VIARS

.00נo?

$2.16390-2 \mathrm{u} 2$

$1.110594-6020$

$x-\operatorname{coOR} 0$.

FEE I

$2.34923 \cdot 002$

Y-COORD

F E. I I

PATH LENGIH

$2.52595-(31 i)$

$2.45158-001$

$4.52434-$ Cu2

1. . $00000 \cdot 0002$

$2.42385+100^{3}$

$8.55050+001$

PEET

$5.0351400-010 ?$

$4.49472-601$

$2.45019-(012$

$2.00000+002$

$3.81626 \cdot 003$

$3.84569 \cdot 002$

$2.21991 \cdot 003$

$7.57765-110 ?$

$5.991 ? 1-1101$

$2.02137-\cos 2$

$3.00000 \cdot 002$

$5.09253 \cdot 003$

2.08266 .002

$1.71810+002$

12

$3.62395 \cdot 003$

$4.90122+003$

1. $01035-301$

$7.34532-0.31$

$2.01965-\{0 ?$

ม. vưunoง

f. $.26392+1003$

$1.71670 \cdot 002$

$6.07262 \cdot 003$

$1.26297-5141$

$\varepsilon .69197-1111$

1.80770-cu2

$4.94599 \cdot 0 ! 2$

$7.3 k 818 \cdot 003$

$1.53654 \cdot 0 \cap 2$

$7.19727 \cdot 003$

1.5 TgEs $5-0 \cup 1$

5. 49971-[iul

$9.77566-143$

3.97733011012

$8.49975 \cdot 003$

E. $30931 \cdot 001$

f. 1.50989-!161

9. $99997-701$

$9.77455-0103$

$5.97753+002$

A. $49997+003$

b. $30837+001$

$8.31112+003$

$8.31134 \cdot 1103$

$257 \cdot 000$ $4062 \cdot 000$

$226-001$

$2960-001$ 


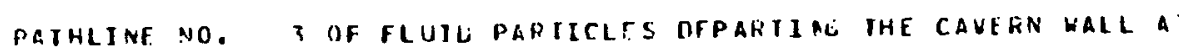

\begin{tabular}{|c|c|c|c|c|}
\hline N & $\begin{array}{l}\text { IIHE } \\
\text { OIMENSIONLESS } \\
\text { - DOOOT }\end{array}$ & $\begin{array}{l}x \text {-CnOFD. } \\
\text { UIMENE } 10 \text { ONLFSS } \\
2.253 \pi 7-002\end{array}$ & $\begin{array}{l}Y \text {-CNORU. } \\
\text { OINFNSIONLESS } \\
1.8905 S-\text { CL2 }\end{array}$ & $\begin{array}{l}\text { I IME. } \\
\text { YEARS } \\
\text {.OCIOOOO }\end{array}$ \\
\hline 1 & $2.52545-002$ & $2.58160-001$ & $1.1124 n-101$ & $1.00000 \cdot 092$ \\
\hline 1 & $3.41261-062$ & $3.2427 u-n 01$ & $1.237 \mathrm{U} 2-101$ & $1.569937 \cdot 002$ \\
\hline
\end{tabular}

$11=\quad$ ONOOOU YEARS

THE IA $=\quad .4011000002$ DE.SREES

HEAOIH/HOI $=\quad .40000 .000$

\begin{tabular}{|c|c|c|}
\hline $\begin{array}{l}x-c(J O R D . \\
F E E \\
1.91511+1102\end{array}$ & $\begin{array}{l}Y-C D O R O . \\
\text { FEE } \\
\text { J.60647.002 }\end{array}$ & $\begin{array}{l}\text { PAIH LENGIH } \\
\text { FEET } \\
\text {-ODNOJ }\end{array}$ \\
\hline $2.19436 \cdot 003$ & $9.45605+002$ & $\begin{array}{l}2.16970+103 \\
.242220000\end{array}$ \\
\hline $.75630 \bullet 00$ & $1.05146 * 003$ & $2.74173+003$ \\
\hline
\end{tabular}

A) $11=$ . HORNO YEARS IHETA $=$. EUNOD.0O2 DEGRE.ES HEAOLH/HIII $=.40000+00 E$ $.21961 \cdot 000$

\begin{tabular}{|c|c|}
\hline i. & $\begin{array}{l}\text { JIME } \\
\text { OIMENS I UNLESS } \\
\text { - OLUOUN }\end{array}$ \\
\hline I & $2.52555-0107$ \\
\hline 2 & $5.0519 n-1102$ \\
\hline 3 & $7.57785-j G 2$ \\
\hline 4 & $1.01039-001$ \\
\hline ! & $1.26297-i)[1$ \\
\hline t. & $1.51557-001$ \\
\hline 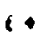 & $1.65750-1101$ \\
\hline
\end{tabular}

\begin{tabular}{|c|c|}
\hline $\begin{array}{l}x \text {-COCIRE. } \\
\text { OIME NS IONLESS } \\
1.47 \text { J59-002 }\end{array}$ & $\begin{array}{l}Y-\text { CONRU. } \\
\text { OIMENSIONIESS } \\
2.54713-C \mathrm{2}\end{array}$ \\
\hline $2.19540-001$ & $1.65291-101$ \\
\hline $3.61203-001$ & $2.11 \times 35-\cos 1$ \\
\hline $5.06577-001$ & $2.37810-\{01$ \\
\hline $6.44297-001$ & $2.51485-(011$ \\
\hline $7.85 .736-10111$ & $2.55267-(0)$ \\
\hline $4.27 ! 72-n u 1$ & $2.51043-(0)$ \\
\hline $9.99994-001$ & $2.52533-c 01$ \\
\hline
\end{tabular}

I IhE.

YEARS

-ouvoo

$X-C O O K O$.

FEEI

1.25000 0002

$\gamma-$ COORT.

FEE 1

$2.16500+002$

PATH LENGJH

1.00000002

1. AE6C9.0U3

1.464970003

FEE I.

2.09090.002

$3.07020 \cdot 003$

$1.80060 \cdot 003$

$2.14331 \cdot 003$

2.05095 .002

$4.30591+003$

$2.02139 \cdot 003$.

$3.41126 \cdot 003$

$3.00000+0112$

$5.47652 \cdot 003$

$2.13762 \cdot 003$

$4.99999 \cdot 002$

$6.63625 \cdot 003$

$2.16994 \cdot 003$

$5.99999 \cdot \mathrm{J} 02$

$7.88011 \cdot 003$

$2.13387 \cdot 003$

$2.14653 \cdot 003$

$4.66728 \cdot 003$

$4.6672 B \cdot 003$
$.28051 \cdot 000$

$5.84375 \cdot 003$

7. $00529 \cdot 003$

$9.24983+003$ 3

6.56219 .002

$8.49995 \cdot 003$

$8.86963 \cdot 003$ 25270.000 $.25219 \cdot 000$ 


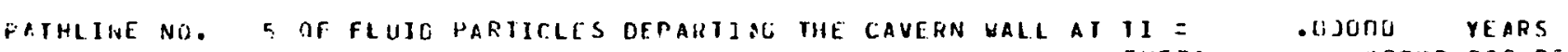

THETA $=$. BOOUD 0032 DEEFEES

HEAD (H/HO) $=.40000+90 U$

\begin{tabular}{|c|c|c|c|c|}
\hline$i$ & $\begin{array}{l}\text { IIHE } \\
\text { DIHENSIONIESS } \\
\text { : UOOUO }\end{array}$ & $\begin{array}{l}X \text {-COOPD. } \\
\text { OIAENSIONLESS } \\
5.10730-003\end{array}$ & $\begin{array}{l}y \text {-COOFD. } \\
\text { OIMFNSIONIESS } \\
2.99649-\text { CU2 }\end{array}$ & $\begin{array}{l}\text { TIML } \\
\text { YEARS } \\
\text {-OUOOOO }\end{array}$ \\
\hline 1 & $2.52595-00 \%$ & $1.66797-001$ & $2.03136-101$ & y.00000 002 \\
\hline 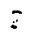 & $5.0518 n-002$ & $3.04591-001$ & $2.58933-101$ & $\bar{c} .00000 \cdot 002$ \\
\hline 3 & $7.57785-i: ? ?$ & $4.440778-001$ & $2.91824-\mid U 1$ & $\Xi .00000 \cdot 002$ \\
\hline 4 & $1.111038-001$ & $5 . a n 573-001$ & $3.10834-101$ & 4.00000 .002 \\
\hline$r$ & $1.26297-001$ & $7 . 2 3 6 \longdiv { 2 - 0 0 1 }$ & $3.10628-\operatorname{ta} 1$ & $4.99999+002$ \\
\hline n & $1.51557-0121$ & $8.81241-0.01$ & $3 . r 8097-[\mathrm{CL}]$ & $5.99999+002$ \\
\hline 6. & $1.7495 t-001$ & $9.99957-n 01$ & $3.12586-601$ & $E .92635+002$ \\
\hline
\end{tabular}

$\begin{array}{ll}X-C O O K D & Y-C O O R O \\ \text { FEET } & \text { FEET } \\ 4.34120+001 & 2.46202+002 \\ 1.41769+003 & 1.72666+003 \\ 2.58894+003 & 2.20093+003 \\ 3.77466+003 & 2.48050+003 \\ 4.93487+003 & 2.64209+003 \\ 6.15071+003 & 2.64034+003 \\ 7.49055+003 & 2.61883+003 \\ 8.49998+003 & 2.65698+003\end{array}$

PATH LENGIH

FEE I

.00002

$2.08199 \cdot 003$

$3.34746 \cdot 003$

$.39201+000$

$4.56647 \cdot 003$

.36223 .000

$5.73808 \cdot 003$

$.34512 \cdot 000$

$6.95997 \cdot 103$

$33234 \cdot 000$

$8.30047 \cdot 1003$

$32523 \cdot 000$

$9.31063 \cdot 003$

$.32268 \cdot 000$

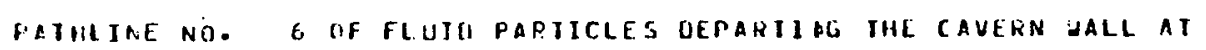

$I I=$. DOOONO YEARS

THETA $=\quad$ IONON.003 DELREES

HEACL(H/HO) $=\frac{.400000000}{}$

\begin{tabular}{|c|c|c|c|c|c|c|c|}
\hline A & $\begin{array}{l}\text { IIHE } \\
\text { DIMENSTOGLESS } \\
\text {-UORDO }\end{array}$ & $\begin{array}{l}\text { X-COOFO. } \\
\text { OIMENSIONLESS } \\
\text { - S.1U7 } 20 \text { DUS }\end{array}$ & $\begin{array}{l}Y \text {-COORD. } \\
\text { UIMENSIONLESS } \\
2.89649-\operatorname{CO2}\end{array}$ & $\begin{array}{l}\text { I IME } \\
\text {-EARS } \\
\text {-OOOOOO }\end{array}$ & $\begin{array}{l}X-\operatorname{COORD} . \\
\text { FEET } \\
-4.34120 \cdot 001\end{array}$ & $\begin{array}{l}Y-C O O H D \\
\text { FEET } \\
2.46202+002\end{array}$ & $\begin{array}{l}\text { PAIH LENGTH } \\
\text { FEEI } \\
\text {.0O0OJ }\end{array}$ \\
\hline 1 & $2.525,85-402$ & $1.00748-001$ & $2.23614-\{01$ & $\therefore .00000 \bullet 002$ & $8.56356+002$ & $1.90072+003$ & $\begin{array}{rl}1.97487 & 003 \\
& .56355 \cdot 000\end{array}$ \\
\hline 5 & $5.05180-n 0 ?$ & $2.3 n 538-501$ & $2.92098-[01$ & $2.00000 \cdot 0.22$ & $1.95957 \cdot 003$ & $2.48283+003$ & $\begin{array}{l}3.22597+003 \\
.47332+000\end{array}$ \\
\hline 3 & $7.57785,-00 ?$ & $3.65215-901$ & $3.31784-101$ & $3.00000+002$ & $3.10432+003$ & $2.82016 \cdot 003$ & $4.42038 \cdot 003$ \\
\hline 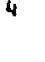 & $1.0 \ln 38-001$ & $4.99691-0 i 11$ & $3.56572-601$ & $4.00000 \cdot 002$ & 4.24738 .003 & $3.03087+003$ & $\begin{array}{c}5.58298+003 \\
.41428 \cdot 000\end{array}$ \\
\hline ? & $1.26297-901$ & $6.12213-001$ & $3.91572-(01$ & $9.99999 \cdot 0 \cap 2$ & 5.20381 .003 & $3.24336+003$ & $\begin{array}{r}6.57807+003 \\
.39857+000\end{array}$ \\
\hline c & $1.51557-001$ & 7.35 c89- 1001 & $4.56091-\mathrm{CO} 1$ & $5.99999 \cdot 002$ & $6.24825+003$ & 3.67677 .003 & $\begin{array}{r}7.83104 \cdot 003 \\
.38966 \cdot 000\end{array}$ \\
\hline 8 & $1.76816-001$ & $6.633 .34-0011$ & $4.70316-[01$ & $0.95999 \cdot 002$ & $7.33808 \cdot 003$ & $3.99768+003$ & $\begin{array}{r}8.92881+003 \\
.38576 \cdot 000\end{array}$ \\
\hline & $2.02076-001$ & $9.85198-0.01$ & $4.77905-(i)$ & $1.99998 \cdot 002$ & $8.37418+003$ & $4.06219 \cdot 003$ & $\begin{aligned} 9.96692 \cdot 003 \\
.38093 \cdot 000\end{aligned}$ \\
\hline$\vdots \bullet$ & $2.05162-001$ & $9.99990-001$ & $4.78722-[u ̈ 1$ & $3.12215 \cdot 0 \cap 2$ & $8.49992+003$ & $4.06914 \cdot 003$ & $1.00928+004 \quad \vdots$ \\
\hline
\end{tabular}




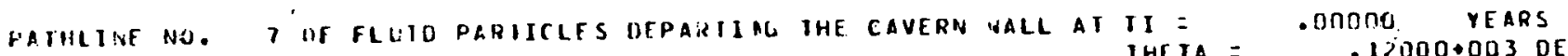

THCTA $=\quad .120000003$ DEGREES

HEAC(H/HO) $=\quad .4000$ OODL

\begin{tabular}{|c|c|c|c|c|c|c|c|c|}
\hline \multirow{11}{*}{$\begin{array}{l}\infty \\
1 \\
1 \\
\infty\end{array}$} & i: & $\begin{array}{l}\text { TIFE } \\
\text { OIMENSIONLESS } \\
\text {.OUOUO }\end{array}$ & $\begin{array}{l}\text { X-COORD } \\
\text { DIHENSIONLESS } \\
-1.47059-902\end{array}$ & $\begin{array}{l}Y \text { Y-COORD. } \\
\text { OIMENSIONLESS } \\
2.54713-\text { CU? }\end{array}$ & $\begin{array}{l}\text { IIHF } \\
\text { YFARS } \\
\text {.OOOOU }\end{array}$ & $\begin{array}{l}x-\operatorname{coOHO} . \\
\text { rEt } \\
-1.2 \operatorname{sinnO+002}\end{array}$ & $\begin{array}{l}Y-C O O F L . \\
\text { FEE } \\
2.16506+002\end{array}$ & $\begin{array}{l}\text { PAIH LENGIH } \\
\text { FEET } \\
\text { PIOONOS }\end{array}$ \\
\hline & 1 & $2.52595-017 ?$ & $2.31458-1.02$ & $2.21881-101$ & $1.00000+0112$ & $1.96740 * 002$ & $1.68599 \cdot 003$ & $\begin{array}{l}1 . R 1383 \cdot 00 \mathrm{~J} \\
.65523+000\end{array}$ \\
\hline & $?$ & $5.05190-002$ & $1.371033-0101$ & $3.74864-(0)$ & $2.00000+002$ & $1.16495+103$ & $2.59135 \cdot 003$ & $\begin{array}{rl}3.01861 & .003 \\
.54667+000\end{array}$ \\
\hline & 3 & $7.57785-000 ?$ & $2.65565-1001$ & $3.53485-101$ & $3.00000 \cdot 002$ & $2.25731+003$ & $3.00463+003$ & $\begin{aligned} & 4.18809 \cdot 003 \\
& .50100 \cdot 000\end{aligned}$ \\
\hline & 4 & $1.01038-1301$ & $3.97(: 27-1) n 1$ & $3.85171-101$ & $4.00000 \cdot 002$ & $3.37473 \cdot 003$ & $3.27395 \cdot 003$ & $\begin{aligned} 5.33791 & +003 \\
& .47521 \cdot 000\end{aligned}$ \\
\hline & 5 & $1.26297-301$ & $5.2 n 582-001$ & $4.08904-101$ & $.4 .99999 \cdot 002$ & $4.42495 \cdot 003$ & $3.47568 \cdot 003$ & $\begin{aligned} 6.40773 \cdot 003 \\
.45675 \cdot 000\end{aligned}$ \\
\hline & $i$ & $1.51557-401$ & $6.18425-601$ & $4.55537-101$ & $5.99999 \cdot 0 \cap 2$ & 5.25661 .003 & $3.47208+003$ & $\begin{array}{rl}7.33126+003 & .446030000\end{array}$ \\
\hline & 7 & $1.76416-001$ & $7.42274-5101$ & $4.76838-101$ & $6.99999 \cdot 002$ & $6.30933+003$ & $4.05312 \cdot 003$ & $\begin{array}{r}8.40476 \cdot 003 \\
.44090 \cdot 000\end{array}$ \\
\hline & $\varepsilon$ & $2.02076-301$ & $8.65159-0.01$ & $4.86371-101$ & $7.99998 \cdot 002$ & $7.35385 \cdot 003$ & $4.13416 \cdot 003$ & $\begin{array}{r}9.45243 \cdot 003 \\
.43509 \cdot 000\end{array}$ \\
\hline & $\because$ & $2.2939-1001$ & $9.89 .3 ? 7-301$ & $4.95153-[01$ & $3.99998 * 1102$ & $.4 n 928 \cdot n 03$ & $4.20880 \cdot 003$ & $\begin{array}{r}1.05105 \cdot 004 \\
.42798 \cdot 000\end{array}$ \\
\hline & $\therefore$ & $2.29392-001$ & $9.9999 u-001$ & $4.96043-(6) 1$ & $9.118142 * 002$ & $8.49992 * n 03$ & $4.21636+003$ & $\begin{array}{c}1.06015 \cdot 004 \\
.42734 \cdot 000\end{array}$ \\
\hline
\end{tabular}




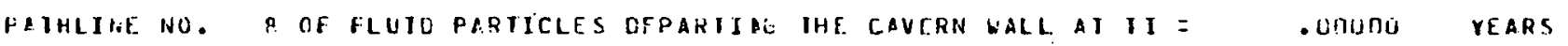

THFIA $=\quad .140000003$ DEFIEEES

HEAL(H/HO) $=\quad .401000$ DODO

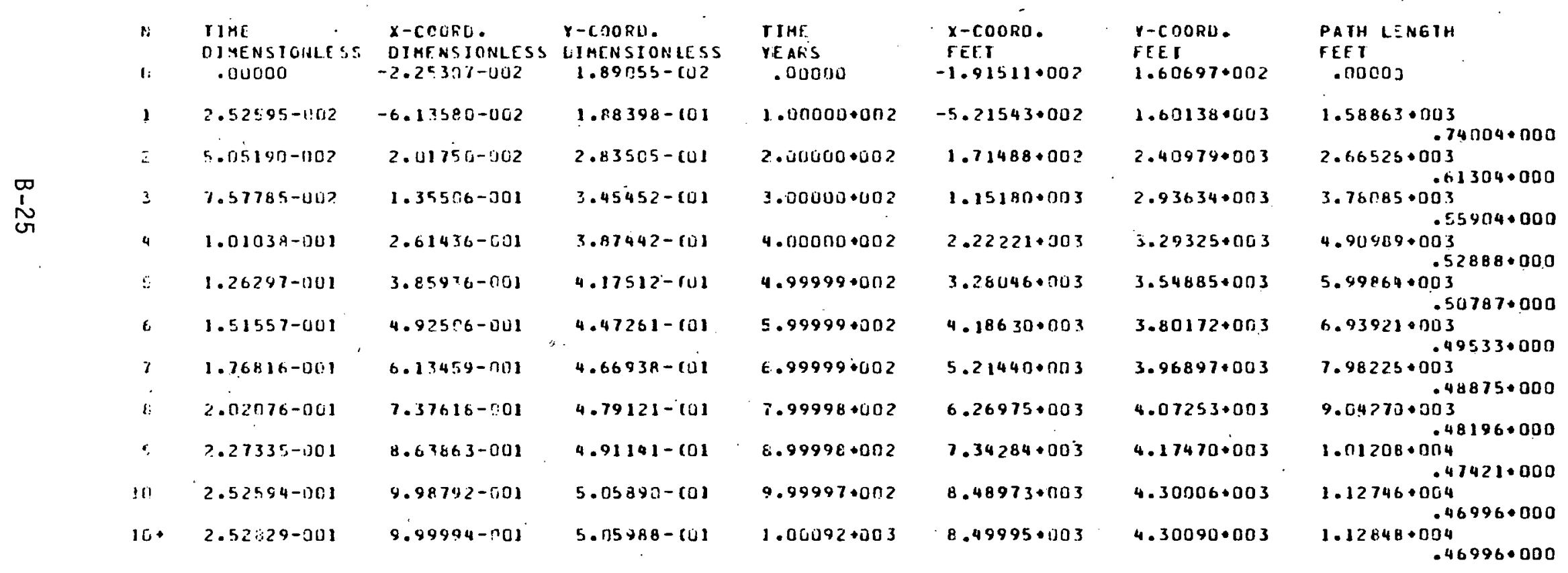




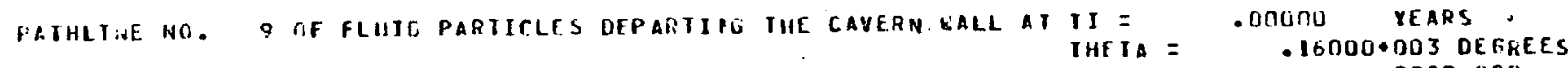
THEIA $=$
HEAOIH/HO) $=$
$.16000+003$ DEFKEES

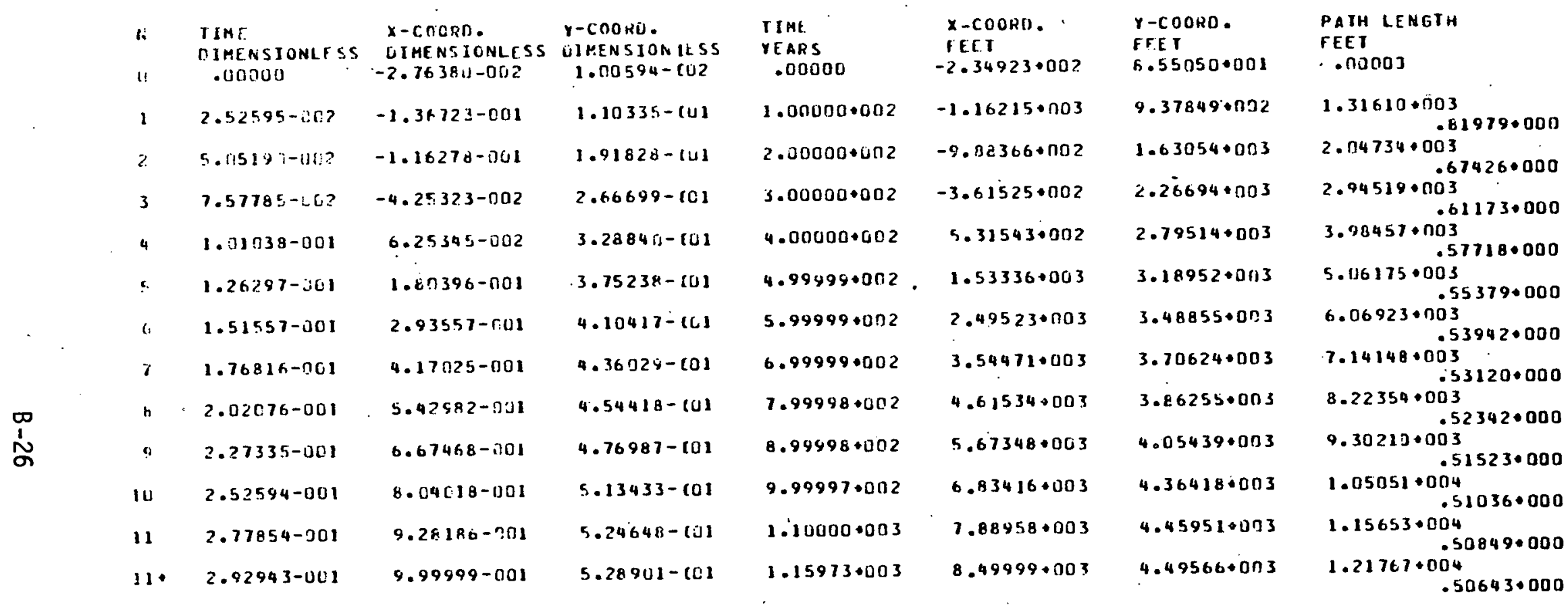

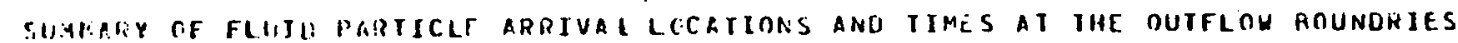

\begin{tabular}{|c|c|c|c|c|c|}
\hline \multirow[b]{3}{*}{ PAIH } & \multirow[b]{3}{*}{ NC } & \multicolumn{2}{|c|}{ 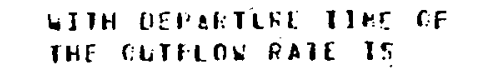 } & \multicolumn{2}{|c|}{ - UCUYEARS ANU } \\
\hline & & AND THE IZE & LAIIUF CAVERN & HEAD IS & .4000 \\
\hline & & $\begin{array}{l}\text { WRL.AHFIIIME } \\
\text { YEARS }\end{array}$ & $\begin{array}{l}x \\
\text { FEE }\end{array}$ & $\begin{array}{l}\text { Y } \\
\text { TEEI }\end{array}$ & $\begin{array}{l}\text { PAIH LENGIH } \\
\text { FEEI }\end{array}$ \\
\hline & 1 & $5.933 \mathrm{~L} 0+1 \mathrm{LL} 2$ & $8.49596+003$ & $-5.95580 \cdot 102$ & $8.2 t 084 \cdot u \cap 3$ \\
\hline & 2 & $5.9775 .3+502$ & $6.49997 \cdot 1003$ & $6.30837 \cdot 101$ & $A .31134 .003$ \\
\hline & 3 & $1.50 \% 37+39 ?$ & $2.75630+003$ & $1.05146 \cdot c 03$ & 2.741700003 \\
\hline & 4 & $6.56210+00 ?$ & $8.49995 \cdot 003$ & $2.14653 \cdot 103$ & e. $86933 \cdot 003$ \\
\hline & 5 & 0.926350062 & $6.4999 E \cdot 003$ & $2.6564 \mathrm{~h}+103$. & $9.31063 \cdot 0 \pi 3$ \\
\hline & $i$ & $5.12218 \cdot .202$ & $H .49992 \cdot \mathrm{rin} 3$ & $4 \cdot 1: 6914+603$ & $1.0092 t \cdot 0004$ \\
\hline & 7 & c. 018.142 .002 & 8.49992 .003 & $4.21636 \cdot \operatorname{cus} 3$ & $1.06015 \cdot 0 \cap 4$ \\
\hline & is & $1.11 \sin 92+103$ & $8.49995+003$ & $4.300 y n \cdot[43$ & 1.12848 .094 \\
\hline & " & $1.15973+003$ & $8.49999 \cdot 003$ & $4.49566 \cdot[\mathrm{cJ} 3$ & $1.21767 * 074$ \\
\hline
\end{tabular}



WAIHIIISE NO. I OF FLUIL FGRIICLES DEPARTIRL THE CAVERN WALL AT TIE
THFIA = . TULOO OEBTEES
HEAD(H/HO) = .72UDO+DOOO

n TIME

MIRENSTGNIT!S

$1.31488-a L^{3}$

3. $12744-119 ?$

$5.60359-i j 6$ ?

8. $25933-30 ?$

1. $147353-1 ; 61$

$1.3261 ?-.31$

$\therefore \quad 1.55547-1001$ $x-\operatorname{cocha}$.

X-CRORO.

$2.94118-302$

IIIEN SIOH

.70000

$3.01 \geq 530-001$

$-1.70248-102$

$4.65192-001$

6.1 ?355-801

$-3.98131-$ cu2

$-4.65619-102$

$7.48297-901$

$-4.95835-102$

E. $90479-001$

$-5.58146-00 ?$

$3.9999 t-[: 6]$

$-6.42062-\{112$
IIME.

2.500 No.001

1.250no*002

2.25000 .002

$3.25000 \cdot 002$

$4.25000+002$

$5.24999 \cdot 002$

$c .15405+002$ x-cooro

FEE I

2.5000n+002

$2.58001 \cdot 003$

$3.95413 \cdot 003$

s. $20256+003$

$6.36044+003$

7.46407 .003

8.49997 .003
$y-\operatorname{COORO}$.

FE.E T

- anodo

$-1.44711 \cdot 002$

$-3.38412 \cdot 0112$

$-3.95776+0 n 2$

$-4.21460 \cdot 002$

$-4.74466 \cdot 002$

$-5.45752 \cdot 002$
PAIH LENGTH

FEET

$2.33656 \cdot 003$

.00000

$3.72457 \cdot 003$

$4.97447+203$

6.13264 .003000

$6.13264+003$

$7.25785 \cdot 003$

$8.27634 \cdot 003000$

.00000
FAHLINE NU. P OF FLUID PARIICLES DEPAFIIAS IHE CAVERN WALL AT II

IHCTA =

MEAD(H/HI)
$25, C H D+002$ YEARS

. $20000+0$ UL 2 DERREES .12 unotoná IIME
DIMENSIONLES DIMENSTUNLES $x-$ CONOFL .76390-J02 1. $00594-$ CO?

\section{IHE}

TEARS

2.SUOOOOOOI

$x-\operatorname{coO} O$

$3.15744-n 67$

$2.91315-001$

9. $0.399 t-t 42$

$4.5>535-r i v 1$

?. $112855-102$

$1 \cdot 25000 \tan 2$

FEE.

$2.34923+00 ?$

Y-COORO.

$Y$ FET
४.55050+001

2.47621 .003

$4.11397 \cdot 002$

$2.25000 \cdot 002$

$3.84658+403$

$2.57427 \cdot 002$

$3.25000+002$

5.137600003

$2.94664 \cdot 002$

$4.25000 \cdot 002$

$6.22331 \cdot 003$

$2.48502+002$

$7.59215-001$

2. $02355-102$

$5.24999+002$

$7.41748 \cdot 003$

$6.20520 \cdot 002$

F. $49991 \cdot 003$

6.20531 .002

R. $49996 \cdot 103$

$2.0969 .7+002$

$1.45172+002$

$1.45170 \cdot 002$
PATH LENGTH

FEE I

. ngoos

$2.27768 \cdot 003$

.116390000 03

$4.92873+003$

$.95930-001$

$6.09442 \cdot 103$

$.92192-001$

$7.22975 \cdot 103$

$8.31424 \cdot 0.03$

$89061-001$

$.87894-001$

$8.31429 \cdot 9103$

$.87894-001$ 


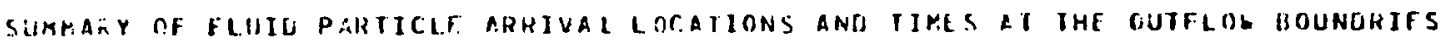

"ITH OHPIITLE II:T WF THE NUTFLCI FATI IS

AND TIIF. H.elative CAUERN HE.AD IS 25.0 RIYIARS $23412536+407$ CU3IC FEE ANO A.T THAT TIME .7200

PAIH NG BEL.ASR - THIAE reAOS

f. $.15805 \cdot 30 ?$

i. $211531+0102$

$1.737511+00$ ?

$476709+00$ ?

7.22298402

3.6447i1.100?

$3.35417+136$ ?

$1.0214 \% 00 ?$

$1.1349011+043$
TEE.

8. $4 \cong 897 \cdot 103$

$6.45996+i] 03$

$2.76759+003$

$8.49497+1103$

$4.49406+0113$

E.49906+003

$8.45992+003$

8.49994 .003 $\checkmark$

FEET

$-5.45752+102$

$1.4517 n+\cos 2$

$1.119059 \cdot \mathrm{CU} 3$

$2.11145 \cdot 103$

$2.47694 \cdot 103$

$4 \cdot 1.3255 \cdot 103$

$4.11276 \cdot(03$

$4.23936+103$

$4.48393 \cdot 103$
FEE 1

$3.27634 \cdot 003$

$8.31429+003$

$2.76971+003$

8.891154 .403

9.36508 .003

$1.511374 \cdot 004$

$1.06124 \cdot 004$

$1.21552+004$
FAIH LENGTH

1.12991 .004
WITH DEPAPILRE TIRE CF THE OUTFLOW RATE IS

YELARS TIME $X$

PAIII NO

$$
\text { HEL.A.TR }
$$

YEARS

$6.4427 ? \cdot 10$ C

t. $45139+602$

$3.97969 \cdot 00 ?$

?. $15467+00 ?$

$7.599411+307 ?$

$0.53543+302$

$1.03490+103$

$1.19591+.1133$
FEET

$0.49997 \cdot 003$
$0.40996+203$ $0.40996+703$ $2.75401 \cdot 003$
$8.50000 \cdot 003$ $6.49992+003$ d. $49996 \cdot 0 C^{3}$ $8.49995+103$ $8.49997+0113$ 8.49992 .003
50.0 GYYEAPS .26013932 4UU7 CUBIC FEEJ .8000 ANU AT IHAT IIAE.

PER YEARS $\gamma$

TEET

$-5 \cdot C 9674 \cdot 102$

1.69 inun t cú2

$1.04166 \cdot 103$

$1.98081+103$
$2.28031+103$

$2.28031+103$
$3.76889+103$

$3.76889 \cdot 103$

$4.13285 \cdot 103$

$4.44686 \cdot 103$
PATH LENGTH

FEE I

$8.27246 \cdot 003$

8.31108 .003

2.74483 .003

$8.87172+003$

9.35466 .003

$1.00172 \cdot 004$

$1.05210+004$

$1.12053+004$

$1.20545 \cdot 004$ 


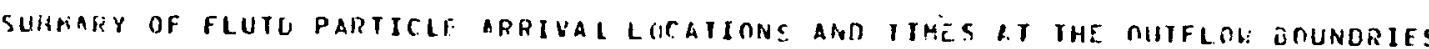

WTH OHIATLEE TIPF OF JHE CIUTFLOY PATE IS

RISD IHE HELA IIVE CAYERN MEAT

75. U COYEARS EOI3j\%क 1LOT CHBIC FEET

.7642

HAI:1 NO

KFL.AD:Z. IJHE

YHALS

$6.754 i 19+060$

1.. $7 \times 120+60 \%$

$2.23750 \cdot 10017$

$7.3 \div 101+1302$

$7.97468 .10: 2$

$6.2578 n+i a ? ?$

9.615660.

1.2472401013

$1.21: 37+n 6: 3$ TEET

$8.50000 \rightarrow 003$

8.49998 .003

2.751010003

$8.49905 \cdot 003$

$3.40996+003$

$5.20115+003$

a. $49908 \cdot 003$

$3.49994+603$

$8.49495+003$

$y$

I C..

$-4.79828 \cdot 102$

$1.90083 \cdot \cos 2$

$9.94651 \cdot(1) 2$

$1.54740+103$

$2.16790+103$

$.01284+813$

$3.76178+143$

$4.02515 \cdot 103$

$4.41386+\mathrm{Cii}^{3}$
ANU A I IHAT IIME

LENG TH

FEET

$8.26922+603$

B. $30631+003$

2.72958 .003

8.84921 .003

$4.31745 \cdot 0 \cap 3$

$6.48338+003$

1.041750004

$1.10963 \cdot 0114$

1.19479 .004

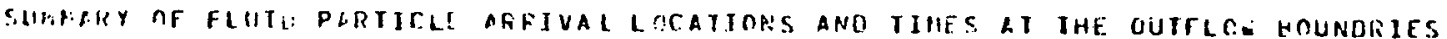

WITH DIPARTLRE IIMF OF

Jif. OUIILLW RATE IS

A in $\operatorname{ron}$

.23400 . LICOYTAKS

$23412535+$ HOT CUEIC FEET

.7200
ANU AI IHAT IIRE
PER YEARS

HIL.AYR. ITRE X

YEAIS

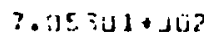

7. i) $8710+26 ?$

$2.4429 .7+130 ?$

7.661160 .502

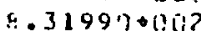

1. $40+56+i u ?$

S. $814(14+002$

$1.055: 21+.003$

$1.22057+103$
FEE I

E. $4 \div 995003$

$\because .49998 \cdot \operatorname{arn} 3$

$2.75317+003$

$8.49995+1003$

$8.49995 \cdot 003$
5.499960003

$5.28993+103$

c. $49594+6103$

$8.49995+003$

$8.49995+003$
$Y$

E.F.

$-4.51666+[U 2$

$1.97493+$ Lu2

$9.44981+16 ?$

$1.74204 \cdot 103$

$2.12219+103$

$2.78649 \cdot$ (i)

$3.60551+103$

$3.92967+10$

$4.37838 \cdot 103$
PAIH LLNOTH

FE.E T

d. $20650+003$

8. 30397.003

$2.72273+003$

$8.82916+403$

9. $26,877+003$

6.50529 .003

1.03247 .004

$.05926 \cdot 0104$

1.184710004 


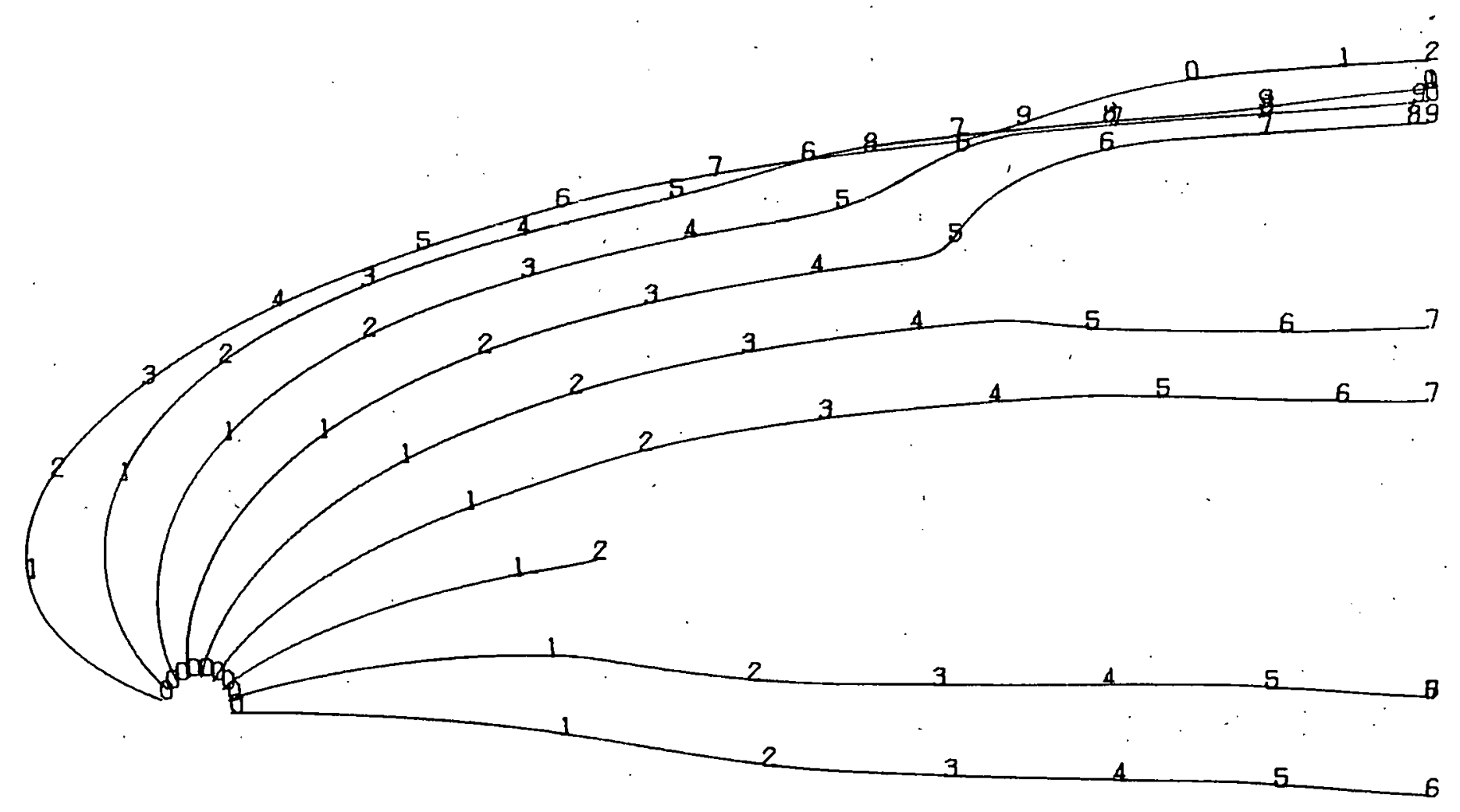

EXAMPLE TRANSIENT CASE (TWO WELLS) DEPARTURE TIME $=0.00$ SCALE 1 INCH $=1000$ YE'ARS

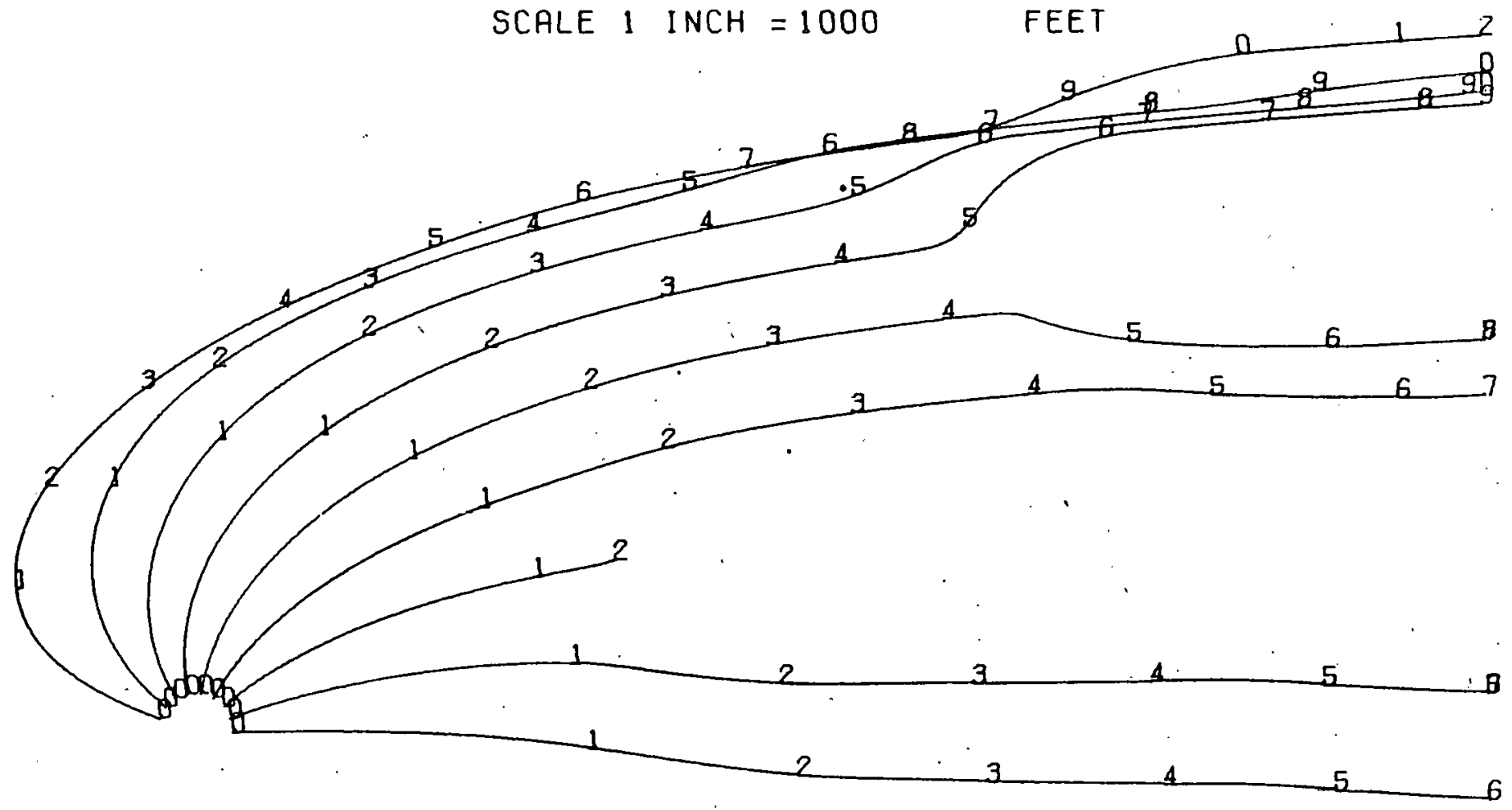

EXAMPLE TRANSIENT CASE (TWO WELLS) DEPARTURE TIME $=25.00$ SCALE 1 INCH $=1000$ YEARS FECT 


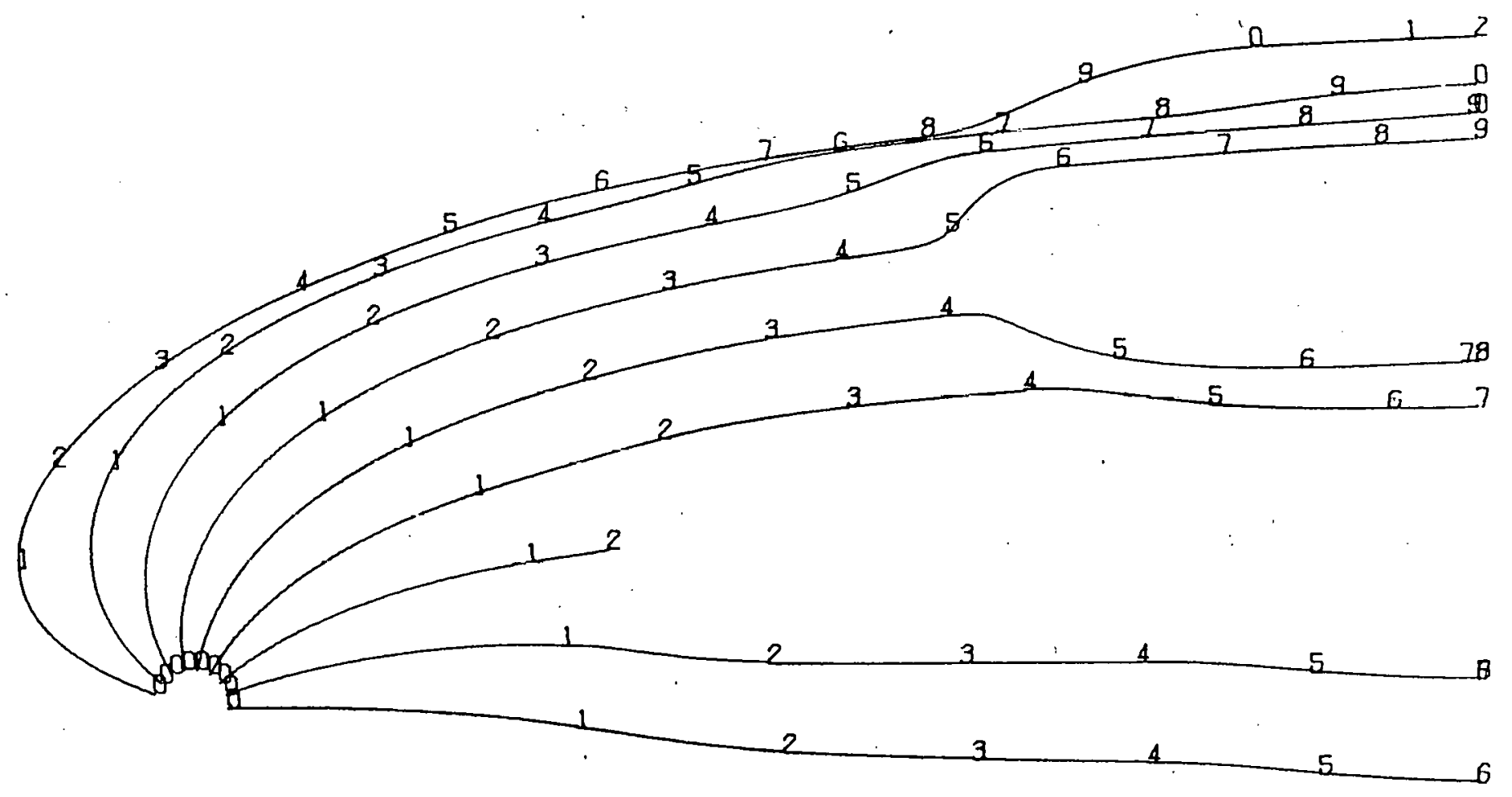

EXAMPLE TRANSIENT CASE (TWO WELLS) DEPARTURE TIME $=50.00$ SCALE 1 INCH $=1000$ FEET

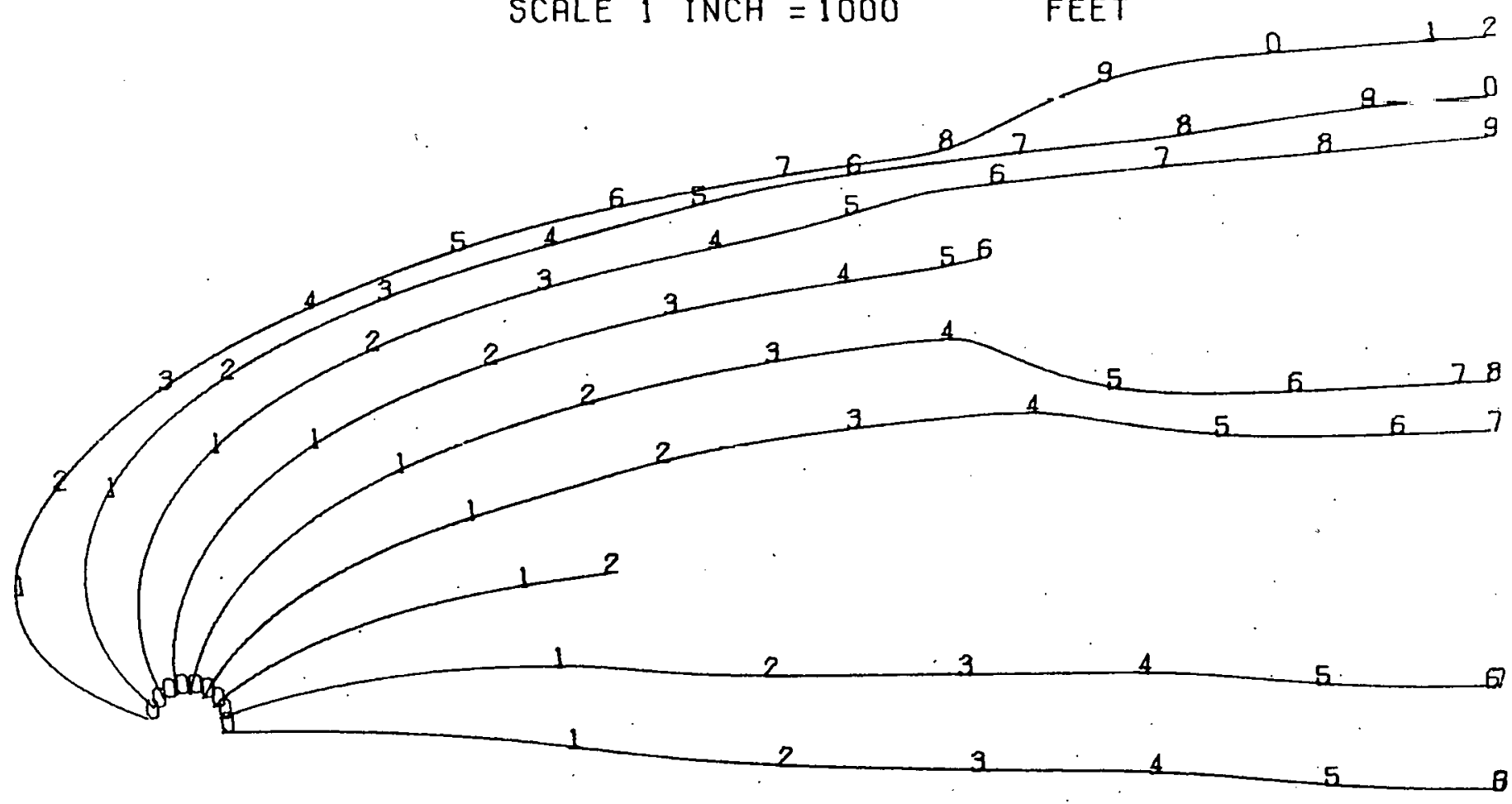

EXAMPLE TRANSIENT CASE (TWO WELLS) DEPARTURE TIME $=75.00$ SCALE I INCH $=1000$ YEARS FEET 


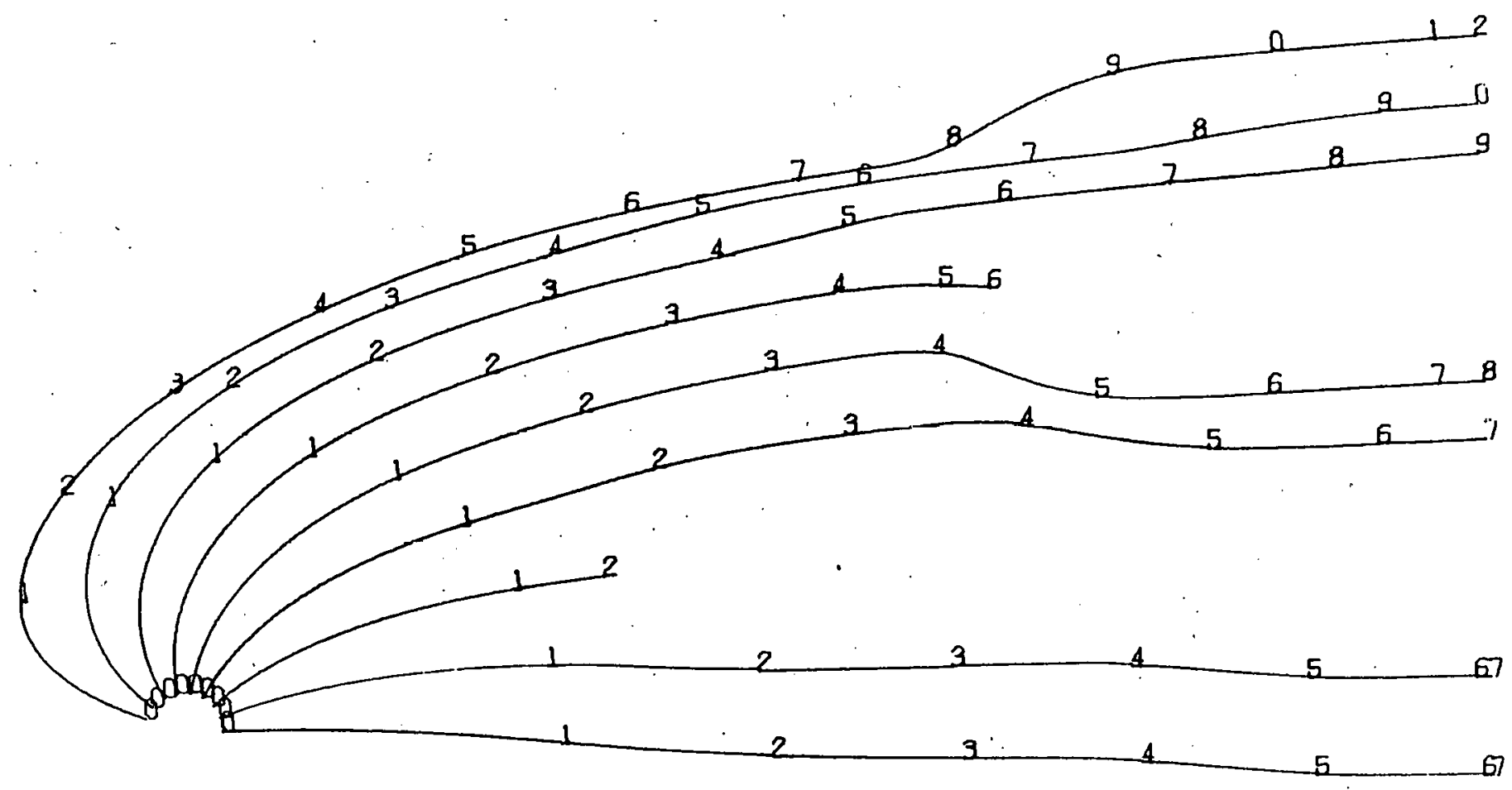

EXAMPLE TRANSIENT CASE (TWO WELLS) OEPARTURE TTME $=100.00$ YEARS

SCALE 1 INCH -1000 FEET 


\section{CASE: Steady Flow with $T_{c}-99$ Exchange}

1. $\frac{100 \mathrm{ft}_{1}}{8500 \mathrm{ft}}=0_{0}$ is the stratum thickness.

2. $8500 \mathrm{ft}_{.}=\mathrm{R}$ is the distance to the boundary. Units must_be the same as $D_{0}$.

3. $8500 \mathrm{ft} .=X M A X / T M A X$ are the stopping distance or time for pathlines.

4. $250 \mathrm{ft}_{1}=r_{0}$ is the cavern or pond radius. Units must be the same as $D_{0}$.

5. $4 \mathrm{ft}_{0}=\mathrm{H}_{0}$ is the head in the cavern. Units must be the same as $0_{0}$.

6. $1825 \mathrm{ft}_{\mathrm{f}} \mathrm{r}=\mathrm{K}_{0}$ is the stratum hydraulic conductivity. Length units must be the same as $D_{0}$. Whatever time units are in $k_{0}$ sets the units of the travel time.

7. $\frac{0.2}{2}=P$ is the effective porosity.

8. $\frac{S}{S}=S$ or $T$. A steady $(S)$ or transient $(T)$ case.

9. $0.001=40$ is the initial uniform gradient value. See Figure 1 .

10. $=U M$ is the laterial gradient value. See figure 1 .

11. $=M$ in time units of $K_{0}$.

12. ______ $=A, B, C$ are three time-related integers.

13. $-S$ or $E$ or $C$. Use the $\operatorname{serpin}(S)$, exponential $(E)$, or cyclic (C) head variation in the cavern.

14. $4 \mathrm{ft}=\mathrm{HI}$ is the initial head.

15. $=H M$ is the maximum head.

16. $=T N$ in time units of $K_{0}$ :

17. ___ _ $=0, E, F$. See Figure 1 .

18. $-\frac{1}{5}=\mathrm{J}$ is total number of wells.

19. $\frac{5^{\circ}}{5^{\circ}}=00$ is the angle (deg) around the cavern wall to the starting point for the first pathline.

20. $5^{\circ}=O M$ is the maximum angle (deg) to the last pathline starting point along the cavern wall.

21. $\frac{18}{18}=N \Theta$ is the number of pathlines to be generated see back of form from $\theta 0$ to and including $O M$.

22. $=k \theta$ is the number of pathlines wanted between $\Theta M$ and $179.99+^{\circ}$.

23. $=t_{0}$ is the departure time of the first fluid particles leaving the cavern.

24. $=t_{f}$ is the departure time of the final fluid particles.

25. $=N T$ is the number of equally spaced departure times beginning

with $t_{0}$ and ending with $t_{f}$.

26. $0.5 \mathrm{ml} / \mathrm{gr}=\mathrm{K}_{d}$ is the equilibrium exchange distribution coefficient.

27. $1.9 \mathrm{gr} / \mathrm{cc}=B_{d}$ is the bulk density of the porous material.

28. 1110 e inch wide plots are desired. Request either a 30" or 11" wide by 30 " plot.

29. $\frac{319}{\text {. }}=$ XCENTER The location ( $x \& y$ in inches) on the plot where

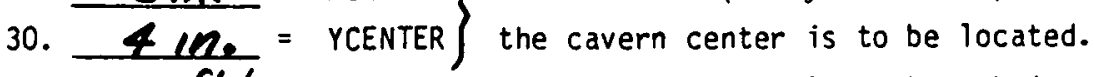

31. 1000 ff./ms. SCALE is the scale for the plot. Length in units of $D_{0}$ per inch. 


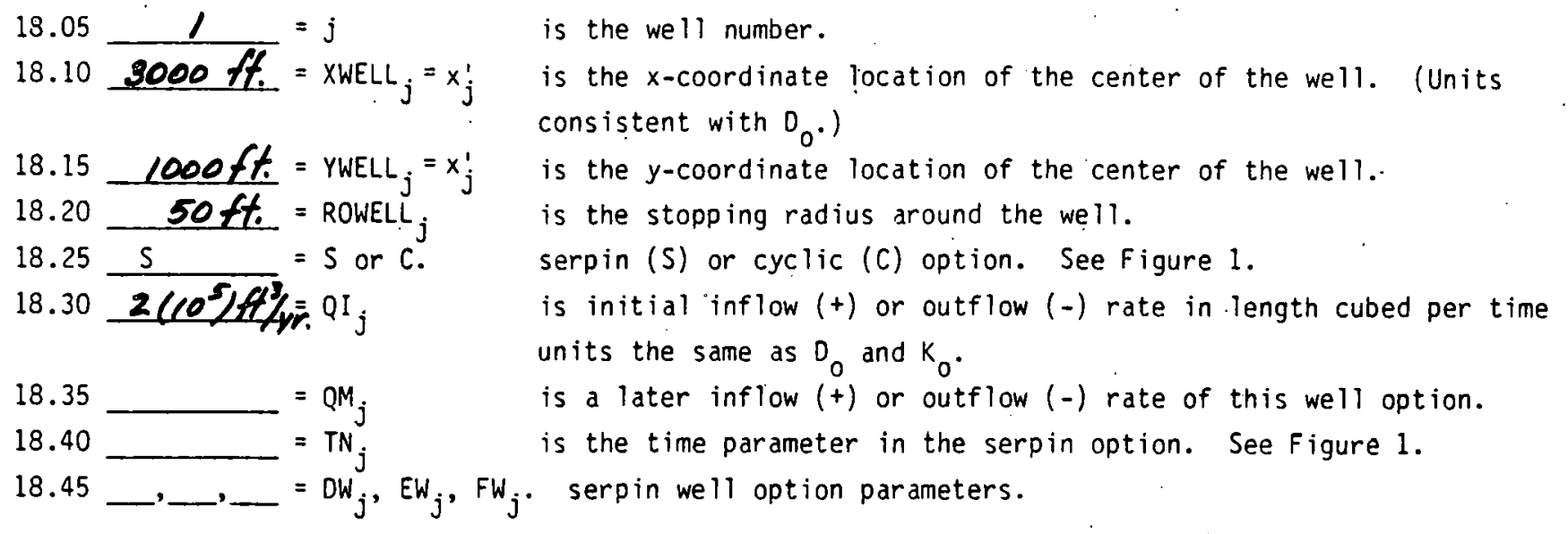

\section{CYCLIC OPTION}

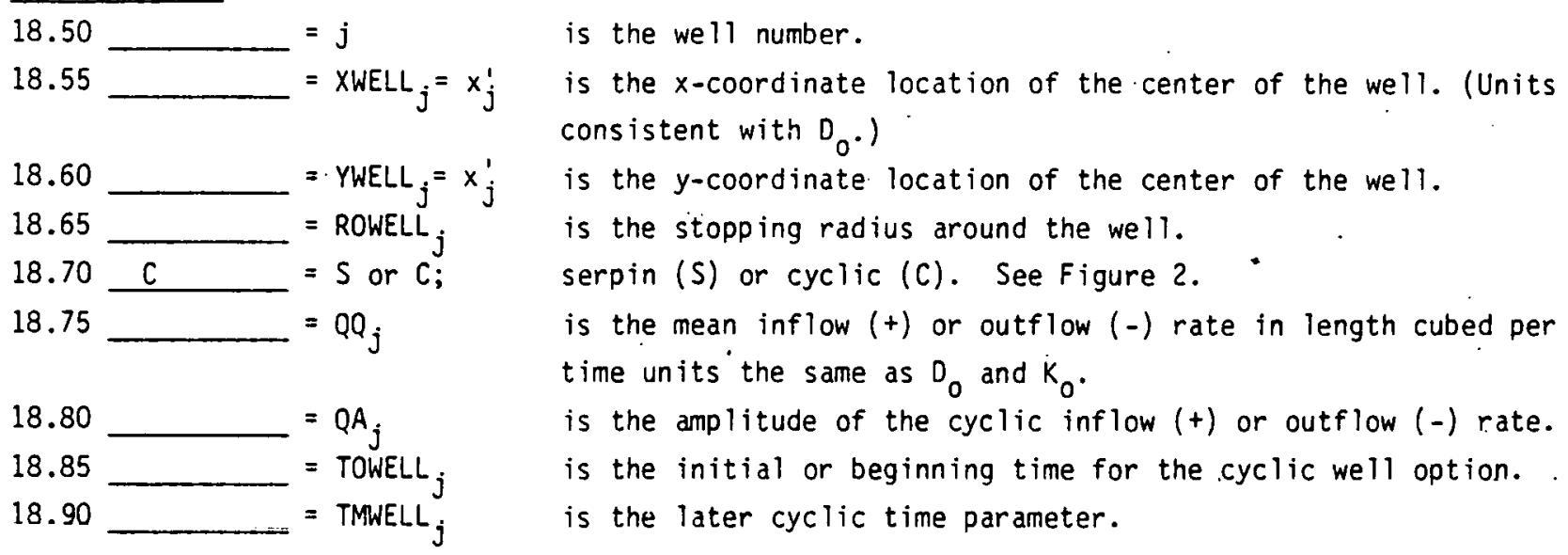

PATHLINE - IRREGULAR STARTING COORDINATES

(If 00 in Item 19 equals $O M$ in Item 20 then NO pathlines will be generated from the individual coordinates provided below.)

21. $\angle 8=N O$ is the number of input data sets to be entered for starting pathlines $(1 \leq i \leq N \theta)$.

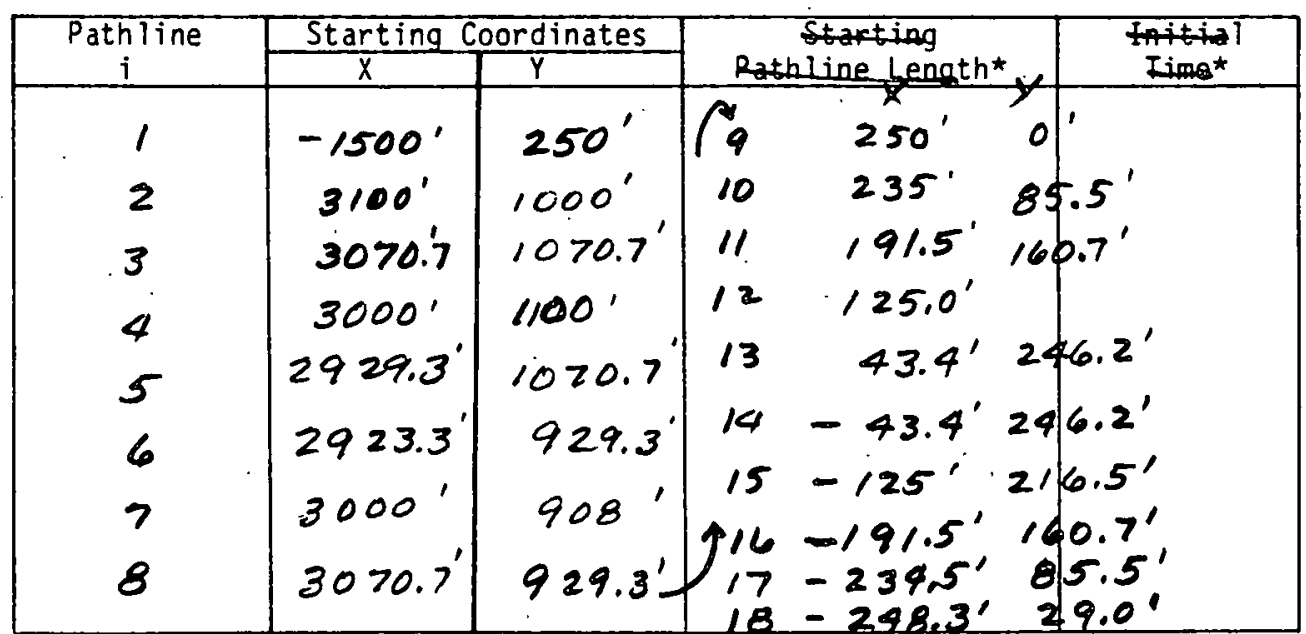




\section{EXAMPLE STEADY CASE}

The second example case involves a steady flow system but the ion exchange delay for a single contaminant is illustrated. Also the special irregular starting location feature for pathlines is used. The completed input parameter worksheet for the example steady case in Table B-1 is shown.

After signing on the Univac and providing user ID, passwords, etc., then PATHS can be executed as follows using the input values from the worksheet or as requested by the program.

WET MELETHFATHE. DIII

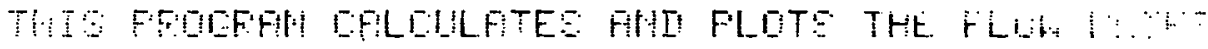

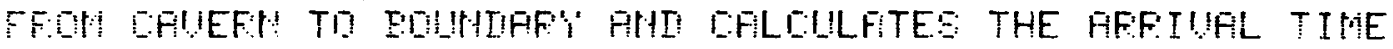

DETFIEUTIEH OF FLUII FIT THE EOUHIIAFY'

FLEFEE EHTEF: THE FELLUIHG FUF THE FHTH FOETIUH DF

THE DUI, FFESE THE CFFFIALE FETUFH FIFTEF FESFOHDIHO

EITEF UIUF: FICIOUITT HIIUEEF:

Pिए1E:

TIER IIEEFII

गीII

DHET FETEET IT

PELIII

DITEF: IATE FTIIFESE

YITLL VLIHE THE DLI. FI: 20

ETEF FHEOUER

\section{ris:}

NIIN ENTEE THE TEST CFSE NHME--A TINE LINE TITLE.

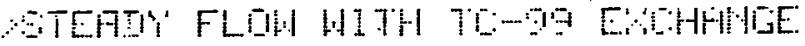

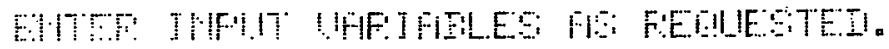

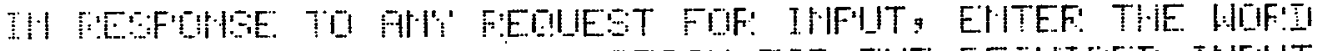

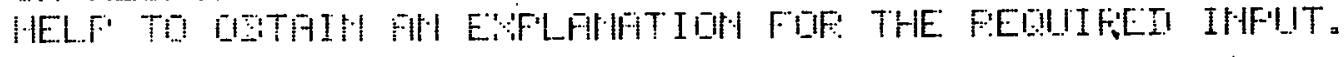

III

1019

$\because$

95E

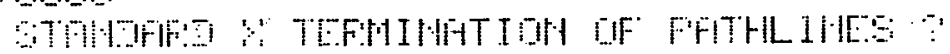

YES 


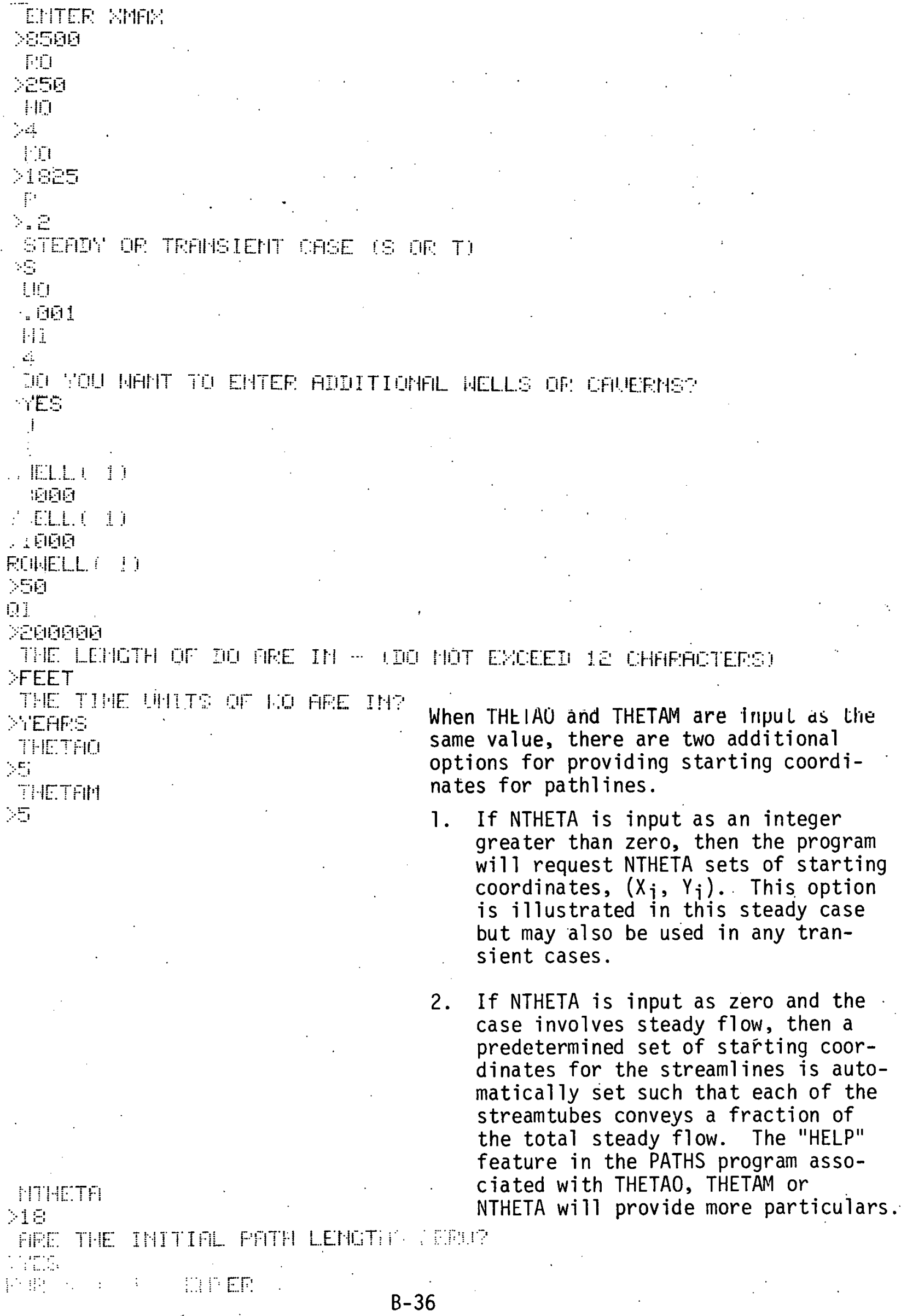

When THEIAU and THETAM are inpul ds the same value, there are two additional options for providing starting coordinates for pathlines.

1. If NTHETA is input as an integer greater than zero, then the program will request NTHETA sets of starting coordinates, $\left(X_{i}, Y_{j}\right)$.. This option is illustrated in this steady case but may also be used in any transient cases.

2. If NTHETA is input as zero and the case involves steady flow, then a predetermined set of starting coordinates for the streamlines is automatically set such that each of the streamtubes conveys a fraction of the total steady flow. The "HELP" feature in the PATHS program associated with THETAO, THETAM or NTHETA will provide more particulars.

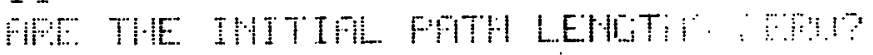




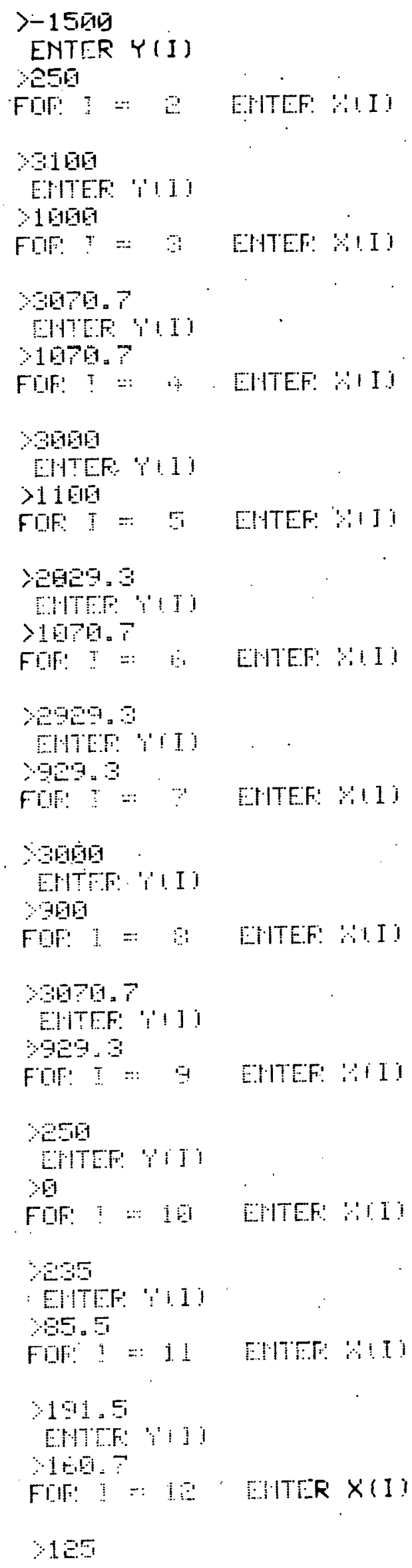

The control key and letter $\mathrm{H}$ erase and back up option was used in $X(I)$ for $I=5$. 


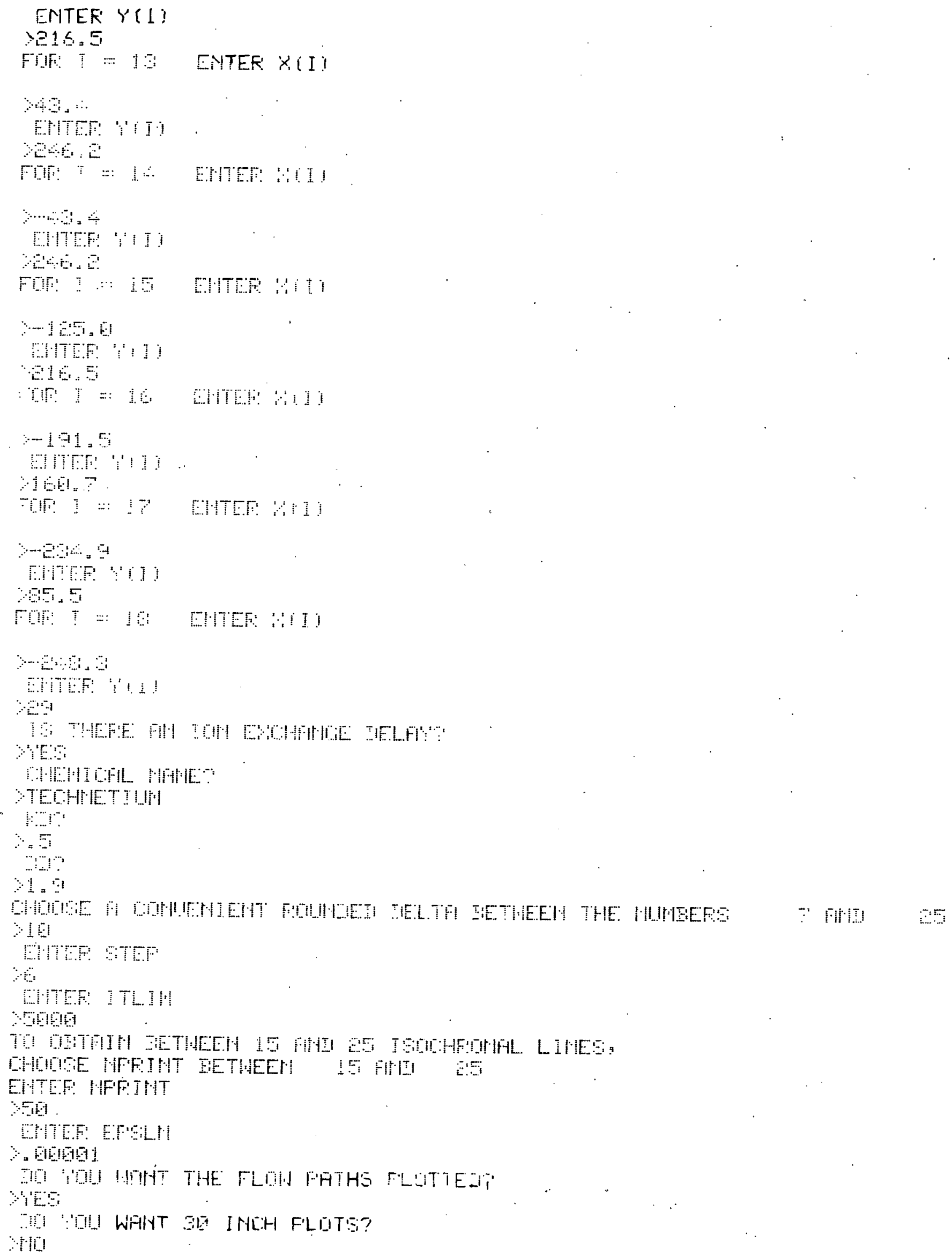




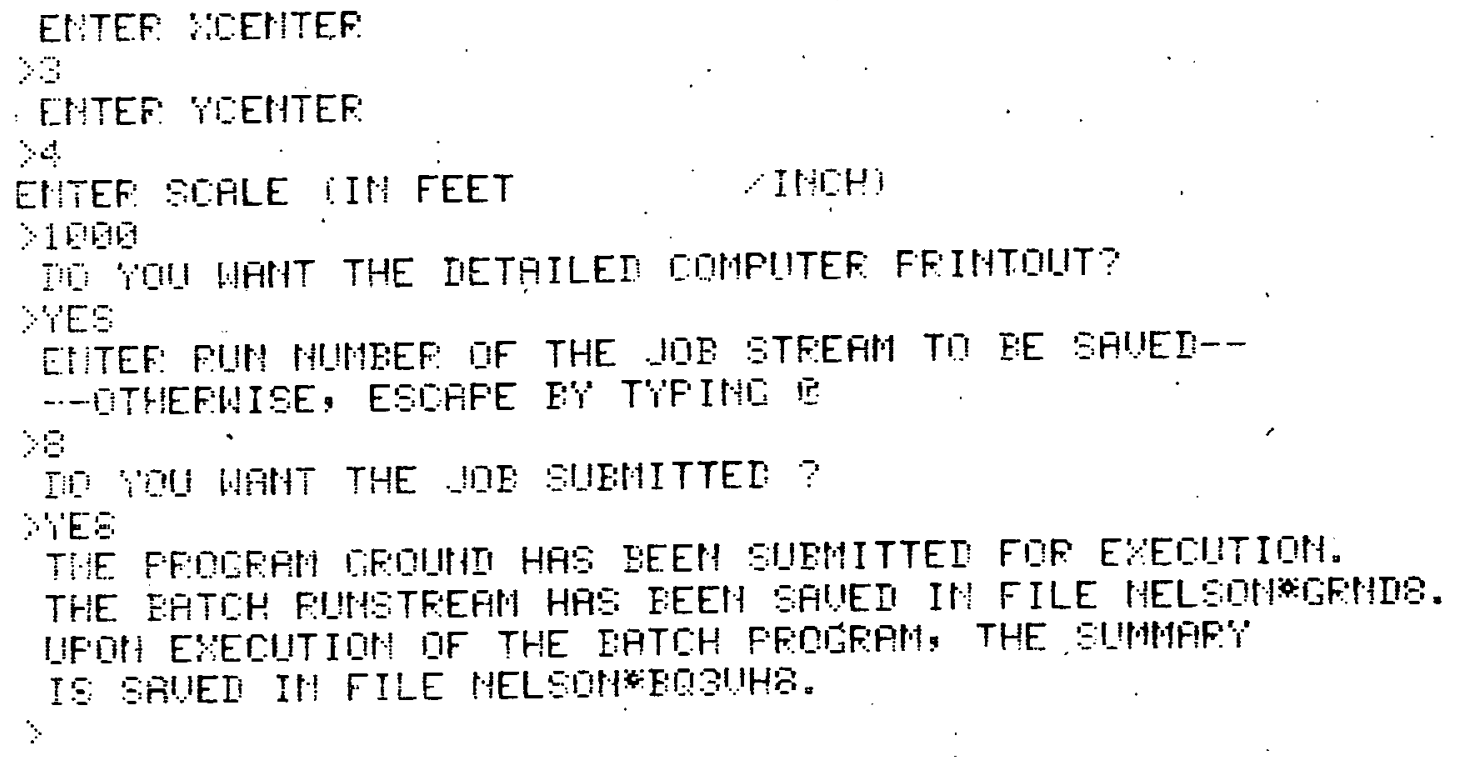

The last computer output indicates the summary input file was completed and the batch run submitted. The summary file is:

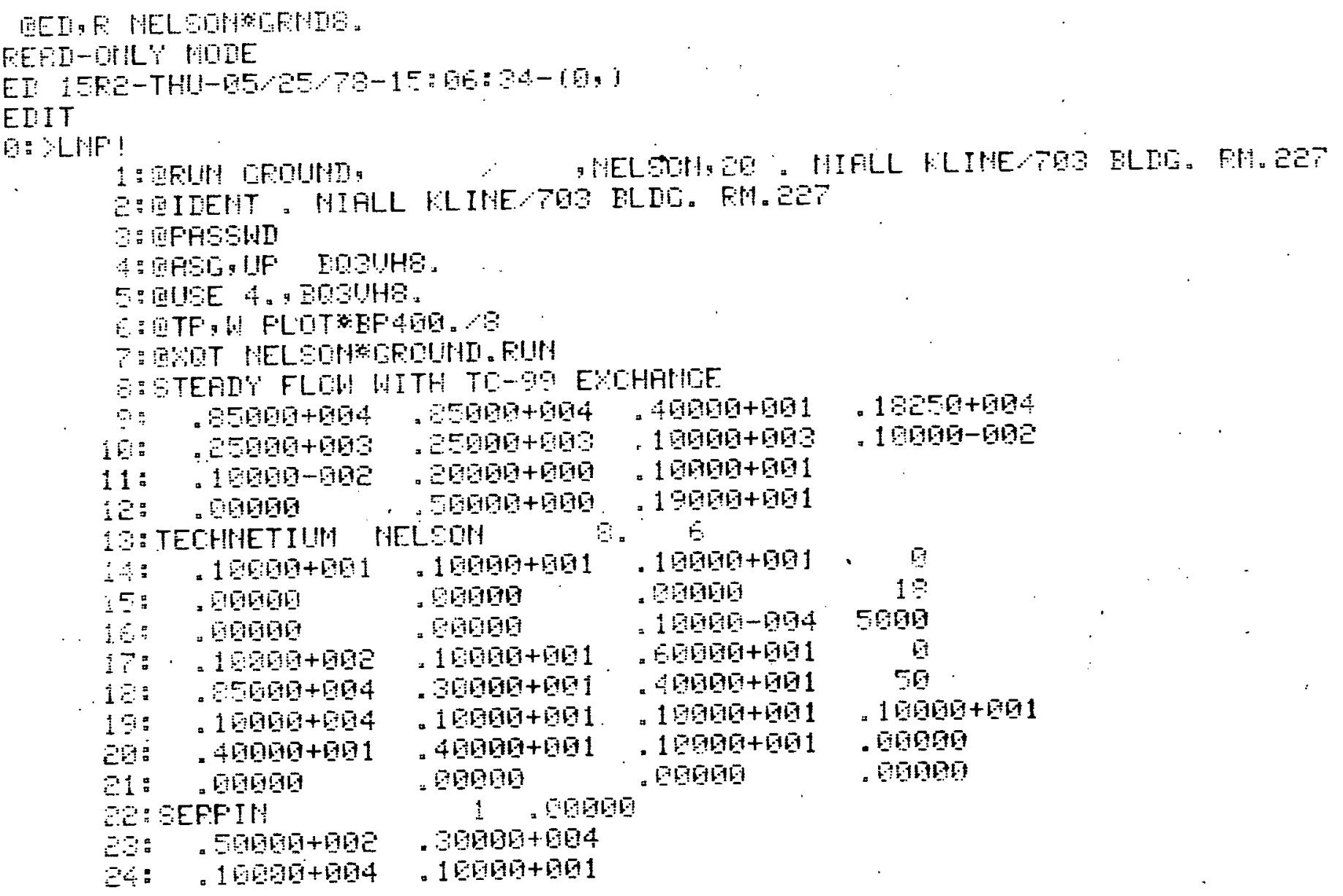




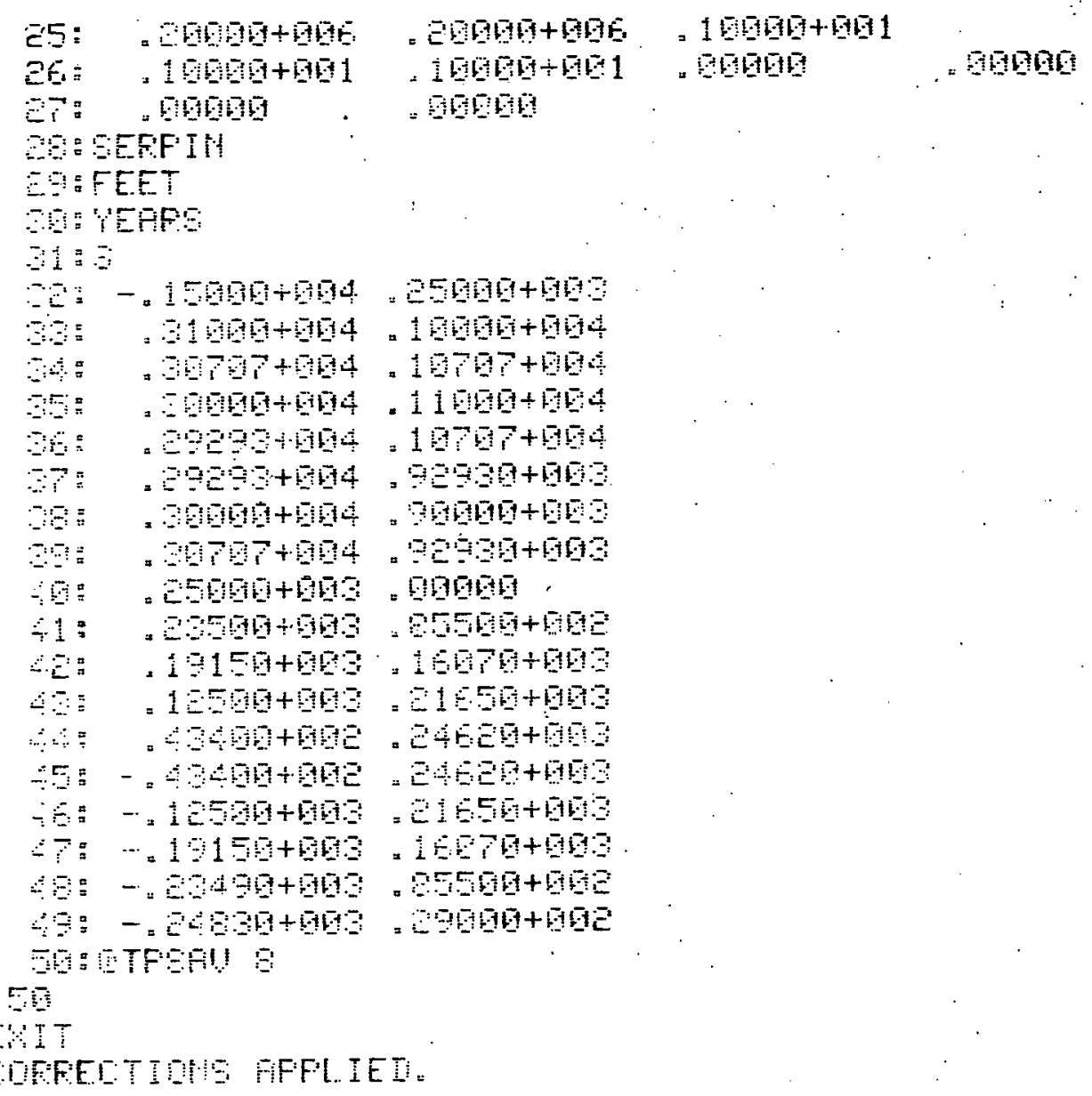

ECFE

MI COPEETIMS MFFLIED.

With the successful completion of the batch run GROUND, the user may obtain the summary arrival results over the terminal. To do this, you type QED,R PROJID*BQ3VH_ (use 8 in the blank for this example) followed by P!. The results obtained are: 
IEET, F NELSIIN:BBOUHE:

* FEFII-DHL $\%$ HOTE

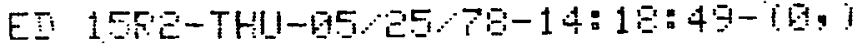

EIIT

Ba $\mathrm{F}$ !

OTEFIY FLEH HITH TE-GQ EYHAHCE

THE IEFFIFTUFE TINE. IS

THE IHITIAL DUTFLOH FATE IS

FEF YEAFE
THE IUITIFL FELATIUE EFIUFH HEAT IS

GD UFFE:

FFTH MO. TFEUEL TIME YEPFE

$17.6099+903$

\& $2.6090+60$

$2.6060+010$

$2.62+2+003$

$\therefore=7 \mathrm{~B}=1+009$

ㄹ. $72789+609$

2. $6218+193$

$2.6040+069$

$\because=7194+60$

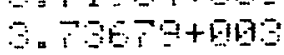

$\because 60+96$

12
$13 \quad-65101+063$

$14 \quad \therefore 4094+903$

$15 \quad \therefore 7095+093$

15 5. $50045+019$

i $7.92404+063$

$18 \quad 8.7069+903$ $\because$

FEET

B. $990+009$

$8.9996+019$

6. $49999+098$

0. $4996+968$

6. $4999+6198$

$8.49997+609$

8. $49996+6169$

9. $49996+649$

6. $4998+093$

0. $49999+913$

6. 4.975 509

6. $49993+619$

6. $49995+609$

6. $6995+013$

8. $49997+069$

0. $49994+619$

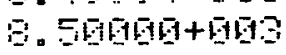

6. $4998+009$ $\because$

FEET

$\therefore$ OEEOE+RES

1. $19431+003$

1. $09817+609$

1. $55520+003$

1. $64711+0.9$

$7.76991+962$

6. $52859+102$

$9.9799+619$

$-3.9130+902$

G. $91907+901$

$5.5550+00 \%$

1. $9005+003$

2. $32210+060$

$2.6444+609$

$2.95771+063$

$8.20748+063$

$042508+003$

$3.55977+969$
H!H Fla!: 30

$5.92124-001$

1 . $9805-001$

E. $15107-901$

2. $1120-001$

2. 56091-001

1. $13947-0181$

1. $26493-041$

1. $50195-001$

$9.20118-001$

1. $92150-50$

7. . $9015-602$

․ बอ275-01

$3=5779-61$

4. $21149-601$

4. $6844-61$

5. 6061 4-01

5. $4551-61$

5. $55093-091$
FFTH LETHTH FEET

1. $1020+004$

$5,40405+602$

5. $4050+000$

$5,5644+063$

5. $6700+098$

5. $6998+60$

$5.5256+015$

$5.4515+069$

Q. $28442+00$

E. $29923+063$

8. $4904+903$

$8.7245+902$

9. $60049+60$

9. $3406+000$

$9,770+000$

1. $01819+604$

1. $97400+904$

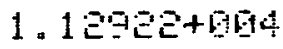

EDF::1

E) $Y E S I T$

NO COFFEETIOHS FFFLIEI.

$>$

The detailed computer printout for the example steady case is provided on the following pages. Also at the end of the printout, the plot for the steady flow system is shown. 


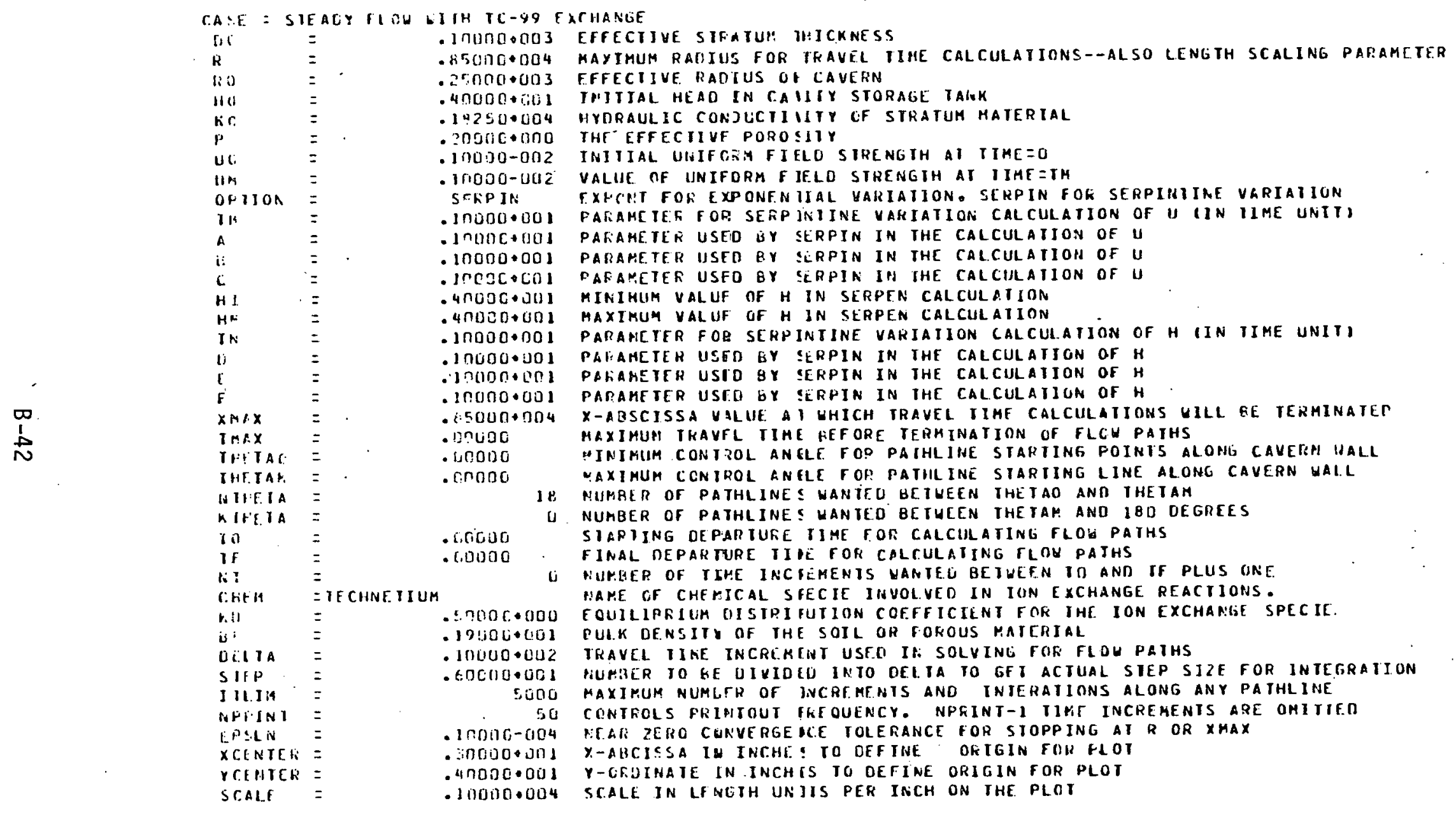




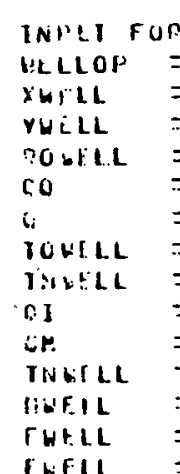

IHF DI REC I INPII

$x$

- I:100 - vutio

?10ก. .

$3 i 15.7 \mathrm{ill} 0$

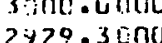

$2979.30 n$

2.29 .31100

$3: 300.05100$

3:37.7 7.60

25.0000
235.0000

$191.5 \div 00$

12 . un 0

43.4100

$-43.4180$

$-125 \cdot 153 \pi(50$

$-191.5: 6 i$

$-234.9 \cdot \mathrm{Cl}$

$-24 n .31160$
SERPIN

- 3 CRUIJ +2j4

- Ilonoo tolia

- ilnogeos

- rionoo

- conua

- .7croo

- 2 croa nilis

$.20000 \cdot 006$

- 1 unoovenos

- 1 (nntosenes

- $10 n n 0 \cdot n o 1$

- innogenos

$x$-CCOORDINATE OF THE TELL

Y-COOROINATE OF THE SELL

STOPPING RACIUS OF IHE HELL

IHE MEAN INFLOUIOI UR OUIFLOHI-1 RATE OF THE HELL

IHE MAXIHUR INFLOA1 $10 R$ OUTFLOW $1-1$ RAIE. OF IHE WELL

IHE TEGIINIPG IJME CE THE CYCLIC FLON FOF THE UELL.

IHE CNDING IIHE OF THE CYCLIC FLOW FOR THE WELL

THE INITIAL FLOU RA $X$ OF THE WELL

THE MAXIMLIM FLOW RA It OF THE HELL

PARAMETER USED IN C LLCULAIIHL WELE FLOW FATH

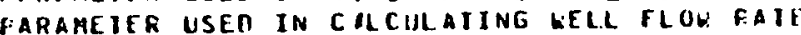

PARGMETLR USER IN C ILCULAIING HELL FLOH FATE

PARAMETER USEO IN CILCILATIMG UELL FLOU FAIE

COOROINATES P LE NEIIS ANU IIMES FOLLON

$$
\text { Y }
$$

P LENGIH

TIME

1) $7(1 . .7011:$

$10 n \cdot 13 n 00$

10711.70100

925.3000

ini cinuo

$\rightarrow$ ?. 9.31100

$-\ln 00$

Es.s $\sin (30$

160.71100

216.5 nitio

246.2000

$24 t .20: 50$

216.5000

116.5002
160.7000

पe. $\sin$

exison

h) THE SUCCLSSFIC COMCLUSION OF GROUAS IHE FOLLOHING F ILES ARE CATALOUGED: NELS:N*IOC.OE. AND NELSON\#POBUTIS.

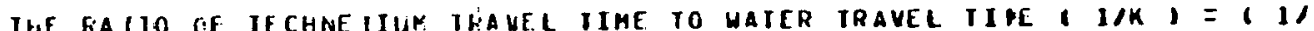




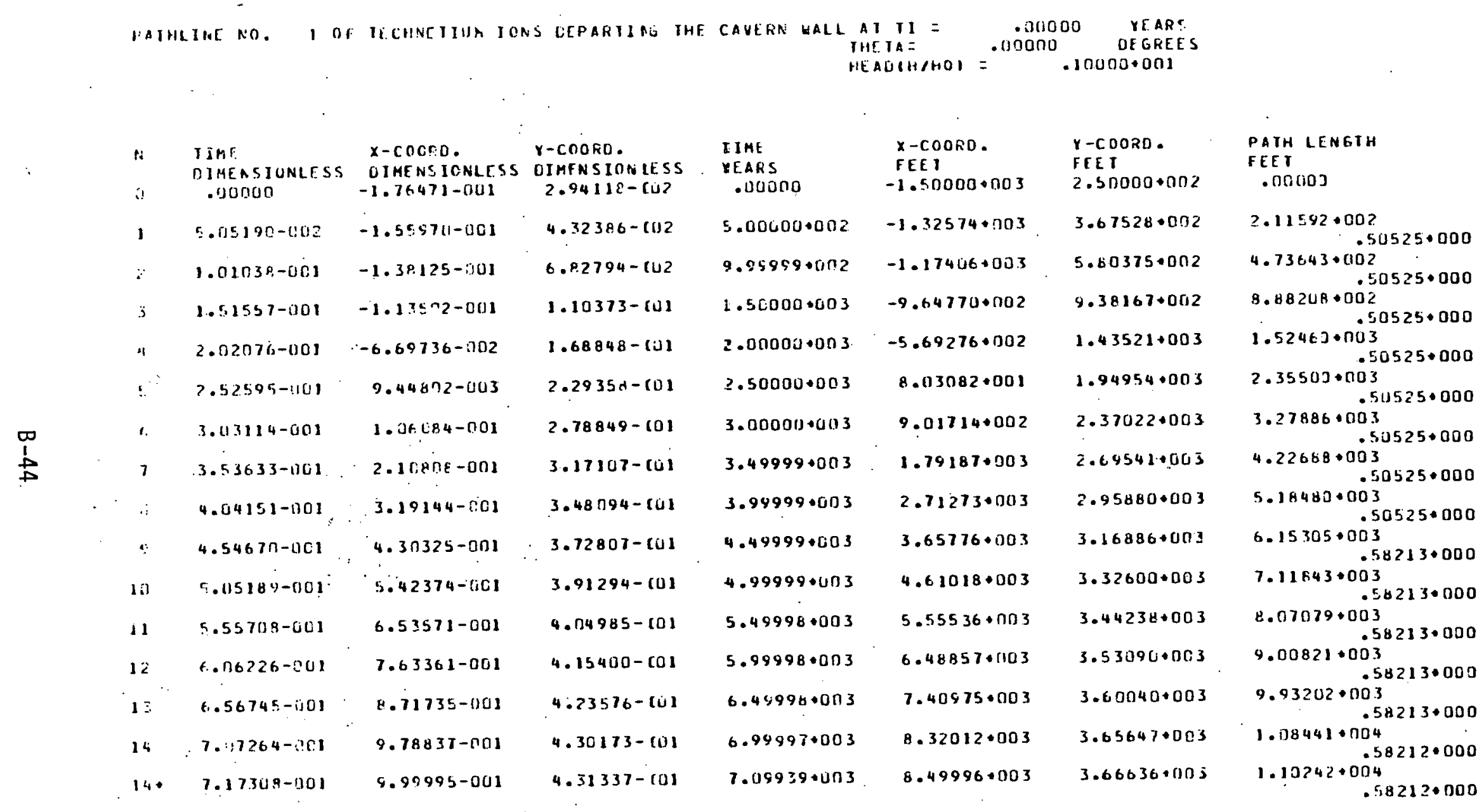




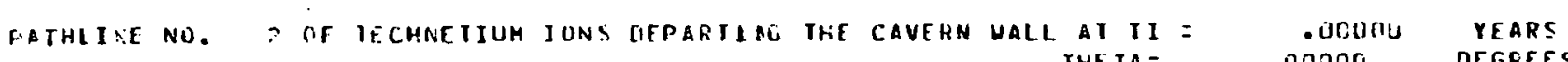
THETA $=$.ONDOO DEGREE

HEAU(H/HO) = .1000O+DOI

N TIM

$X$-COORO. $\quad r$-CRORO

OIHFNSIONL

OIRENSIONLIESS
$1.17647-$ IUI

TIME

.NOODO

3.64706 -001

$1.26323-601$

$1.31533-9$ ii l

$6.3+92.4-101$

1. $35168-(0)$

$1.37936-601$

1. 4n093-C01

$1.40550 d-c 01$

\section{YEARS}

- UnUUO

$5.00000 \cdot 002$

$9.99999 \cdot 002$

$1.50000+003$

$2.00000 \cdot 003$

$2.50000+403$

$2.60996 \cdot 005$ $x-\cos 0$.$$
\text { FEE T }
$$

3. 10000.003

$4.36838+003$

$5.41386 \cdot 003$

$6.40363 \cdot 003$

$7.36112 \cdot 003$

$8.29657 \cdot 003$

$H .49996+003$
Y-CDORD.

$$
\text { FEE T }
$$

$1.00000 \cdot 003$

$1.07374+0103$

$1.11803 \cdot 003$

$1.14910 \cdot 003$

$1.17246 \cdot 003$

$1.19079 \cdot 503$

$1.19431 \cdot 003$
PATH IFNGIH

FEE T

- Do.noJ

$1.27054 \cdot$ nos

$.31696+003$

$.18226+000$

$3.30722 \cdot 003$

$18226 \cdot 000$

$4.26501 \cdot 003$

$.18226 \cdot 000$ 03

$5.40405 \cdot 003$

03

$.18226+000$

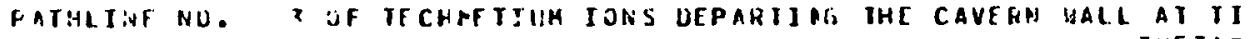

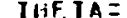

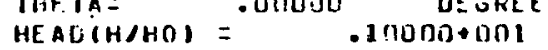
. unojo

YCARS

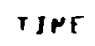

$1.64256-$ COI
$X$-COORO.

FEET

$3.07070 \cdot 003$

$Y$-COORO.

FE.E I

. DOnOOO

5.00000+0 22

$3.99999 \cdot 002$

$4.32108 \cdot 003$

$5.36555 \cdot 003$

$6.35484 \cdot 003$

$7.31210 \cdot 003$

$8.24745 \cdot 003$

$8.49999 \cdot 003$
$1.07070 \cdot 0$ n 3

$1.24175 \cdot 003$

$1.30021 * 003$

$1.33937 \cdot 003$

$1.36832 \cdot 1013$

$1.34085+003$

$1.39617 \cdot 003$
PATH LENGTH

FET.T

. uonon

$1.26639+003$

$.21520 \cdot 000$

$2.31252+003$

$3.30259 \cdot 0.21520 \cdot 000$

3.302590003

$.21520 \cdot 000$

$4.26029+003$

$5.19593 \cdot 003$

.215200000

$5.44853+003$

.21520 .000 


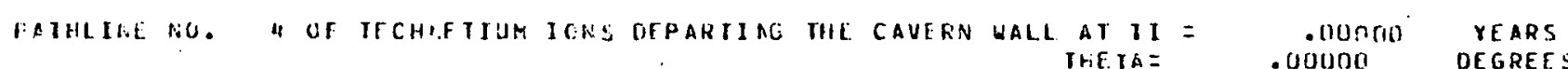
HEADIH/HOI = .1OOOD

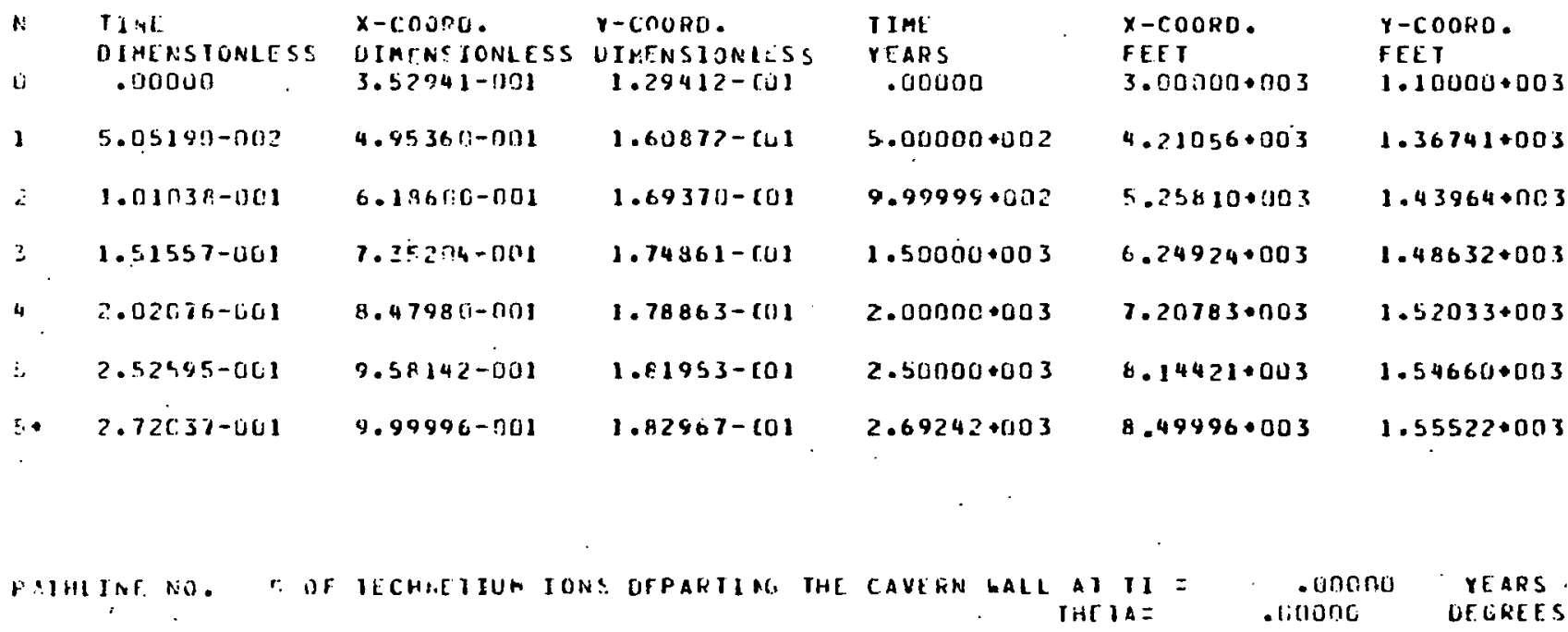

\begin{tabular}{|c|c|}
\hline 8 & $\begin{array}{l}\text { IIME } \\
\text { DUMERSIONLES S }\end{array}$ \\
\hline 1: & .170000 \\
\hline J & $\because .05190-002$ \\
\hline$?$ & 1. in $11338-0$ (i) \\
\hline$\because$ & $1.51557-i 1013$ \\
\hline 4 & $2.02 ! 176-0001$ \\
\hline ذذ & $2.52545-1101$ \\
\hline Ł. & $2.7 .93311-n u 1$ \\
\hline
\end{tabular}

\begin{tabular}{|c|c|c|}
\hline $\begin{array}{l}X \text {-COOSD. } \\
\text { GIMENSIONLESS } \\
3.44 t ? 4-001\end{array}$ & $\begin{array}{l}Y \text {-COURD. } \\
\text { CIIENSIONLESS } \\
1.25 \text { - } 65 \text { - TUI }\end{array}$ & $\begin{array}{l}\text { IIAL } \\
\text { YEAFS } \\
\text {. DOUOOO }\end{array}$ \\
\hline $4.77670-001$ & $1.68226-101$ & $5.00000+002$ \\
\hline $6.01800-001$ & $1.78184-C u 1$ & $9.99999+002$ \\
\hline $1.18980-901$ & $1.94389-101$ & $1.50000+003$ \\
\hline $8.32003-001$ & $1.88848-t$ & 2.00 \\
\hline $9.424 n 7-001$ & $1.92265-101$ & $2.50000 * 003$ \\
\hline $9.99999-501$ & $1.03777-(0)$ & $2.76461+003$ \\
\hline
\end{tabular}

$x-\cos 0$.

FEEI

$2.42930 \cdot 00 ?$

$Y-C O O R O$

EEE T

$1.07070+003$

4. $06020 \cdot 003$

$5.11537+003$

$1.42992 \cdot 043$

$1.51456 \cdot 003$

f. $11065 \cdot 003$

$7.07203 \cdot 003$

$4.01046 \cdot 003$

$8.49999 \cdot 003$
1.567301003

$1.60521+003$

$1.63425+003$

$1.64711 \cdot 003$

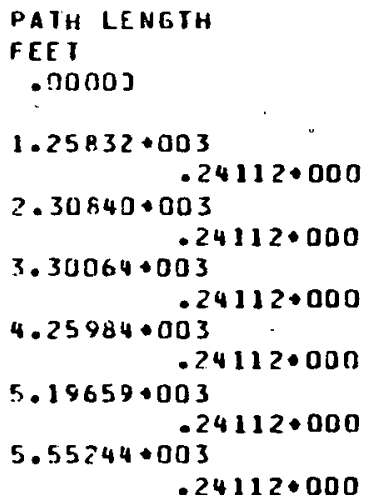

PATH LENGTH

FEE I

.00003

$1.23296 \cdot 0 n 3$

$.25609+000$

$2.29163 \cdot 003$

$3.28829+00356590000$

$4.25041+003$

$25609 \cdot 000$

$25609+000$

$5.18030 \cdot 103$

$.25609+000$

03

.256090000 


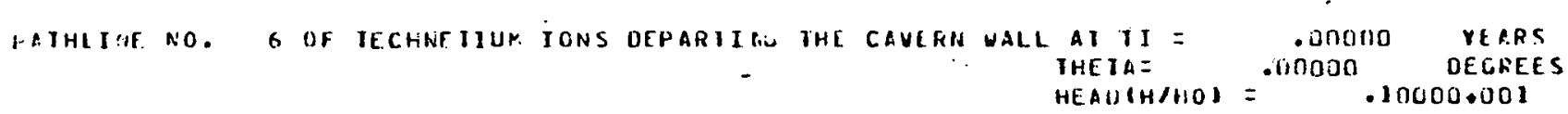

\begin{tabular}{|c|c|c|c|c|c|c|c|}
\hline N & $\begin{array}{l}\text { IIME. } \\
\text { DIMENSTUNLESS }\end{array}$ & $\begin{array}{l}X \text {-CCONO. } \\
\text { UIMENSIONLESS }\end{array}$ & $\begin{array}{l}\text { Y-COORO. } \\
\text { DIMENSIONLESS }\end{array}$ & $\begin{array}{l}\text { IIME } \\
\text { YEARS }\end{array}$ & $\begin{array}{l}x-\operatorname{coO} N D \\
\text { FEE }\end{array}$ & $\begin{array}{l}X-L N O R O \\
\text { FEET }\end{array}$ & $\begin{array}{l}\text { PATH LENGIH } \\
\text { FEEI }\end{array}$ \\
\hline r. &. .110neo & $3.44624-001$ & $1.09329-(0)$ & . อuono & 2.92930 .003 & $9.293 n 0.002$ & .110000 \\
\hline 1 & $5.01519 r-a r: 2$ & $4.81935-001$ & $8.44249-102$ & $5.00000 \cdot 002$ & $4.09645+1003$ & $7.17612 \cdot 002$ & $\begin{array}{r}1.23580+003 \\
.11395 * 000\end{array}$ \\
\hline 3 & $1.0103 n-n 01$ & $6.07871-.001$ & $8.62168-102$ & $9.99999+002$ & $5.16691 \cdot 003$ & $7.32843 \cdot 002$ & $\begin{aligned} & 2.30637 \cdot 003 \\
&=11395 \cdot 000\end{aligned}$ \\
\hline 3 & $1.51557-i) 01$ & $7.25897-001$ & $8.80692-10 ?$ & $1.50000 \cdot 003$ & $6.17013 \cdot 003$ & $7.48586 \cdot 002$ & $\begin{aligned} & 3.30972 \bullet 003 \\
& .11395 \bullet 000\end{aligned}$ \\
\hline 4 & $2.112076-1101$ & $6.39569-1001$ & $8.95866-102$ & $2.00000 \bullet 003$ & $7.13634 \cdot 003$ & $1.61486 \cdot 002$ & $\begin{array}{r}4.27611 \cdot 003 \\
.12395 \cdot 0000\end{array}$ \\
\hline 5 & $2.525 .95-.4111$ & $9.5 \cap 347-001$ & $9.08195-\mathrm{CU2}$ & $2.50000 \cdot 003$ & $A .07795 \bullet 003$ & $7.71966 \cdot 002$ & $\begin{array}{c}5.21769+003 \\
.1139 .5+000\end{array}$ \\
\hline 20 & $2.75569-i 101$ & $9.99997-1.111$ & $9.13048-\mathrm{Cu} 2$ & $2.72738 \cdot 003$ & $8.49997+003$ & $7.76091 \cdot 002$ & $\begin{array}{r}5.63973+003 \\
.11395 \cdot 000\end{array}$ \\
\hline
\end{tabular}

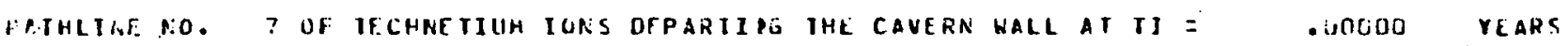 THETA= DONINO DEGKEES HEADIHAHOI =

\begin{tabular}{|c|c|}
\hline N & IIME \\
\hline & DIAENSIONLTSS \\
\hline$\pi$ & - nnouro \\
\hline 1 & $5.05191]-0112$ \\
\hline$\therefore$ & $1.01038-001$ \\
\hline$\Xi$ & $1.51557-401$ \\
\hline 4 & $2.02076-401$ \\
\hline 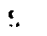 & $2.52595-1301$ \\
\hline מ6 & ?.6898?-701 \\
\hline
\end{tabular}

\begin{tabular}{|c|c|c|}
\hline$x-c \cap 0 \rho 0$ & $x$-cnonn. & TIME \\
\hline $\begin{array}{l}\text { DI HENSIONLESS } \\
3.52941-001\end{array}$ & $\begin{array}{l}\text { DIRENSIONLLSS } \\
\text { 1.C5BE?-COI }\end{array}$ & $\begin{array}{l}\text { YEARS } \\
\text {.OOUOO }\end{array}$ \\
\hline $4.991 .91-001$ & $9.21079-802$ & $5.00000+002$ \\
\hline $0.23693-001$ & $9.46527-1.02$ & $9.99999 \bullet 002$ \\
\hline $7.40984-901$ & $9.6 \times 285-102$ & $1.50000 \cdot 003$ \\
\hline $8.54185-1001$ & $9.85552-102$ & $2.00000+003$ \\
\hline $9.64629-041$ & $9.95432-102$ & $2.50000 \cdot 003$ \\
\hline $9.99995-\mathrm{J} 01$ & $1.00336-(4)$ & $2.66218+003$ \\
\hline
\end{tabular}

$x-\operatorname{cook} 0$.

FEET

$3.00000 \cdot 003$

$r-C .00 R O$.

FEE T

$4.24304 \cdot 003 \quad T .82917+002$

$9.00000 \cdot 002$

PATH LENGIH

FEE

$5.34139 \cdot 003$

$6.04546 \cdot 1102$

$1.26805+003$
$.12649+000$

$2.32662 \cdot 003$

$6.29837 .003 \quad \$ .23042 .002$

$3.32377 \cdot 103$

$2649 \cdot 000$

$7.26057 .003 \quad 8.37719 .002$

$4.28609 \cdot 103$

3

$8.19934 \cdot 103$

8.49517*nก2

$5.22493+003$

$8.49946+003 \quad$ E.52858+002

$5.52555 \cdot 003$

$12649 \cdot 000$

.12649 .000 


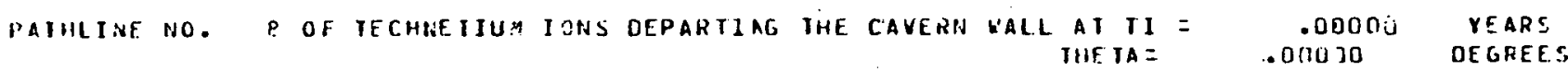
HEADIH/HU) $=$. 100000001

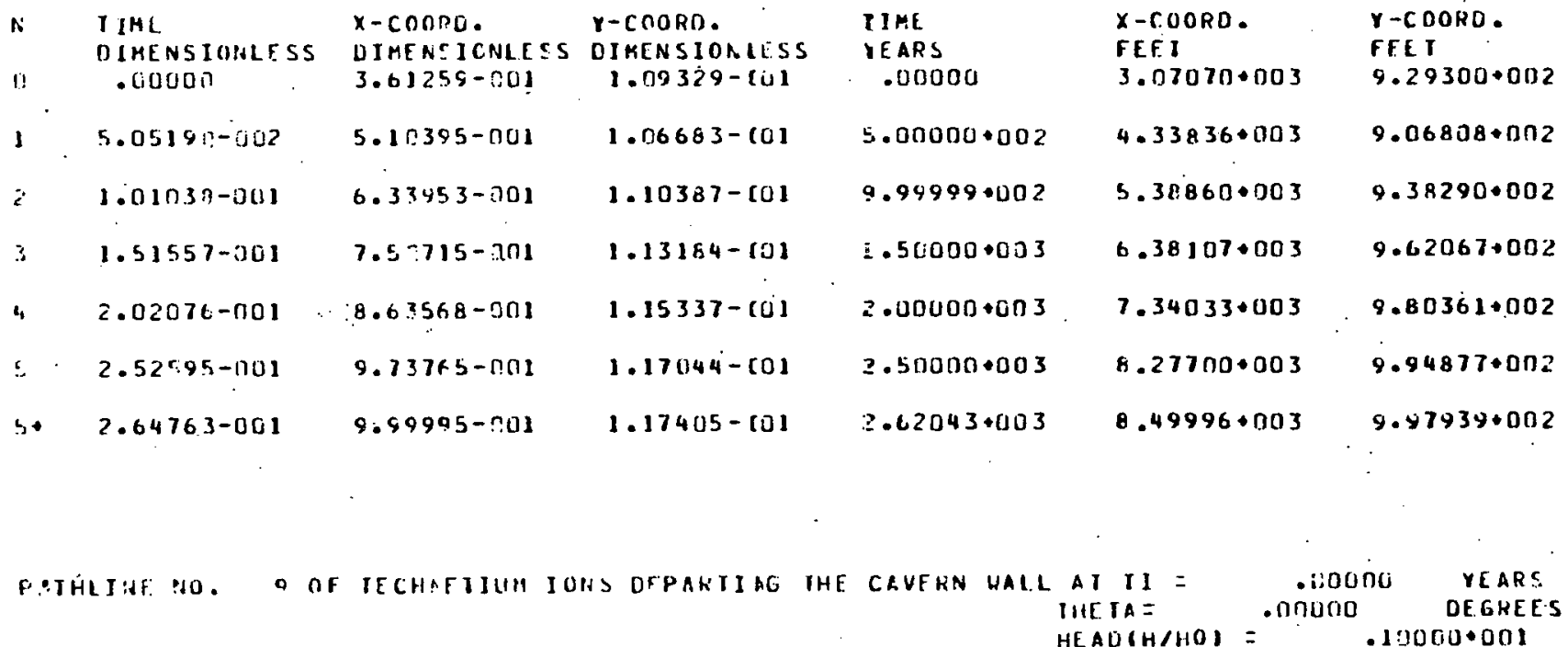
HEAU $(H / H O)=$.1OOOU०OOI

\begin{tabular}{|c|c|}
\hline :. & $\begin{array}{l}\text { TIME } \\
\text { IIMLNSIUNLTSS }\end{array}$ \\
\hline$f_{i}$ & $.0 \mathrm{aros}$ \\
\hline I & $5.05190-00 \%$ \\
\hline$?$ & $1.01039-1.01$ \\
\hline$\therefore \cdot$ & $1.951557-001$ \\
\hline 4 & $2.02076-001$ \\
\hline$\vdots$ & $2.52545-1101$ \\
\hline t & $3.03114-001$ \\
\hline$i$ & $3.53633-001$ \\
\hline 7๑ & $3.75845-001$ \\
\hline
\end{tabular}

$x-\operatorname{COORD}$

FEEI

$2.50000 \cdot 902$

$Y-\operatorname{COORD}$

FF. T

2.00000 .008

$1.94407+00 ?$

$9.99999 \cdot 012$

1.50000 .003

$3.06903 \cdot 00 \mathrm{~J}$

$4.15668+003$

$2.00000+003$

$5.195 a 8+007$

$6.19003+003$

$7.15256+003$

8.119236 .003

$8.49993+003$
$3.71984 \cdot 003$
3.499990003
.60000

$-4.71449+401$

$-1.62433 \cdot 002$

$-2.68095+002$

$-3.21724+002$

$-3.52154+002$

$-3.72051 \cdot 002$

$-3.66283+002$

$-3.9136 .6 \cdot 002$
PATH LENGTH

FEE T

- 00 noo

$1.27252 \cdot 003$

$2.32323+00$

$3.31599 \cdot 003$

$.15020 \cdot 000$

$4.27542+003$

$5.21221 \cdot 003$

$5.43518+003$ $5020 \cdot 000$ $15020 \bullet 000$ $.15020+000$
PAIH LENGTH

FEET

-DUUOD

$1.69496 \cdot 103$

$.10000 \cdot 001$

$2.82602+003$

$3.91894 \cdot 003$

$4.95956 \cdot 003$

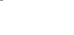
$92312 \cdot 000$

$5.95419 \cdot 003$

.923120000

$6.91692 \cdot 003$ $.92312 \cdot 000$

$7.85683+003$

$8.26442 \cdot 003$ $.92312+000$ 


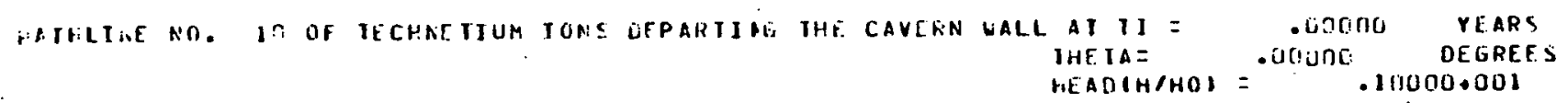

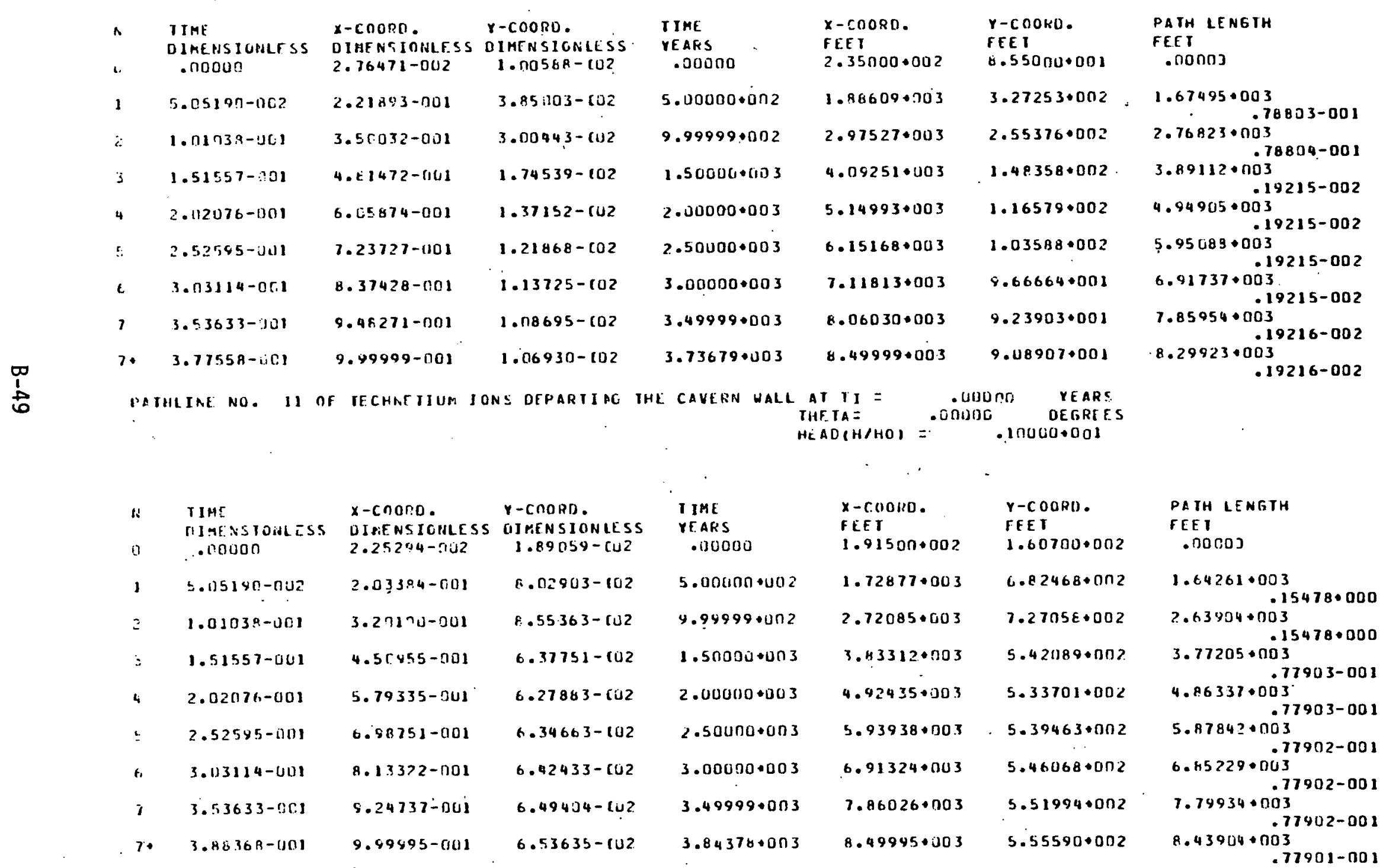




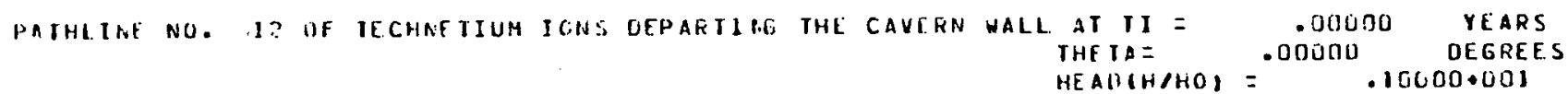

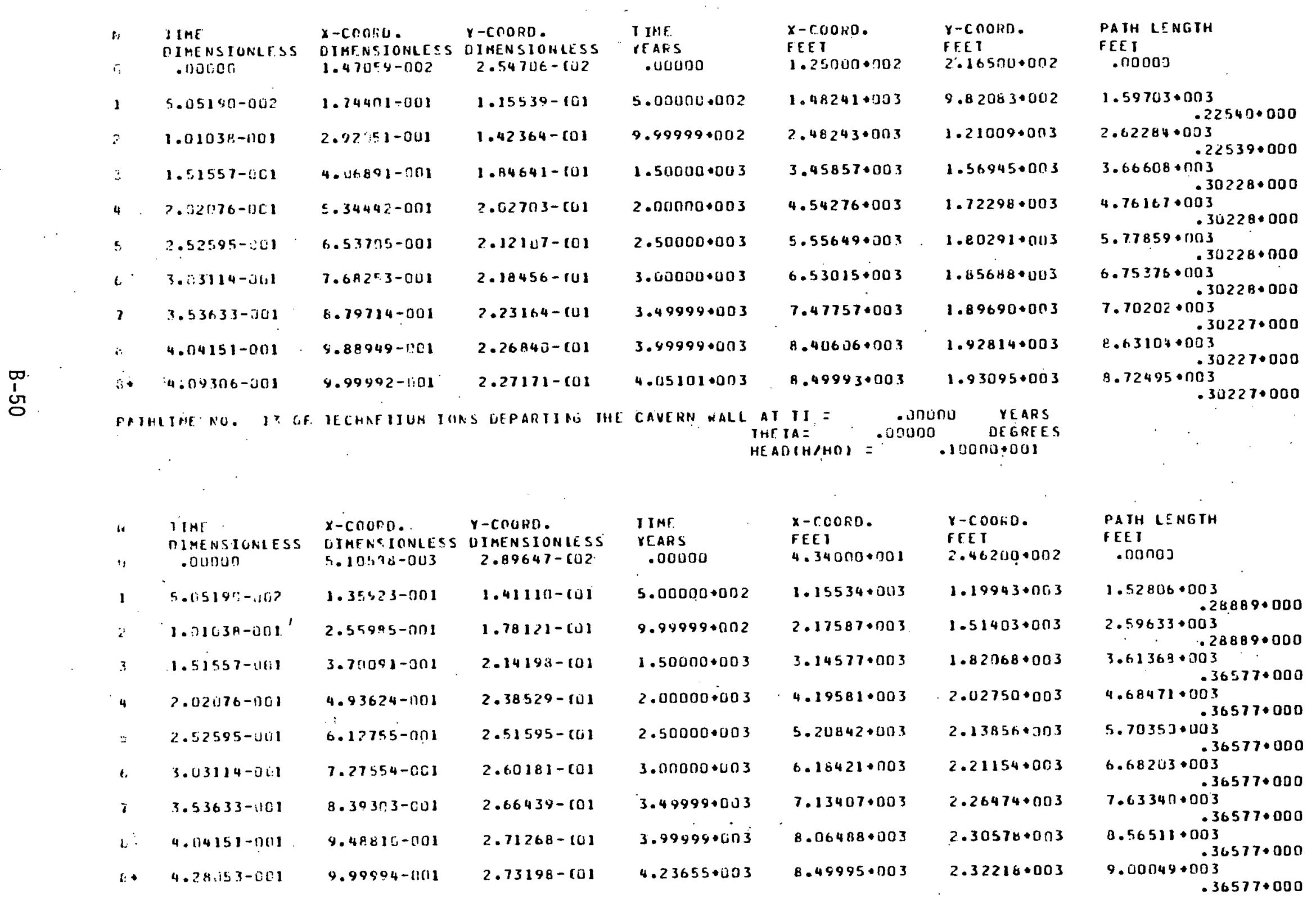




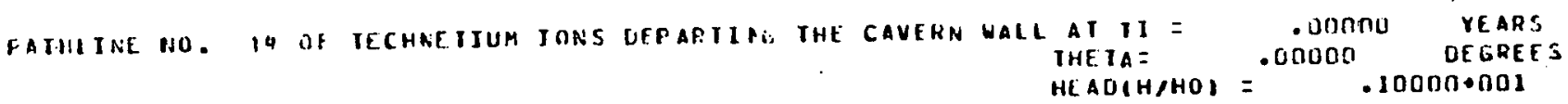

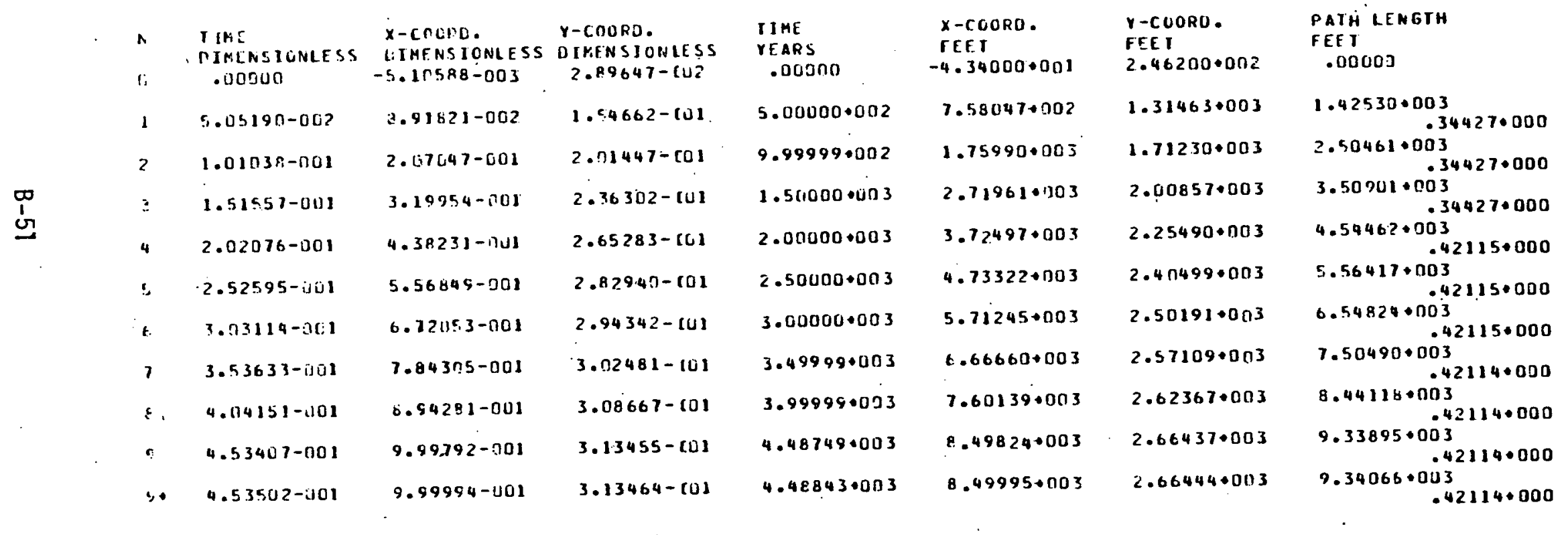




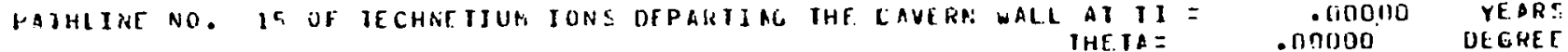

$$
\begin{aligned}
& \text { HEDCLAHCS = }
\end{aligned}
$$

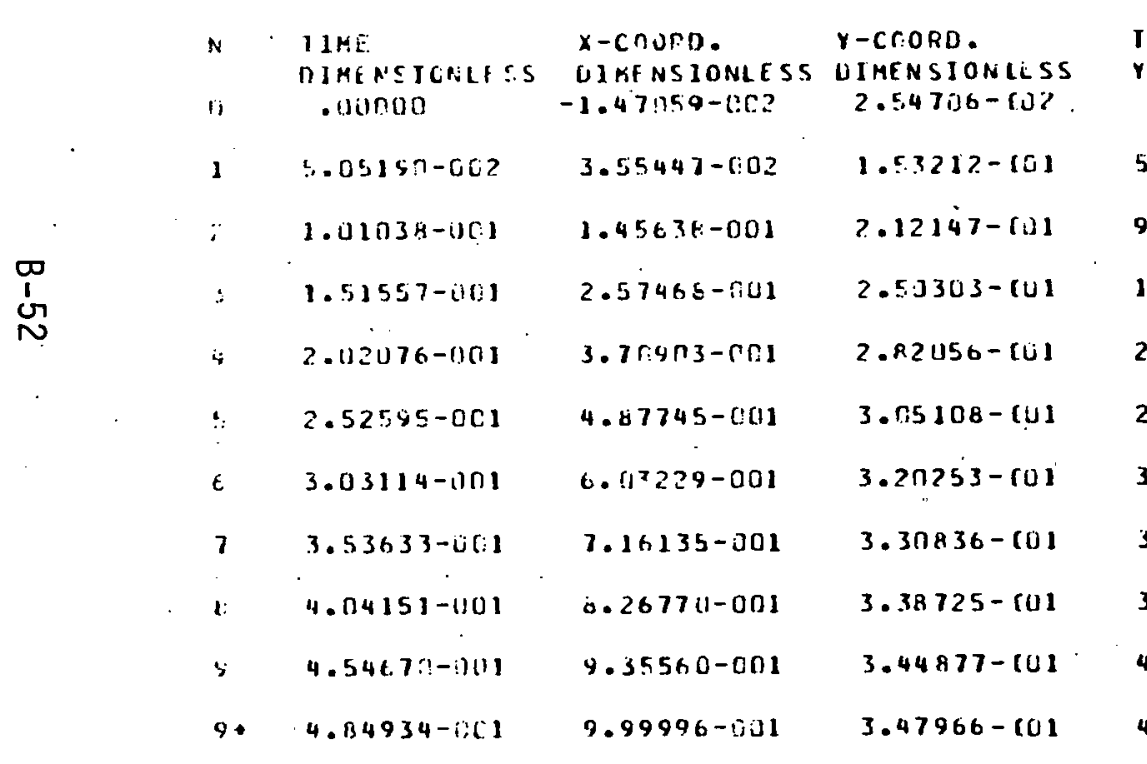

\begin{tabular}{|c|c|}
\hline $\begin{array}{l}\text { TJME } \\
\text { YEARS } \\
\text {-OGODO }\end{array}$ & $\begin{array}{l}\text { X-COORU. } \\
\text { FEEI } \\
-1.25000 \cdot 002\end{array}$ \\
\hline $5.00000+002$ & $3.02130+002$ \\
\hline $9.99999 \cdot 002$ & $1.23792 \cdot .903$ \\
\hline $1.50000+0 n 3$ & $2.15848+003$ \\
\hline $2.100000 * 003$ & $3.15268+003$ \\
\hline $2 \cdot 50000 \cdot 003$ & $4.14583 \cdot 003$ \\
\hline $3.00000 \cdot 003$ & $5.12745 \cdot 003$ \\
\hline $3.49999+003$ & $6.08715 \cdot 003$ \\
\hline $3.99999+003$ & $7.02755 \cdot 003$ \\
\hline $8 \% 98011$ & $7.95226+1003$ \\
\hline $9952+003$ & $\varepsilon .49997 \cdot 003$ \\
\hline
\end{tabular}

$x-c 00 R L$
FrEI
$2.16500 \cdot 002$
$1.30230 \cdot 003$
$1.80325 \cdot 003$
$2.12758 \cdot 003$
$2.39798 \cdot 003$
$2.54342 \cdot 003$
$2.72215 \cdot 003$
$2.81211 \cdot 003$
$2.67916 \cdot 003$
$2.93146 \cdot 003$
2.95711 .003

PAIH LENGTHH

FEE I

.ก000了

$1.27691 \cdot 003$

$.39157+000$

$2.34141 \cdot 033$

$2.34181 .0339157 \cdot 000$

$3.34642 \cdot 003$

$4.34784 \cdot 34157 \cdot 000$

$4.34784 \cdot 003$

$5.36042+003$

408450000

$6.35053+0003$

.46845 .000

$7.31447 \cdot 003$

$8.2572600 .46845+000$

$8.25726 \cdot 003$

$9.18346 \cdot 003$ $46844 \cdot 000$

9.73179 .003

$.46944+000$ 


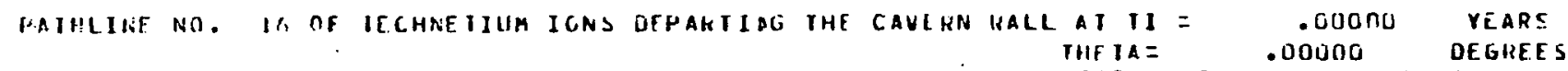
HEAD(H/HOS $=$. $100000 \mathrm{OO}$

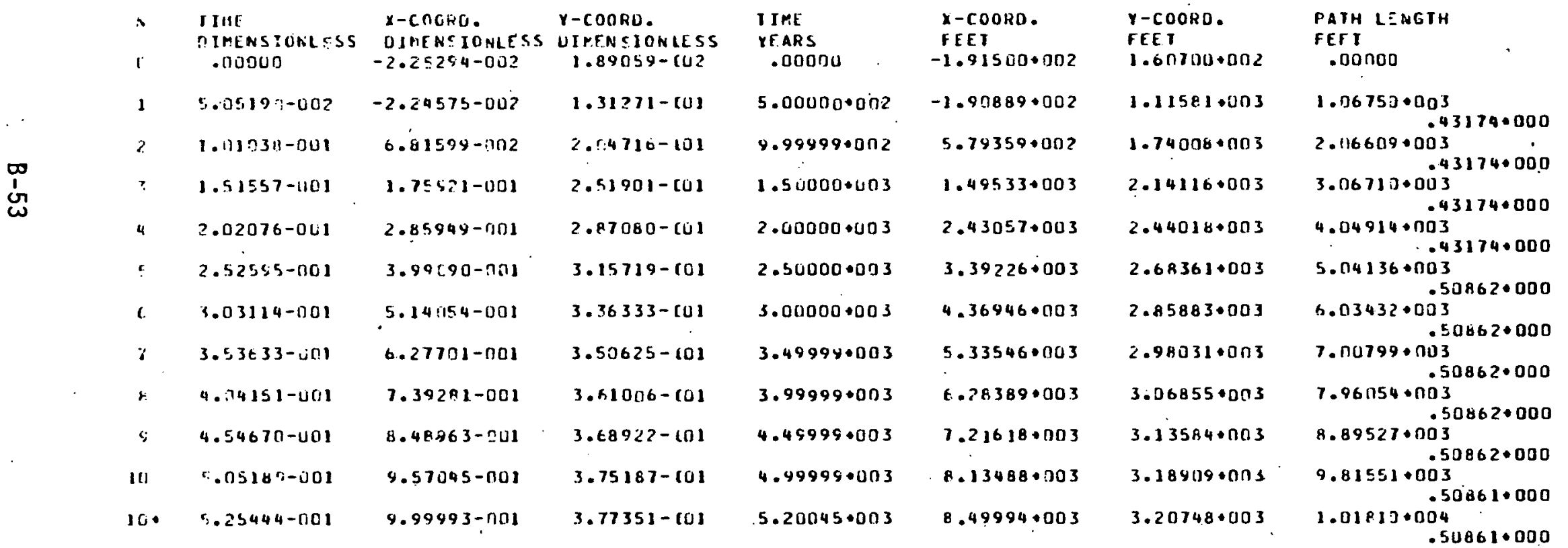




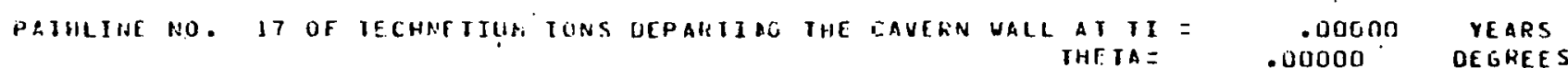
HEAOCH/H:O) = .10000.001

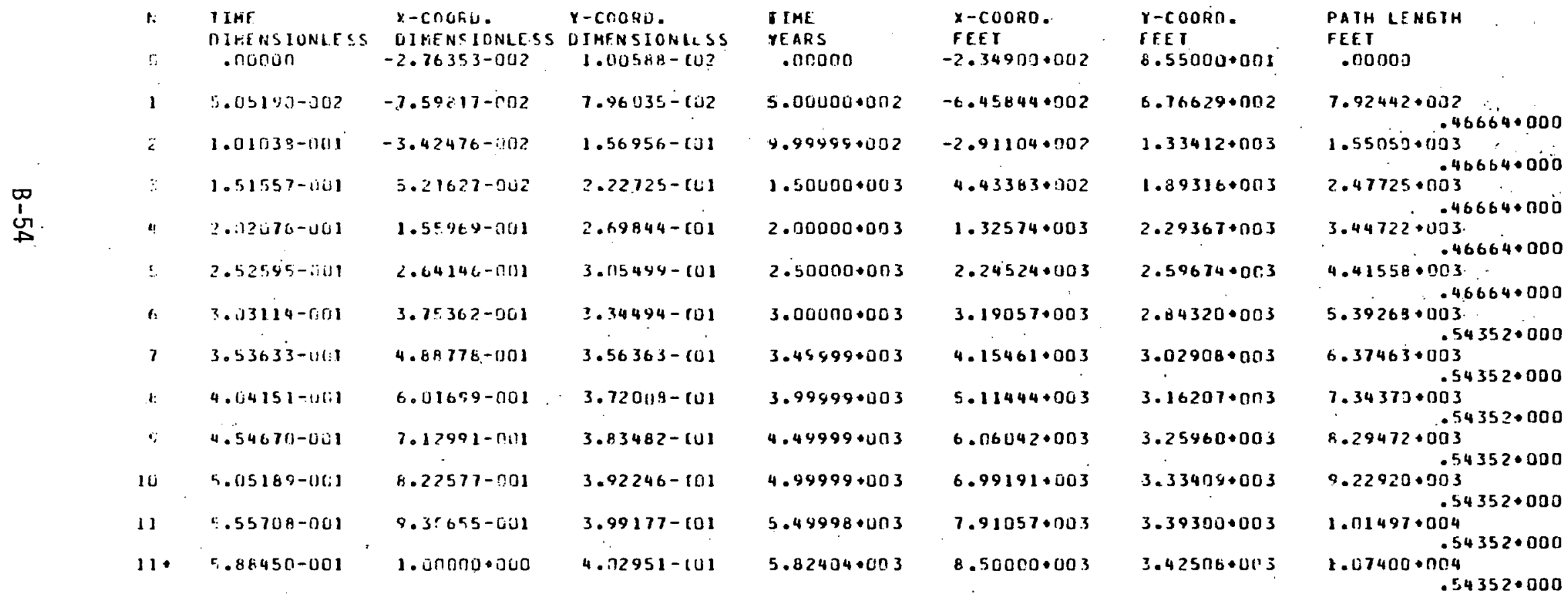


PAIHLIHE NO. Jo OF IECHNFTIUT IGRS OFPARIIDG IHE CAUCRN VALL ATII = .OMGTO YEARS THF TA : DOOOC DEEREES

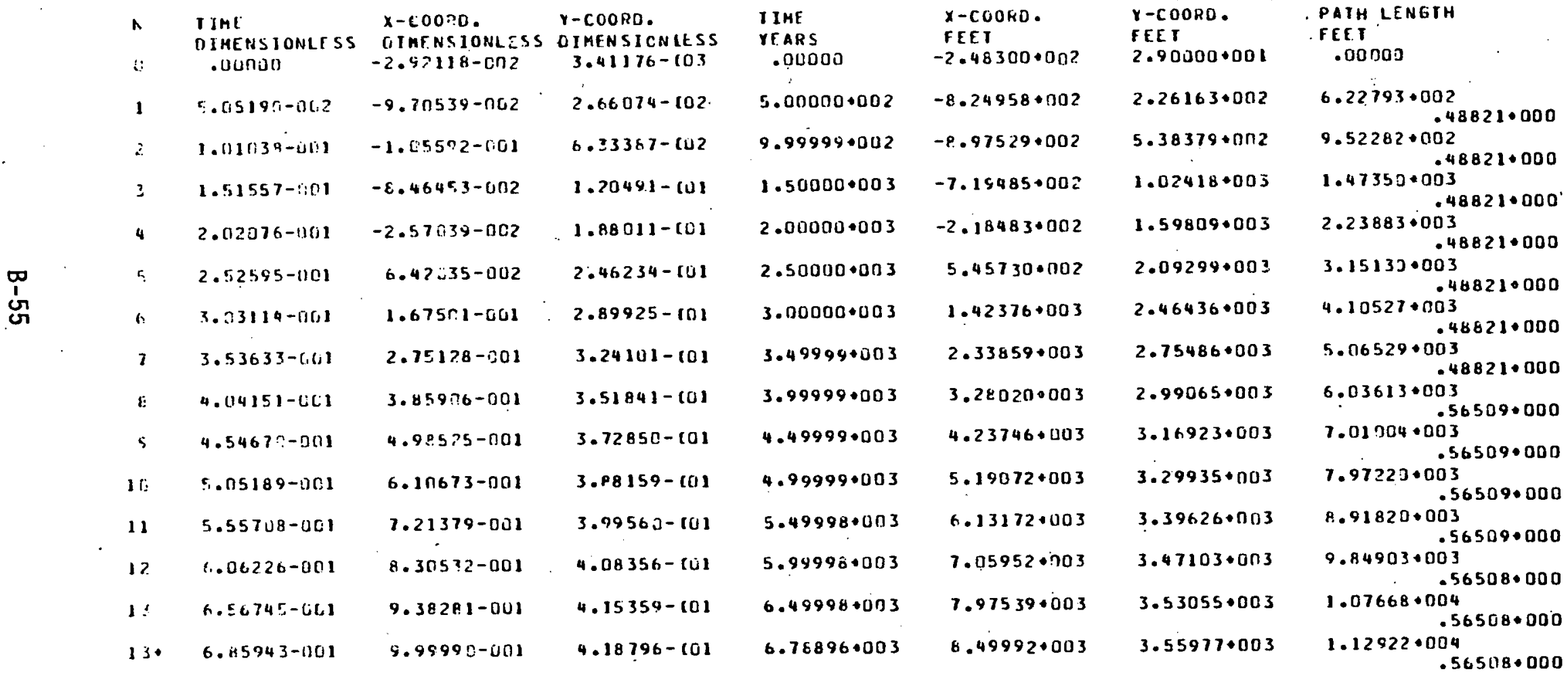




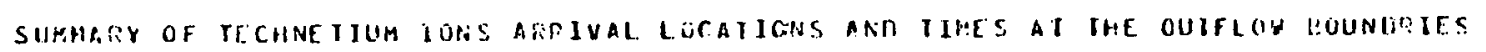

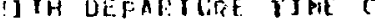

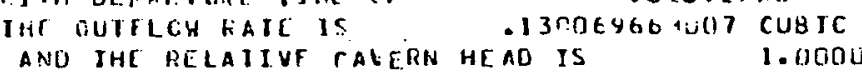 - OCOYEARS
ANO AT IHAI IIME
1.01000

\begin{tabular}{|c|c|c|c|}
\hline$P A M$ & $\mathrm{NO}$ & $\begin{array}{l}\text { IELL.APR - TIRE } \\
\text { YEARS }\end{array}$ & $\begin{array}{l}\lambda \\
\text { FEE. I }\end{array}$ \\
\hline & I & $7 . n 9939.110 ?$ & 8.499960003 \\
\hline & 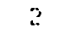 & $2.60 \% 96+003$ & $8.49996 \cdot 003$ \\
\hline & 3 & $2.63660 \cdot 003$ & 8.49999 .003 \\
\hline & 4 & 2.69242 .0013 & $8.49996 \cdot 003$ \\
\hline & $\therefore$ & $? .76461+003$ & $8.49999+1 ; 03$ \\
\hline & ¿ & $2.72739 \cdot 003$ & $8.49897+0103$ \\
\hline & 7 & $2.66210+0103$ & $8.49996+1003$ \\
\hline & e & $2.62043+003$ & $8.49996+003$ \\
\hline & $?$ & $3.71984+1003$ & 8.49993 .003 \\
\hline & 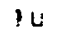 & $x . j j 6,7 y+110 ?$ & $0.40995+003$ \\
\hline & 11 & $3.9 .4378+\Gamma 03$ & $8.45295 \bullet 003$ \\
\hline & 12 & $4.05101+100.3$ & $8.49995+003$ \\
\hline & $1 \overline{3}$ & $4.23655+063$ & $8.49995+003$ \\
\hline & 14 & $4.48843+16^{2}$ & 8.49995 .003 \\
\hline & $1 !$ & $4.79452+1003$ & 8.49997 .003 \\
\hline & 16 & $5.21,545 \cdot 003$ & $y .49994+503$ \\
\hline & 17 & $5.82404 \cdot 00 ?$ & $8.5 n 00,0+003$ \\
\hline & 11 & $t .7 \div 696+003$ & $6.49992+1103$ \\
\hline
\end{tabular}

$Y$

$3.66636 \cdot 103$

$1.19431+103$

$1.39617+103$

$1.55522+603$

$1.64711+103$

$7.76091+602$

$7.76091+102$
$8.52854 \cdot 102$

$9.97939 \cdot \mathrm{CJ} 2$

$-3.91366 \cdot \mathrm{Ca2}$

$9.08907 \cdot$ (u)

$5.5559 \mathrm{i} \cdot 102$

1.93 ก95 cú 3

$2.32218+103$

$2.66444 \cdot 103$

$2.95771+603$

$3.20748 \cdot 103$

$3.42508+103$

$3.555 .77 \cdot[03$

\begin{tabular}{|c|c|}
\hline CUM.FL.IIX & PAIH LENGIH \\
\hline$n / 00$. & FEEI \\
\hline $5.82124-U C 1$ & $1.14242 \cdot 004$ \\
\hline $1.82262-U C 1$ & $5.40405+303$ \\
\hline $2.15197-401$ & $5.44850 * 003$ \\
\hline $2.41123-401$ & $5.55244 \cdot 003$ \\
\hline $2.56091-001$ & $5.67900 \cdot 003$ \\
\hline $1.13947-\mathrm{JM} 1$ & $5.63973+003$ \\
\hline $1.26493-001$ & c. $52556 \cdot 003$ \\
\hline $1.50196-u n 1$ & $5.43518+1303$ \\
\hline $9.2311 z-001$ & $8.26442 \cdot 003$ \\
\hline $1.92158-003$ & A. $29923+003$ \\
\hline $7.79015-002$ & $8.43904 \bullet 003$ \\
\hline $3.02275-001$ & P. $72495 \cdot 003$ \\
\hline $3.65770-001$ & $9.130049+003$ \\
\hline $4.21143-001$ & $9.34066+003$ \\
\hline $4.68443-001$ & $9.73179 \cdot 003$ \\
\hline $5.06614-001$ & 1.01810 .004 \\
\hline $5.43521-001$ & $1.07400 \cdot 004$ \\
\hline $5.65023-051$ & 1.12922 .004 \\
\hline
\end{tabular}




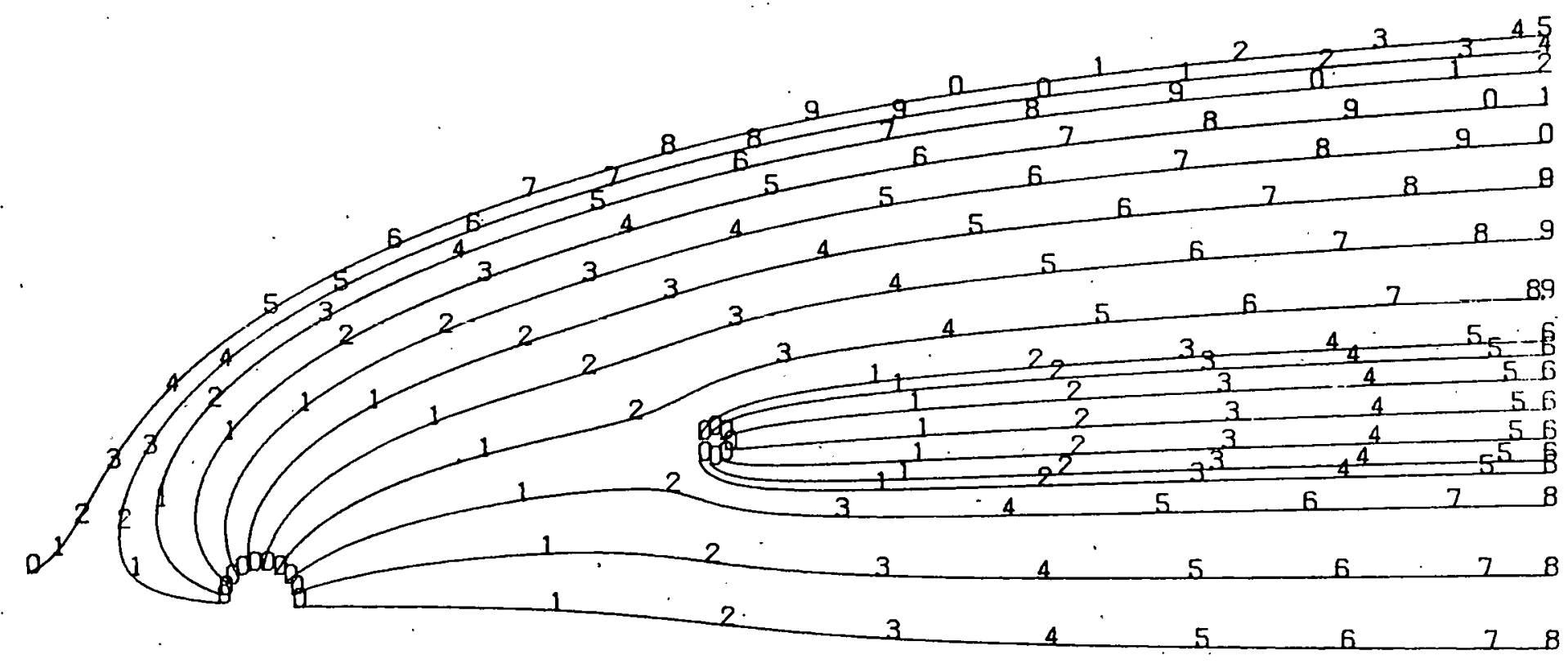

STEADY FLOW WITH TC-99 EXCHANGE DEPARTURE TIME $=0.00$ SCALE 1 INCH $=1000 \quad$ FEET 
APPENDIX C

MAINTAINING OR MODIFYING THE COMPUTER PROGRAMS

4 
APPENDIX $C$

\section{MAINTAINING OR MODIFYING THE COMPUTER PROGRAMS}

A synopsis of the overall PATHS program and related routines is presented here. A complete listing of the codes and test cases, on microfiche, is included at the end of this appendix. The following discussion also shows the relationships between the various programs and the corresponding files they generate.

In large measure, the information in this appendix is incidental to what the program user needs to get $h$ is work done. For someone who must maintain or modify the PATHS system, however, this overview is essential.

\section{OVERVIEW OF PATHS SYSTEM}

What we so far have called PATHS is actually a global name for three related FORTRAN programs. These programs are PATHS, GROUND, and LOCQAR. PATHS and LOCQAR previously were coded in BASIC; now all three are available in ASCII FORTRAN on the Univac 1100/44 time sharing EXEC operating system.

PATHS is an interactive program that prompts the user to enter all information necessary to create a coded file. The file is a run streanl thal cari be batched to execute GROUND. This batch program performs the lion's share of the calculations. GROUND calculates the fluid travel time along each flow path, the coordinates of each path, and the distance traveled. In addition, calculations are saved that make it possible to generate Calcomp plots showing the flow paths graphically. GROUND also writes a file summarizing the fluid arrival calculations. This may be viewed from the terminal after GROUND finishes execution, thereby giving the user a capsulized view of results before the run is printed and delivered. GROUND also generates a binary data file. This file feeds LOCQAR, which can be executed after the completion of GROUND. 
Like PATHS, LOCQAR is interactive, but solicits very little data before calculated results of outflow location and rates are printed.

Pictorially, the flow through the system is as follows:

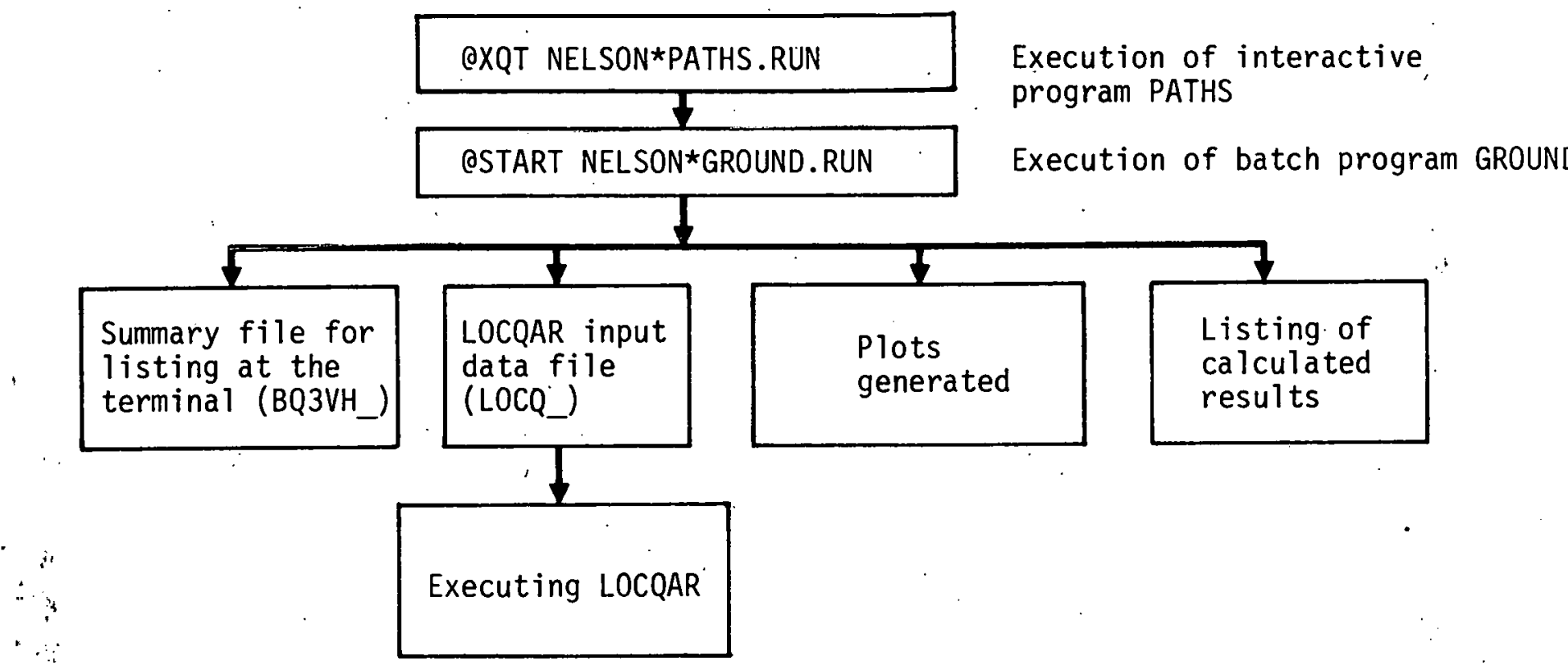

\section{PROGRAMS}

LOCQAR

LOCQAR is the simplest of the three programs. It is a short (325-cards) program that reads the binary data file created by GROUND and then interacts with the user for more information, asking about ten questions. (See Appendix B for an example of usage.) Only the last 100. lines of code are used to process data and print out the results via the terminal. LOCQAR uses only one subroutine, SEEBIT, which interprets information from the terminal. 
Currently LOCQAR is maintained as source, relocatable, and absolute under the file and element name NELSON*LOCQAR.RUN: :

\section{PATHS}

PATHS is relatively long (1440 cards), because it is an interactive code. Operationally, it is simple and straightforward, flowing linearly through the code, asking the user questions, slowly building up a reservoir of data to create a job stream for the GROUND program.

By using CALL FACSF, PATHS creates internally an SDF file catalogued under the user's project ID and the file name GRND_. GRND has appended the job number entered by the user. This file is opened, closed, and freed by PATHS. It is also batched for execution if the user desires.

PATHS has several subroutines, all but two of which are trivial, only writing out information helpful to the user. The two non-trivial subroutines are SEEBIT and BLANKS, used to read information from the terminal. Currently PATHS is maintained as source, relocatable, and absolute under the file and element name NELSON*PATHS.RUN.

\section{Data Entered}

The following detailed input sequence has been prepared to show the procedure for using PATHS to collect draft input data.

The PATHS input sequence list includes all of the variables that the program requires, in the order each is requested. It also shows explicitly the program flow and how various input variables are skipped from entry based on the responses to the questions. While probably too detailed for most terminal work, it is useful in maintaining or modifying the interactive PATHS program. 
Detailed Input Data Sequence List

(CONTROL CARD INFORMATION)

1 .

$=$ ACCT Enter your account number.

2.

$=$ USERID Enter your user ID.

3.

$=$ PROJ

Enter your project ID.

4.

$=$ ADDRES

Enter your name/address.

5.

$=$ PASSWD

Enter your password.

(DATA FOR PROGRAM GROUND)

6. $=D O=D_{0}$ is the stratum thickness.

7 . $=\mathrm{R}$

is the distance to the boundary. (Units consistent with DO).

8. Standard distance or $T$ termination of pathline. (Yes or No) If Yes:

9. $=$ XMAX is the terminating abscissa value.

If No:

9. = TMAX is entered if desired; the maximum travel time for flow paths.

10. $=R O=r_{0}$ is the cavern radius. (Units consistent with DO.)

11. $=\mathrm{HO}=\mathrm{H}_{\mathrm{O}}$ is the head in the cavern. (Units consistent with D0.)

12. $=K O=K_{0}$ is the stratum hydraulic conductivity. (Units consistent with $\mathrm{DO}$. Whatever time units are involved in hydraulic conductivity sets the units for the travel. time.)

13. $=P$ is the effective stratum porosity.

14. S or $T$ steady or transient cases.

15. $=U 0$ is the initial uniform gradient.

If STEADY case skip to 22

16. $=U M$ is a later gradient value. (See Figure 1.) 
If no STEADY case skip to 21

17. $=\mathrm{TM}$

is the time parameter of the gradient equation in time units of Ko.

18.

19. $=A$

20.<smiles>CCCCN=[R](C)C</smiles>

Parameters used in the calculation of the uniform gradient.

21.

Enter $S, E$ or $C$ (serpin, exponential or cyclic) for computing variation in the cavern head. (See Figures 1 and 2.)

If $E$ skip to 32 . If $C$ skip to 28.

22. $=\mathrm{HI}$

23. $=H M$

If $H I$ is equal to $H M$ skip to 32 .

24. $=\mathrm{TN}$ is the initial value of the cavern head in units of $\mathrm{H}_{0}$. Maxmimum value of the head in units of $\mathrm{H}_{\mathrm{O}}$.

is a time parameter. Units consistent with TM for the variation of the uniform gradient $U$.

Parameter used in serpin option to calculate H. Sk ip to 32 . is the mean cavern head. is the amplitude of the cyclic head. is the beginning time of the cyclic flow from the cavern.

31. is the ending time of the cyclic flow from the cavern.

32. Are there additional wells or caverns? (Yes or No) If no skip to 48 .

33. $=\mathrm{J}=\mathrm{j}$ is the number of wells. 34. $=X W E L L=x_{j}$ is the $x$ coordinate of the well.

35. $=$ YWELL $=y_{j}$ is the $y$ coordinate of the well. 36. $=$ ROWELL is the stopping radius of the well.

If steady case skip to 38 
37. Is well serpin or cyclic? (S or $C$ )

If cyclic skip to 44

38. $=Q I$ is the initial flow rate of well (see Figure 2).

39. $=Q M$ is the maximum flow rate of well.

40. $=T N W E L L=T N_{j}$ is time parameter in calculating well flow rate

41. Parameters used by the serpin

42. $=D W E L L=D W_{j}$ 43. $\ldots=F W E L L=F W_{j}$ rate. $=$ EWELL $\left.=E_{j}\right\}$ option to calculate the well flow

Return to 34 until all wells have been read. After all wells have been read skip to 48 .

44. $=Q_{j}$

45. $=Q A_{j}$

46. $=$ TOWELL

47. = TMWELL is the mean inflow $(+)$ or outflow $(-)$ rate of the well. is the amplitude about the mean inflow $(+)$ or outflow (-) of the well. is the beginning time of the cyclic flow of the well. is the ending time of the cyclic flow of the well.

Return to 34 until all wells have been read.

After all wells have been read continue at 48 .

48.

$=$ VS

Max 12 character unit label of DO's length.

49.

= WS

Max 12 character time units of $\mathrm{K} 0$.

50.

$=$ THETAO $=\theta 0$ the angle in degree around the cavern well to the starting point for the first pathline.

51.

$=$ THETAM $=O M$ the maximum angle in degrees to the lost pathline starting point along the cavern wall. 
52. $=$ NTHETA $=$ Ne the number of equally spaced pathlines desired along the cavern wall that will be generated beginning with THETA and ending with THETAM.

If THETAO is not equal to THETAM skip to 58.

53.

54.

55.

If initial path lengths are zero skip 56 and 57.

56.

57.

Enter L-path length in units of 00 .

Enter starting TIME in units the same as time units of KO.

Return to 54 until NTHETA have been read, then skip to 59.

58.

$=$ KEHETA is the number of pathlines that will be generated between THETAM and $179.99(+)^{\circ}$.

59. $=T 0=t_{0}$ is the departure time in units of K0 of first fluid fluid particles leaving the cavern for which calculations will be made.

If steady case skip to 63.
60. $=T F=t_{f}$

61. $=N T$

is the departure time in units of $\mathrm{KO}$ of final fluid particles leaving the caverin for which calculations will be made. is the number of equally spaced departure times beginning with TO and ending with TF that will be calculated.

If TO is not equal to TF skip to 63.

62. $=\mathrm{T}$
Enter all NT time increments from the terminal.

Repeat 62 until all NT have been read.

63. Is there an ion exchange delay? (Yes or No) If no skip to 67.

64. $=$ CHEM

65. $=K D=K_{d}$ is the chemical name of the ion (12 character name max.)

is the equilibrium distribution coefficient 
66.

$=B D=B_{d} \quad$ is the bulk density of the porous material in units consistent with KD.

67. $=$ DELTA is the time increment used in computing flow along a given path. (Program PATH, aids in providing range for proper selection.)

68. Enter the number of steps to be used for integration over the delta increment (six usually suffices).

69. $=$ ITLIM is the number of iterations (5000 is the upper limit).

70. $=$ NPRINT is the value $N$ such that every Nth time increment is printed. (Program PATH aids in this selection).

71. $=$ EPSLN is the near zero convergence for finding R.

72. Are plots desired? (Yes or No).

If no skip to 77 .

73. Are 30-inch-high plots desired? (If not 11 inch high plots result.)

74. = XCENTER

The $(x, y$ coordinates in inches of the cavern

75. center to be plotted from $(0,0)$ lower

'76. $=$ SCALE left corner of the plot window. is the scale factor in units/inch to be used in the plot.

77. Is detailed computer printout desired? (Yes or No)

78. Enter the job run number. (Digits from 1 to 9)

79. Is the job to be submitted? (Yes or No)

(Note: The job stream created is saved as the runstream PROJ*GRND_. Where PROJ is the project ID (item number 2 ) and is the job run number (item number 78). PROJ*GRND_ is available for modification through EDITOR for job submittal also.) 
GROUND

The GROUND program calculates flow pathlines and arrival times. It is a program of about 1150 cards. Apart from the output data GROUND generates on each path of flow, it creates a summary file BQ3VH_ of path data, a binary file for LOCQAR called LOCQ_, and CalComp plots. (NOTE: The dash is for the appended number, the number of the run set in the PATHS program.)

GROUND begins by reading the data created by PATHS. It then prints this data read, identifying it for the user. Next the variables read in are scaled and the beginning time loop is started. If the run is a steady case, only one starting time for the flow paths calculated is used. However, for transient cases, the program loops back to pick up the next starting time flow paths are to be calculated for. Execution continues like this until the final starting time is reached that flow paths are to be calculated for.

With the beginning of each pathline to be calculated, initializing is done, including the initializing for setting. up the $x$ and $y$ arrays for plotting the paths. Depending on cavern behavior or type of flow subroutines HM, SERPIN or CYCLE will be called to calculate exponential, serpin or cyclic flow. Next, the possible influence of wells on the flow is introduced. A call to subroutine RKDE is made, which in turn calls function DYWELL to obtain the incremental numerical solutiori through a modified Runge-Kutta technique (Gill, 1951). This process is continued for each pathline until the terminating distance (XMAX) or terminating time (TMAX) is reached.

As each pathline is calculated, every NPRINT (see item 70 of PATHS input data sequence list) interval of data is printed; i.e., the $(x, y)$ coordinates of the point plus the time and distance traveled. At the end of the pathline, the final line is printed and also saved for the summary print out of final locations and times for all path lines are calculated. Also if plots are desired, a call is made to subroutine WRIT at the end of each pathline calculated to have it plotted. Then a new pathline is begun and cycled through as before until the find pathline is processed. With the final pathline calculated, GROUND comes to conclusion, unless it is a transient case in which the entire execution of pathline flow begins again, but with a new starting time. 
Apart from the subroutines already mentioned, program GROUND calls subroutine BOX to encase the plots generated. Subroutines SIMP and NEWTON remain a part of the code but they are not used. They are maintained for possible use later.

Currently program GROUND is maintained as source, relocatable, and absolute under file and element name NELSON*GROUND.RUN. Because GROUND calls the CalComp routines in plotting, it is necessary to include this library of routines when creating the relocatable and absolute files, namely:

O MAP , IS , NELSON*GROUND. RUN

IN NELSON*GROUND, RUN

LIB CALCOMP*LIB.

END

Variable Names

Because GROUND reads the variables originally solicited from the user by the program PATHS, a flow diagram of how they are read follows. Also, because GROUND frequent ly renames these variables, this flow diagram should be compared with the variable list in Appendix $B$ under the discussion "Using EDITOR". As an example, note that the variables for row 9 of PATHS are respectively: $R, R, H O, K O$ while GROUND names them respectively: $S$, RMAX; HO, EKO. The lines in this flow diagram are numbered to correspond to the ir counterpart in Appendix B. 
8. TITLEE

9. "S, RMAX,HO,ËKO

10. RO, ROS,TP,UO

11. RM,P,TM

12. PATH, AAKD, BBD

13. CHEM, PROJ, VH3, IPROJ

14. AST, BST, CST, KTHETA

15. THETAO, THETAM, TO, NTHETA

16. TF, TIMEX, EPSLN, ITL IM

17. DELTA, NT , STEP, NT

18. XMAX, XC, YC, ISK

19. SC,DST, EST, FST

20. GST, OST, XTEST, YSTOPI -

21. HMEAN, HAMP, TOCYC, TMCYC

22. PARAMA, NWELL , PI

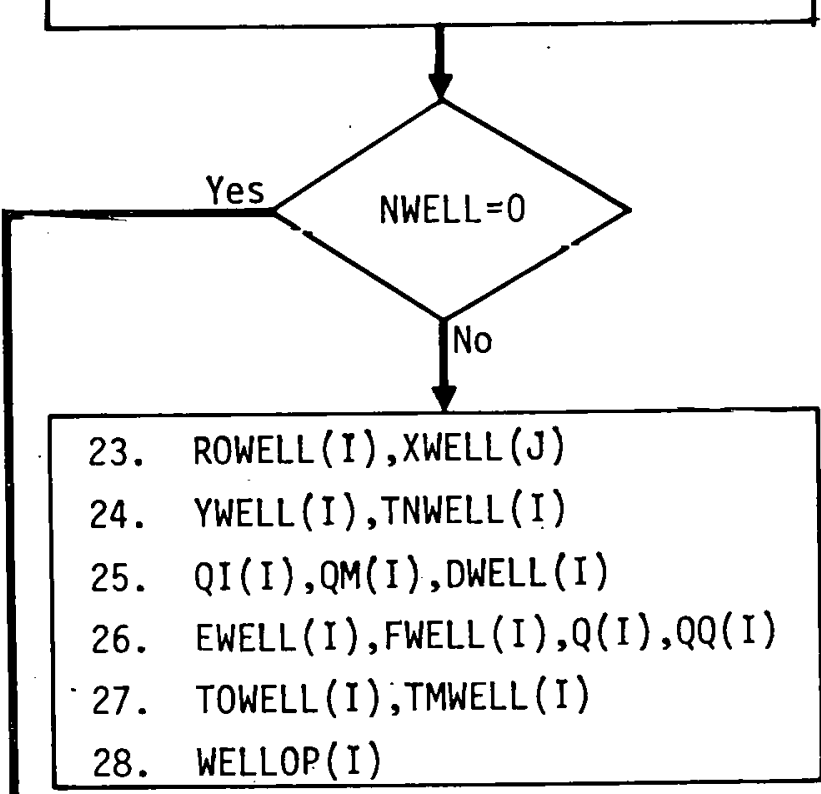

Loops

NWELL times

(Skips these if

NWELL equals zero)

\section{JLEN}

36. JTIM

37. CASE

a 


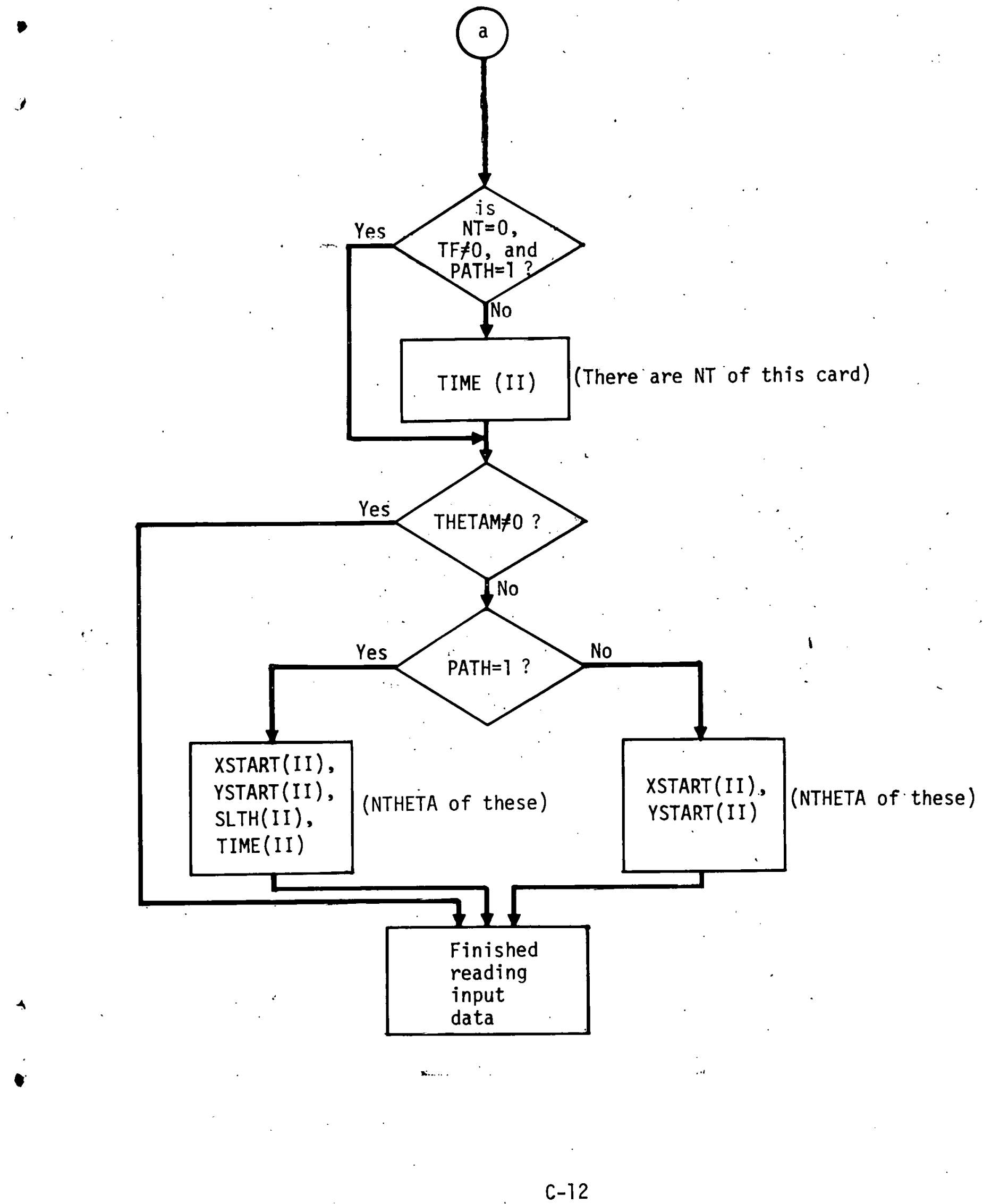


The complete listings of the PATHS, GROUND" and LOCQAR program are provided on microfiche. The first test case is the "Example Transient Case (Two We 11s)" described in the body of the report and illustrated in Appendix $B$. Most of the output of the first test case was also shown in Appendix $B$ though some of the detail printout was omitted. The complete output listing is provided on microfiche below. The second test case is the "Steady Flow with Tc-99 Exchange" illustrated in Appendix B. The complete "listing of the output for test. case 2 is also included in the microfiche envelope.

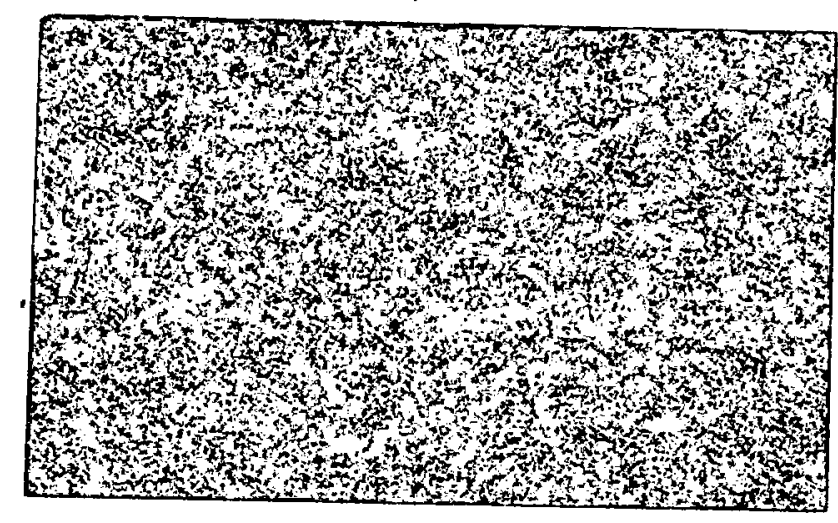


APPENDIX D

DEFINITIONS OF TERMS

$\wedge$ 
APPENDIX D

DEFINITIONS OF TERMS

Units

A is a parameter in the $W\left(t^{\prime}\right)$ and $U\left(t^{\prime}\right)$ time-dependent functions (see Figure 1 ).

T

is a parameter in the $W\left(t^{\prime}\right)$ and $U\left(t^{\prime}\right)$ time-dependent function (see Figure 1).

None

$B_{d}$

is the bulk density of the porous material.

$\mathrm{FT}^{2} / \mathrm{L}^{4}$

C is a parameter in the $W\left(t^{\prime}\right)$ and $U\left(t^{\prime}\right)$ time-dependent function (see Figure 1).

$T^{2}$

$C^{\prime} \quad$ is the contaminant concentration in the flowing groundwater.

$F T^{2} / L^{4}$

$C^{\circ} \quad$ is the dimensionless contaminant concentration (see Equation A-45).

None

$\mathrm{C}_{1}$

is a constant in the dimensionless potential function.

None

is the initial concentration in the pond or cavern.

$\mathrm{FT}^{2} / \mathrm{L}^{4}$

$\mathrm{C}_{0}$ is a constant to be determined in the potential function.

$\mathrm{FL} / \mathrm{F}$

$D=D W E L L$ is a parameter in the $H\left(t^{\prime}\right)$ time-dependent function (see Figure 1). DW
$j \quad j$ is a time parameter in the flow rate, $Q_{j}\left(t^{\prime}\right)$, for the

is the stratum thickness (see Table 1).

$E=E W E L L$, is a parameter in the $W\left(t^{\prime}\right)$ time-dependent function (see Figure 1).

None

$E_{j} \quad$ is a time parameter in the flow rate, $Q_{j}\left(t^{\prime}\right)$, for the jth well (see Figure 1).

None

$F=F W E L L$ is a parameter in the $H\left(t^{\prime}\right)$ time-dependent function (see Figure 1). 
Units

$F(t) \quad$ indicates a function of time, $t$. None

is a time parameter in the flow rate, $Q_{j}\left(t^{\prime}\right)$, for

the jth well (see Figure 1).

$T^{2}$

$\mathrm{FW}$

is the dimensionless head at any time, $t$, in the cavern or pond.

None

H

$H^{\prime}$ is the time-dependent energy head in the cavern or
pond.

$H^{\prime}$ is the time-dependent energy head in the cavern or
pond.

$H^{\prime}$ is the time-dependent energy head in the cavern or
pond.

$H_{0}$ is the initial or steady head in the cavern (see Equation $\mathrm{A}-2$ ).

$\mathrm{FL} / \mathrm{F}$

is a parameter in the time-dependent cavern head.

HI equation (see Figure 1).

$\mathrm{FL} / \mathrm{F}$

is a time parameter in the flow rate, $Q\left(t^{\prime}\right)$, function for the $j$ th well (see Figure 1).

TOWELL $_{j}$ is the initial time parameter in the cyclic flow rate, $Q\left(t^{\prime}\right)$, function for the jth well (see Figure 2).

TMWELL $_{j} \quad$ is the later cyclic time parameter in the flow rate, $Q\left(t^{\prime}\right)$, for the jth well. (see Figure 2).

TNWELL $_{j}$ is a computer-used name equivalent to $\mathrm{TN}_{j}$.

is the time-dependent uniform gradient strength.

$\mathrm{L} / \mathrm{L}$

Uo is a parameter in the time-dependent uniform gradient function (see Figure 1).

is a parameter in the time-dependent uniform gradient function (see Figure 1).

$L / L$

$w\left(t^{\prime}\right)$ is the general serpin equation form of time dependence (see Figure 1 or Equation A-18).

W $_{T} \quad$ is the contaminant outflow rate (see Equation 17 ).

$F / T$

XMAX

is the stopping distance for pathlines in the positive $x$ coordinate direction (see sketch in Table 1).

XCENTER is the $x$-coordinate in inches for the origin $x^{\prime}=0$, $y^{\prime}=0$ for plots (see Table 1). 
$\underline{\text { Units }}$

$\mathrm{XWELL}_{j}=x_{j}^{\prime}$ is the $x$-coordinate location of the center of

YCENTER is the $y$-coordinate in inches for the origin $x=0$, $y=0$ for the automatic machine plots (see Table 1).

$\mathrm{YWELL}_{j}=y_{j}^{\prime}$ is the $y$-coordinate location of the center of

$\mathrm{J}=\mathrm{N} \quad$ is the total number of wells. None

HM is a parameter in the time-dependent cavern head equation (see Figure 1). None

$K$ is the ratio of the exchangeable ion travel time to that of the fluid (see Equation 13). None

$\mathrm{K}_{\mathrm{d}} \quad$ is the equilibrium exchange distribution coefficient $\mathrm{FT}^{2} / 4_{\mathrm{L}}$ (see Equations 13, A-48).

$K_{0} \quad$ is the hydrautic conductivity.

$L^{3} / T^{2}\left(\frac{L}{L}\right)$

$K \theta=K T H E T A$ is the number of pathlines that will be generated between $\theta \mathrm{M}$ and $179.99(+)^{\circ}$ originating on the cavern wall.

None

$L \quad$ denotes length units.

$M_{0} \quad$ is the pond or cavern source strength.

$M_{j}=\frac{Q_{j}}{D_{0} K_{0}}$ is the well strength of the $j$ th well.

$\mathrm{N}=\mathrm{J} \quad$ is the total number of wells in the flow system. None

NT is the number of equally spaced departure times beginning with $t_{0}$ and ending with $t_{f}$ that will be calculated (see Table 1).

None

No is the number of equally spaced pathlines along the cavern wall that will be generated beginning with $\theta 0$ and ending with $\theta M$.

None

$P \quad$ is the effective porosity.

None

Q is the leakage rate from the cavern (see Equation A-40). 
Units

$Q_{i} \quad$ is the cumulative flow rate (see Equation $A-43$ ). $L 3 / T$

$Q_{j} \quad$ is the volume inflow or outflow rate of the $j$ th well. $L^{3 / T}$

is the initial inflow $(+$ ) or outflow $(-)$ rate for the
serpin well option (see Equation $A-18$ and Table $A-1$ ). $L / T$

is the maximum inflow $(+)$ or outflow $(-)$ rate for the
serpin well option (see Equation $A-18$ and Table $A-1) . \quad L / T$

$Q_{j} \quad$ is the mean inflow (+) or outflow (-) rate for the cyclic option of time dependence for well flow (see Equation A-19 and Table A-2).

$Q A_{j} \quad$ is the amplitude of the cyclic well inflow $(+)$ or outflow (-) rate (see Equation A-19 and Table $A-2$ ). $\quad L^{3} / T$

$Q_{0} \quad$ is a constant leakage rate from the cavern used as a scaling value (see Equation 9).

$Q^{\prime} \quad$ is the leakage rate from the cavern (see Equation A-20).

$\mathrm{R}$ is the distance (radial) to the groundwater outflow area, or the remote boundary. It also is used in scaling (see Equation A-2).

ROWELL $_{j}$ is the numerical stopping radius around the $j$ th well (see Table 1).

SCALE is the scale used in the automatic plots (see Table 1).

L/inch

$T$ denotes the arrival time and also time units.

$\mathrm{T}$

TMAX is the stopping time along the pathlines (see. Table 1).

TM is a time parameter in the $U\left(t^{\prime}\right)$ function (see

Figure 1).

TN is a time parameter in the $H\left(t^{\prime}\right)$ function (see Figure 1).

is the gravitational scalar. 
Units

j as a subscript denotes the variable applies to the jth well.

None

None

$\mathrm{F} / \mathrm{L}^{2}$

p is the fluid pressure.

$L^{3} / T / L$

i.e., into the river. $q=\frac{R}{D_{0} K_{0} H_{0}} q^{\prime}$ is the dimensionless fluid flow rate across the

None

$r$ is the dimensionless radial courdinate variable in cylindrical coordinates.

None

$r^{\prime}$ is the radial variable in cylindrical coordinates.

$r_{0}^{1} \quad$ is the effective cavern radius.

$r_{0} \quad$ is the dimensionless effective cavity radius.

None

s is the location along the outflow boundary; i.e., along the river (see Equation 17).

L

$t$ is the dimensionless time variable (see Fquation $A-2)$.

Nune

$t^{\prime} \quad$ is the time variable.

$t_{0} \quad$ is the departure time of the first fluid particles leaving the cavern wall or from the other specified locations.

None

$t_{0}^{\prime} \quad$ is the departure time of the fluid particles from a given location.

T

$w_{0} \quad$ is a parameter in the serpin equation (see Figure 1 or Equation A-18).

None

$W_{O C}$ is a parameter in the cyclic equation (see Figure 2 or Equation A-19).

None

$w_{m} \quad$ is a parameter in the serpin equation (see Figure 1 or Equation $\mathrm{A}-18$ ).

None 
Units

i

)

$Q_{i}$

is the cumulative flow rate (see Equation A-43).

$L^{3} / T$

$Q_{j}$

is the volume inflow or outflow rate of the $j$ th well. $L / T$

QI $j \quad$ is the initial inflow (+) or outflow (-) rate for the serpin well option (see Equation A-18 and Table A-1). L ${ }^{3} / T$

$Q_{j} \quad$ is the maximum inflow $(+)$ or outflow $(-)$ rate for the serpin well option (see Equation A-18 and Table A-1). L ${ }^{3} / T$

$Q_{j} \quad$ is the mean inflow $(+)$ or outflow $(-)$ rate for the cyclic option of time dependence for well flow (see Equation A-19 and Table A-2).

$Q A_{j} \quad$ is the amplitude of the cyclic well inflow (t). or outflow $(-)$ rate (see Equation $A-19$ and Table A-2). L $L^{3} / T$

$Q_{0} \quad$ is a constant leakage rate from the cavern used as a scaling value (see Equation 9).

Q' is the leakage rate from the cavern (see Equation A-20).

R is the distance (radial) to the groundwater outflow area, or the remote boundary. It also is used in scaling (see Equation A-2).

ROWELL $_{j}$ is the numerical stopping radius around the $j$ th well (see Table 1).

SCALE is the scale used in the automatic plots (see Table 1).

T denotes the arrival time and also time units.

T

TMAX is the stopping time along the pathlines (see Table 1).

TM is a time parameter in the $U\left(t^{\prime}\right)$ function (see Figure 1).

TN is a time parameter in the $H\left(t^{\prime}\right)$ function (see Figure 1).

is the gravitational scalar. 
Units

$j$ as a subscript denotes the variable applies to the jth well.

None

In is the natural logarithm to the base e. None

$\mathrm{p} \quad$ is the fluid pressure. $\mathrm{F} / \mathrm{L}^{2}$

$q^{\prime} \quad$ is the unit fluid outflow rate across the boundary; i.e., into the river.

$L^{3} / T / L$

$q=\frac{R}{D_{0} K_{0} H_{0}} q^{\prime}$ is the dimensionless fluid flow rate across the

None

$r \quad$ is the dimensionless radial coordinate variable in cylindrical coordinates. None

$r^{\prime} \quad$ is the radial variable in cylindrical coordinates.

$r_{0}^{1} \quad$ is the effective cavern radius.

$r_{0} \quad$ is the dimensionless effective cavity radius. None

s is the location along the outflow boundary; i.e., along the river (see Equation 17). $L$.

$t \quad$ is the dimensionless time variable (see Equation $A-2$ ).

None

t' is the time variable.

$t_{0} \quad$ is the departure time of the first fluid particles leaving the cavern wall or from the other specified locations.

None

$t_{0}^{\prime} \quad$ is the departure time of the fluid particles from a given location.

T

$w_{0} \quad$ is a parameter in the serpin equation (see Figure 1 or Equation A-18).

None

$W_{0 C}$ is a parameter in the cyclic equation (see Figure 2. or Equation A-19).

None

$w_{m} \quad$ is a parameter in the serpin equation (see Figure 1 or Equation $\mathrm{A}-18$ ).

None 
Units

$W_{\mathrm{mc}} \quad$ is a parameter in the cyclic equation (see Figure 2 or Equation A-19).

None

$x^{\prime}$ and $y^{\prime}$ are the Cartesian coordinates.

L

$x$ and $y$ are the dimensioniess Cartesian coordinates (see Equation $\mathrm{A}-2$ ).

None

$x_{j}$ and $y_{j}$ are the coordinates of the center of the $j$ th well. None

$x_{0}$ and $y_{0}$ are the dimensionless coordinates defining the cylindrical cavern wall (see Equations 5 and 6).

None

$p \quad$ is the fluid mass density.

$\mathrm{FT}^{2} / \mathrm{L}^{4}$

$\theta$

is the angular.coordinate variable in cylindrical coordinates. (The $x$-coordinate axis is along $0=0)$.

Degrees

$\theta_{j} \quad$ is the angular coordinate of the center of the $j$ th well (see Figure A-1).

Degrees

$\theta 0=$ THETAO is the angle around the cavern wall to the starting point of the first pathline generated (see Table 1).

Degrees

OM=THETAM is the maximum angle around the cavern wall to the starting point of the last regularly spaced pathline generated (see Table 1).

Degrees

$\phi^{\prime}=\frac{p}{\rho g}+z$

is the dimensional potential energy in the stratum. LF/F

$\phi \quad$ is the dimensionless potential head (see Equations A-2 and $\mathrm{A}-17$ ).

None

is the del operator; i.e., $\frac{\partial}{\partial x} \underline{i}+\frac{\partial}{\partial y} \underline{j} \quad$ None

$\nabla^{\prime} \quad$ is the dimensionless del operator; i.e.,

$$
\frac{\partial}{\partial x^{\top}} \dot{i}+\frac{\partial}{\partial y^{\prime}} \underline{j}
$$

$1 / L$

U. is the dimensionless macroscopic pore velocity vector (see Equation A-27).

None

$\underline{u}^{\prime}$ is the macroscopic pore velocity vector (see Equation A-25).

$L / T$ 
Units

is the dimensionless velocity component in the $x-$ coordinate direction.

None

is the dimensionless component in the $y$-coordinate direction.

None

is stream function (see Equation A-34). None

$\psi$

is the steady scaling source strength (see Equation A-42).

None

is the cumulative outflow from the circular source (see Equation A-37).

None 